Supporting information for:

\title{
Structural features of small molecules targeting the RNA repeat expansion that causes genetically defined ALS/FTD
}

\author{
Andrei Ursu' ${ }^{1}$, Kye Won Wang ${ }^{2}$, Jessica A. Bush ${ }^{1}$, Shruti Choudhary ${ }^{1}$, Jonathan L. Chen ${ }^{1}$, Jared \\ T. Baisden ${ }^{1}$, Yong-Jie Zhang ${ }^{3}$, Tania F. Gendron ${ }^{3}$, Leonard Petrucelli ${ }^{3}$, Ilyas Yildirim² and \\ Matthew D. Disney ${ }^{1 *}$
}

\footnotetext{
${ }^{1}$ Department of Chemistry, The Scripps Research Institute, 130 Scripps Way, Jupiter, FL 33458 USA

${ }^{2}$ Department of Chemistry and Biochemistry, Florida Atlantic University, Jupiter, FL 33458 USA

${ }^{3}$ Department of Neuroscience, Mayo Clinic, 4500 San Pablo Rd., Jacksonville, FL 32224 USA
}

* Author to whom correspondence is addressed; Email: disney@scripps.edu 


\section{Supplementary Figures}
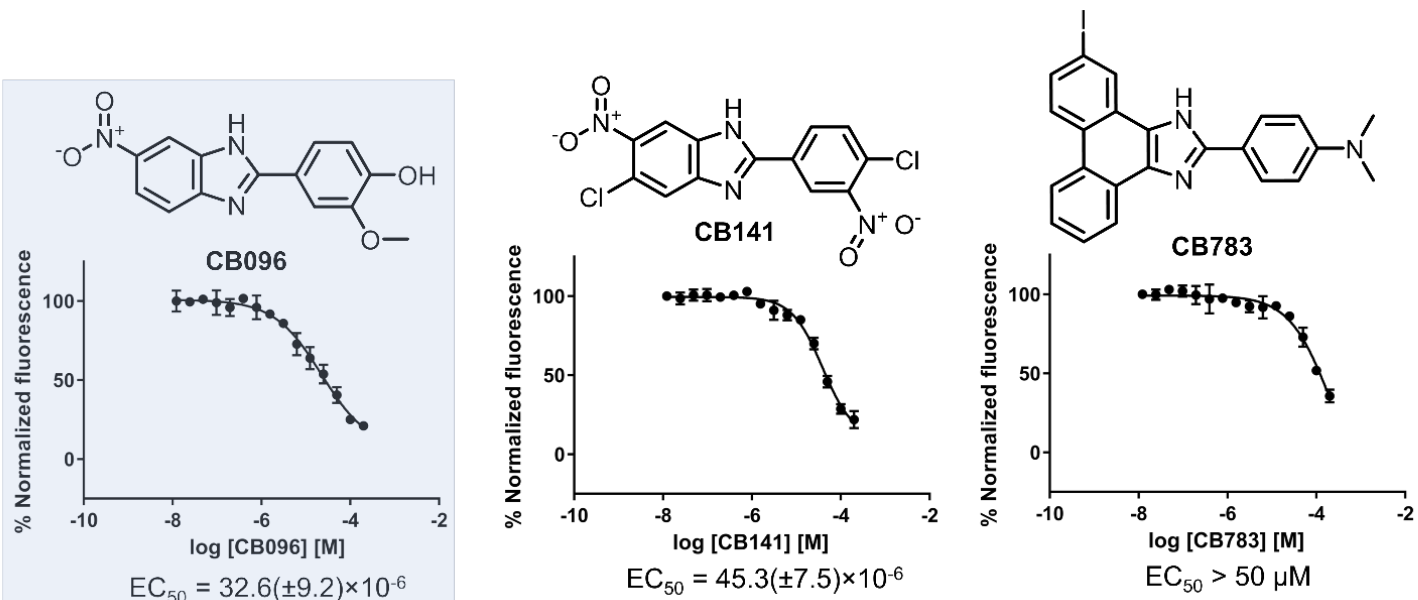<smiles>COc1cc(-c2nc3cc4[nH]c(=O)[nH]c4cc3[nH]2)cc(OC)c1O</smiles>
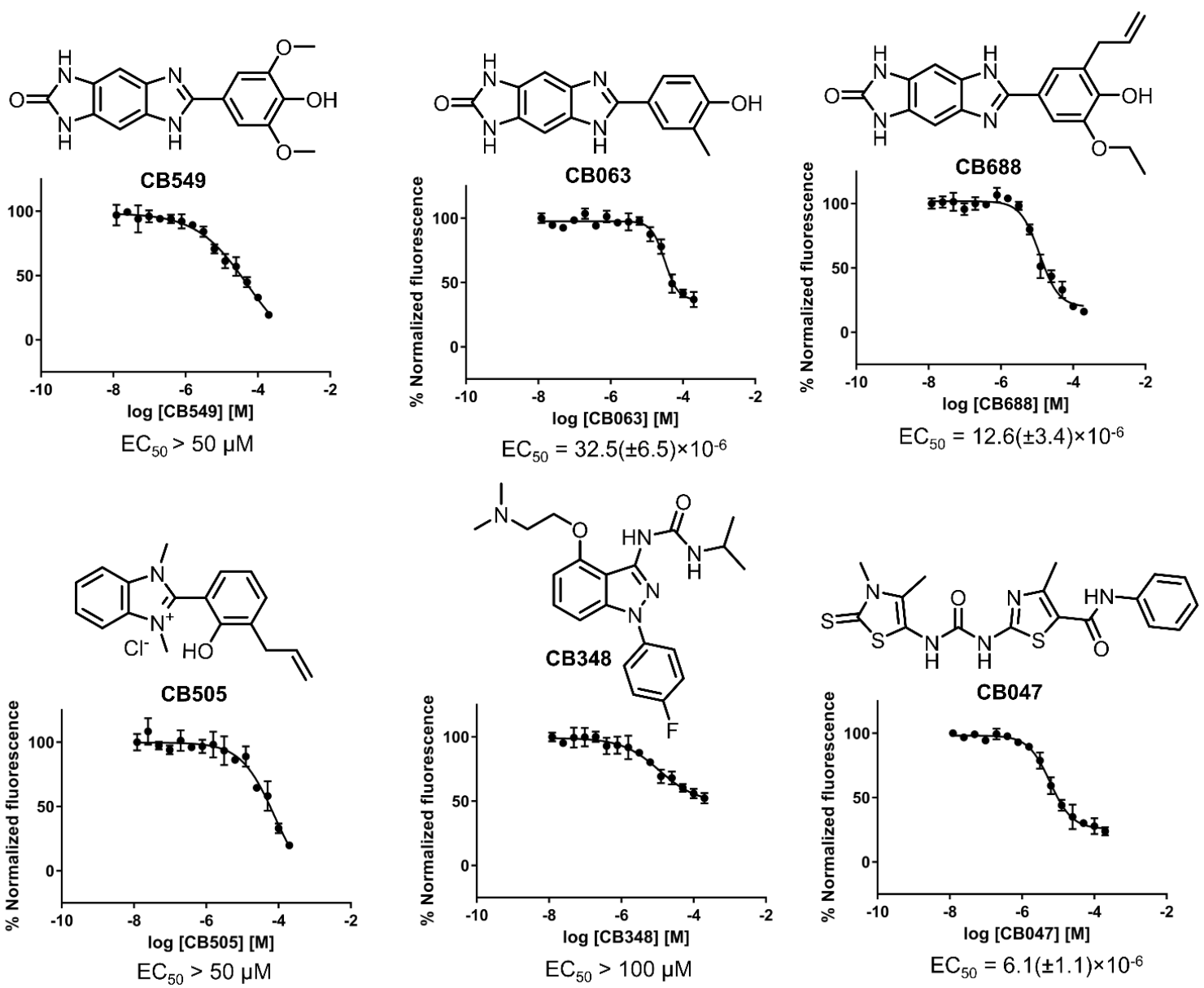


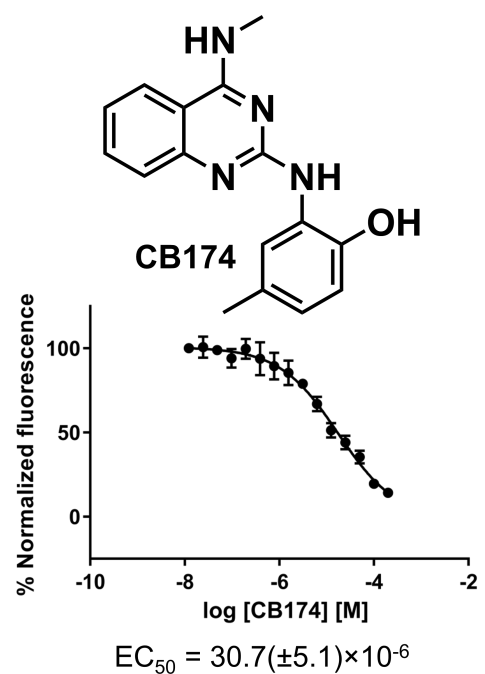

$\mathrm{EC}_{50}=30.7( \pm 5.1) \times 10^{-6}$

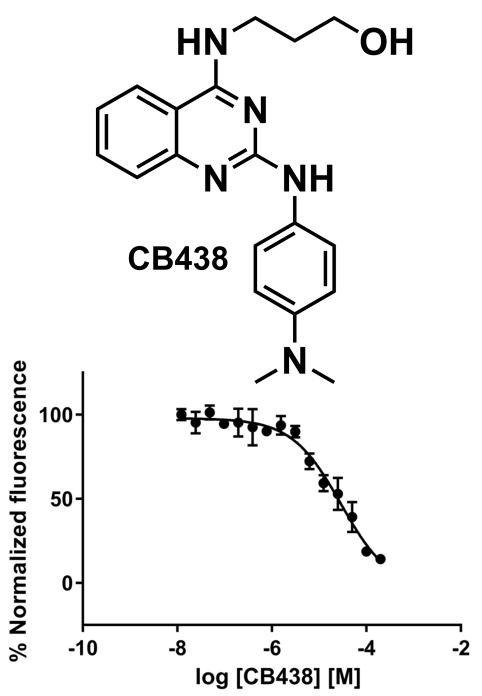

$\mathrm{EC}_{50}>50 \%$ inhibition at $50 \mu \mathrm{M}$
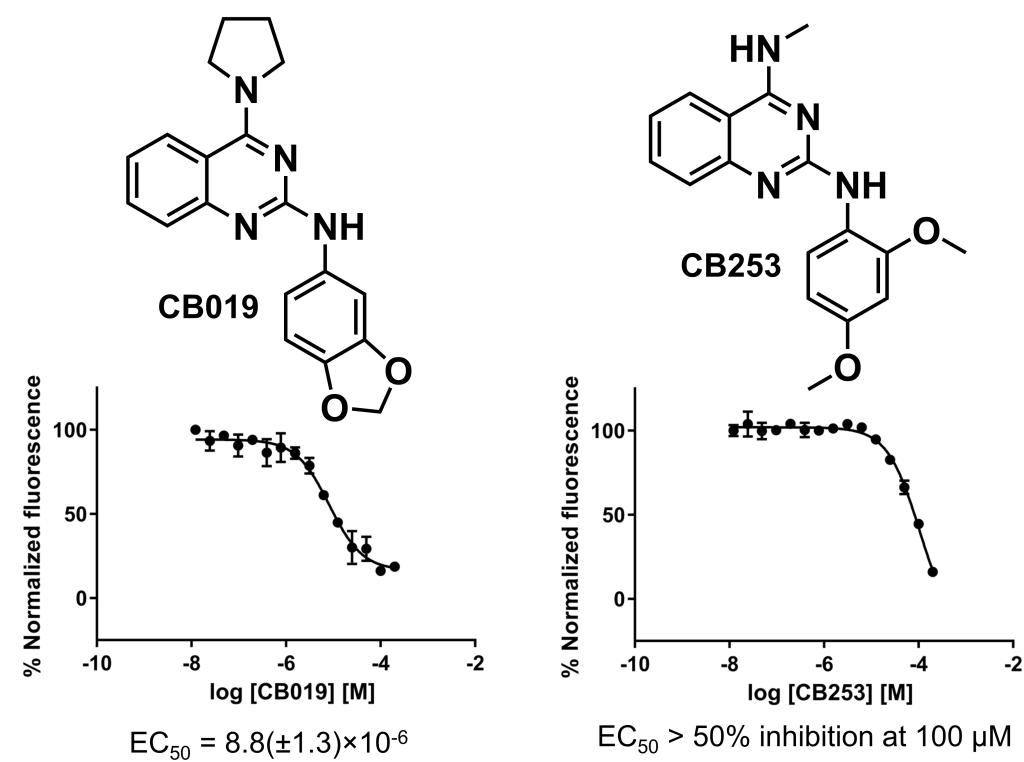

$\mathrm{EC}_{50}>50 \%$ inhibition at $100 \mu \mathrm{M}$

Figure S1. Hit validation of from $r\left(G_{4} \mathrm{C}_{2}\right)_{8}$ binders via TO1 displacement in vitro. $\mathrm{EC}_{50}$ values were determined by plotting the change in normalized fluorescence as a function of compound concentration. Data points are the mean $\pm S D$ of two independent experiments in which each concentration was measured in triplicate. The binding curve was fitted using a four-parameter nonlinear regression equation of the GraphPad Prism 8.1.2 suite. 

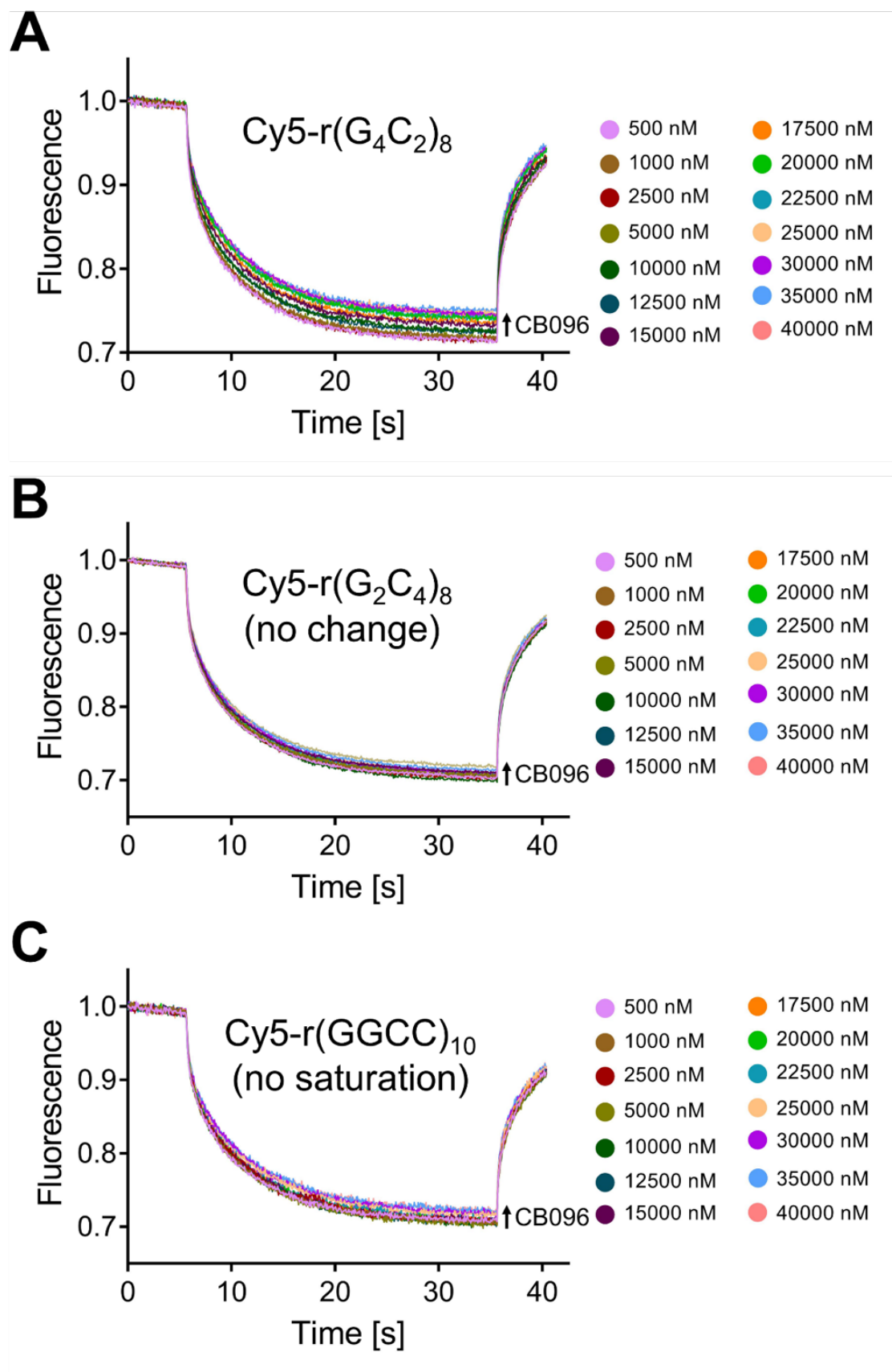

Figure S2. Representative thermophoresis curves of CB096 binding to Cy5-labeled RNAs obtained. Dose dependent addition of CB096: i) increases the thermophoresis of the hairpin form of Cy5-r $\left(\mathrm{G}_{4} \mathrm{C}_{2}\right)_{8}(\mathrm{a})$; ii) leads to minor change of the Cy5-r $\left(\mathrm{G}_{2} \mathrm{C}_{4}\right)_{8}$ (antisense) thermophoresis (b); iii) triggers no saturable change of the Cy5-r(GGCC) ${ }_{10}$ (base pair control) thermophoresis (c). The normalized fluorescence upon dose-dependent addition of CB096 was recorded in the Thermophoresis and T-jump channels. Data points are representative of two independent experiments each performed in duplicate. 
A

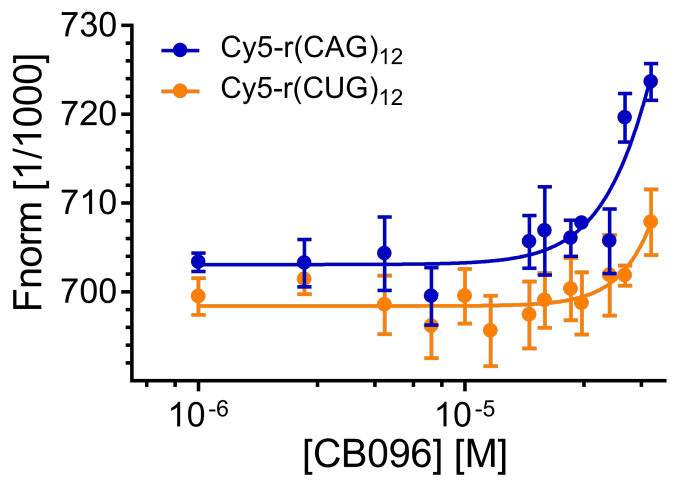

B
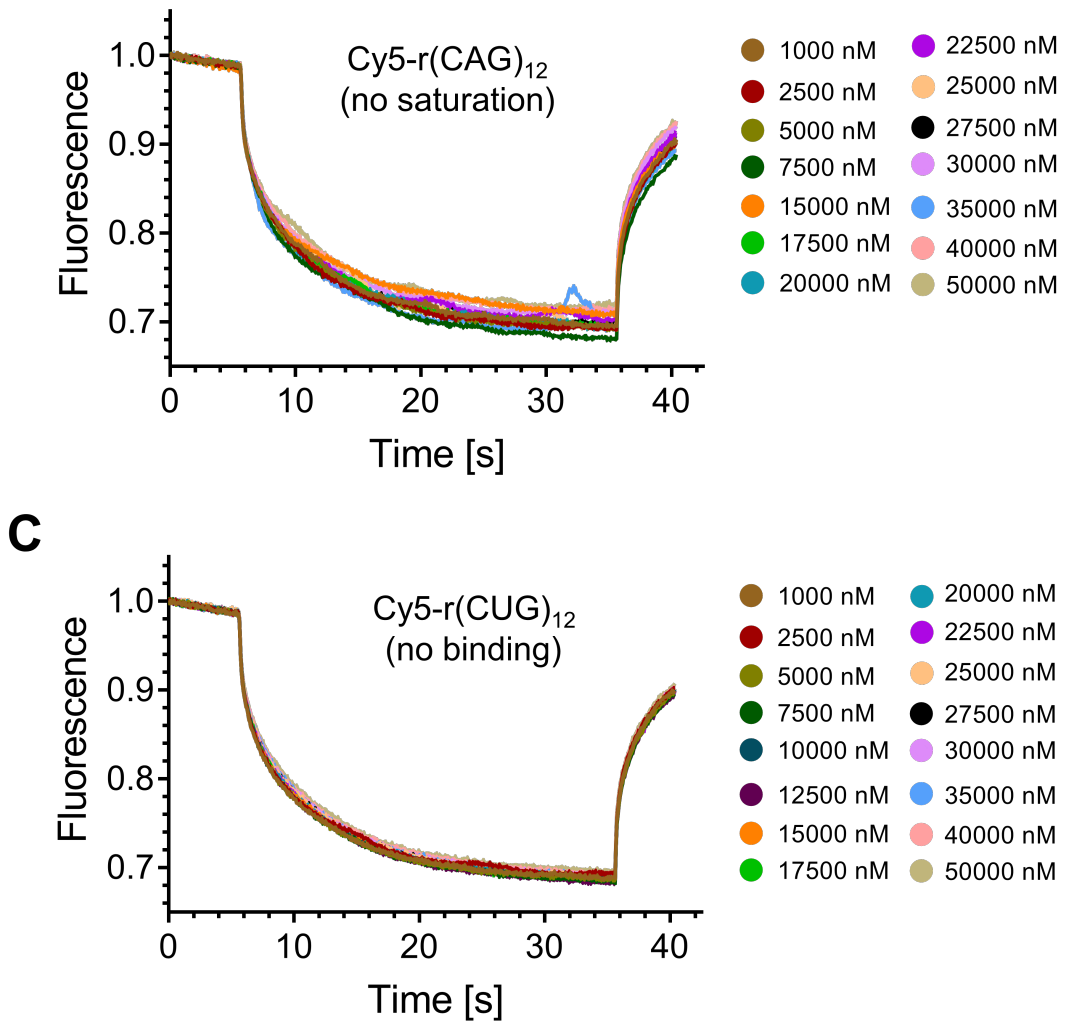

Figure S3. CB096 specifically interacts with the $1 \times 1 \mathrm{GG}$ internal loops within the $r\left(\mathrm{G}_{4} \mathrm{C}_{2}\right)^{\text {exp }}$ hairpin RNA. a) No saturable binding was observed in thermophoresis measurement for CB096 and RNAs featuring $1 \times 1 \mathrm{AA}$ and $1 \times 1 \mathrm{UU}$ internal loops within Cy5-r(CAG)$)_{12}$ and $\mathrm{Cy} 5-\mathrm{r}(\mathrm{C} \underline{\mathrm{U}})_{12}$ RNAs, respectively, as assessed via MST. b-c) Representative thermophoresis curves of CB096 interacting with Cy5-r(CAG) 12 (b) and Cy5-r(CUG) 12 (c) RNAs. Dose dependent addition of CB096: i) triggers no saturable change of the Cy5-r(CAG) ${ }_{12}$ thermophoresis (b); and ii) leads to

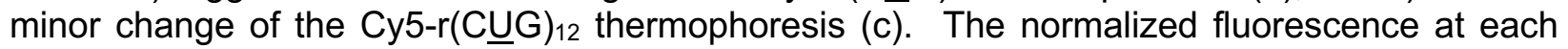
CB096 concentration was recorded in the Thermophoresis and T-jump channels. Data points in panel a were generated from two independent experiments each performed in duplicate. 


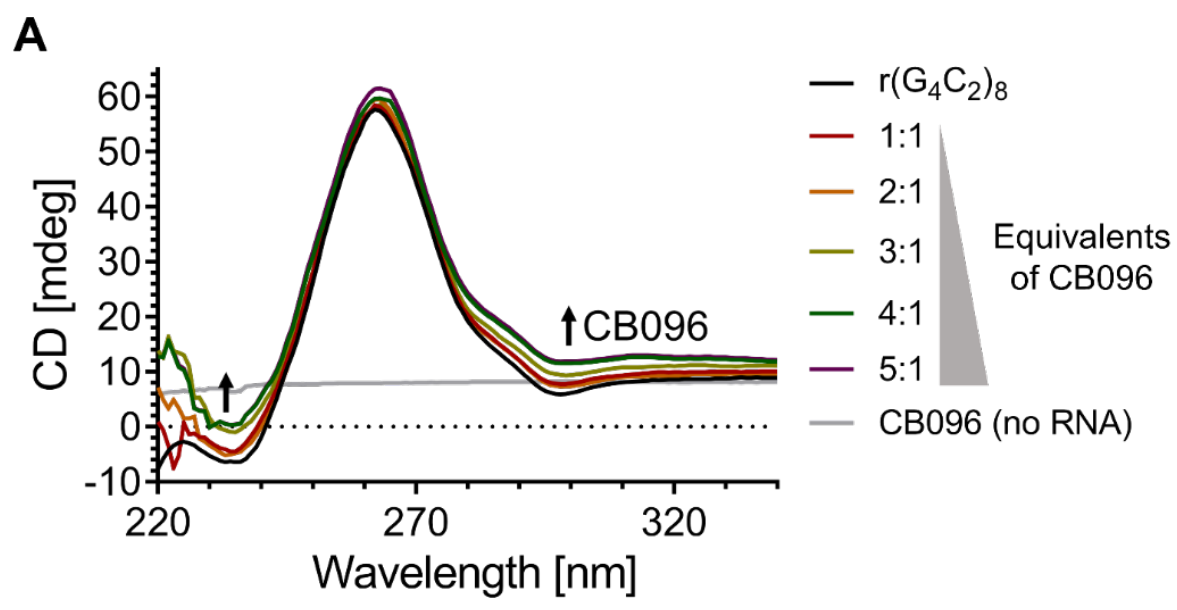

B

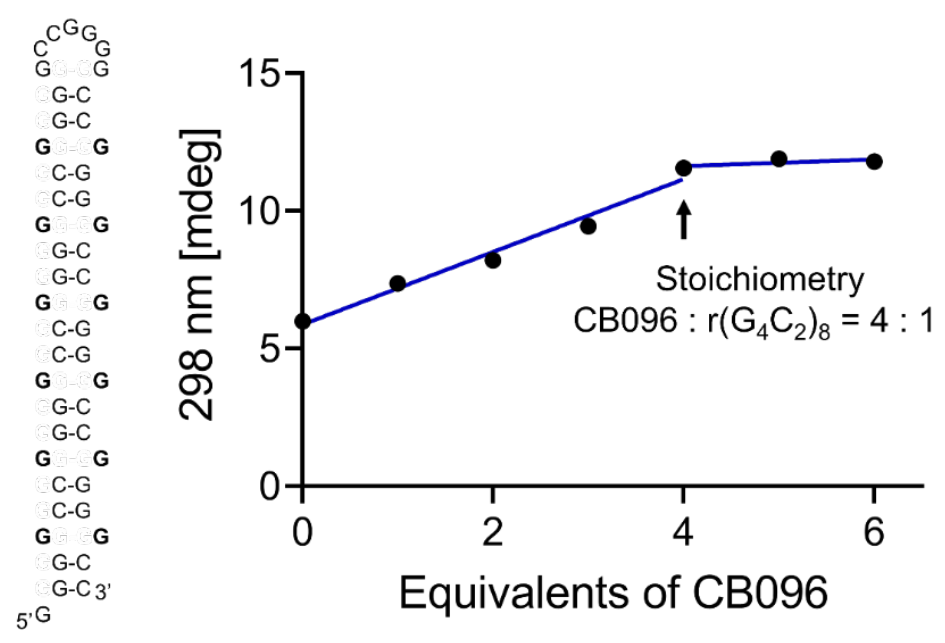

Figure S4. Representative CD spectrum recorded upon dose dependent addition of CB096 to $\mathrm{r}\left(\mathrm{G}_{4} \mathrm{C}_{2}\right)_{8}$ hairpin. Compound addition triggers an increase of $\mathrm{CD}$ signals at 235 and $298 \mathrm{~nm}$ (a) that reached saturation at 4 equivalents CB096, i.e. a binding stoichiometry of CB096 to $r\left(\mathrm{G}_{4} \mathrm{C}_{2}\right)_{8}$ of $4: 1$ (b). The spectra are representative of two independent experiments. 


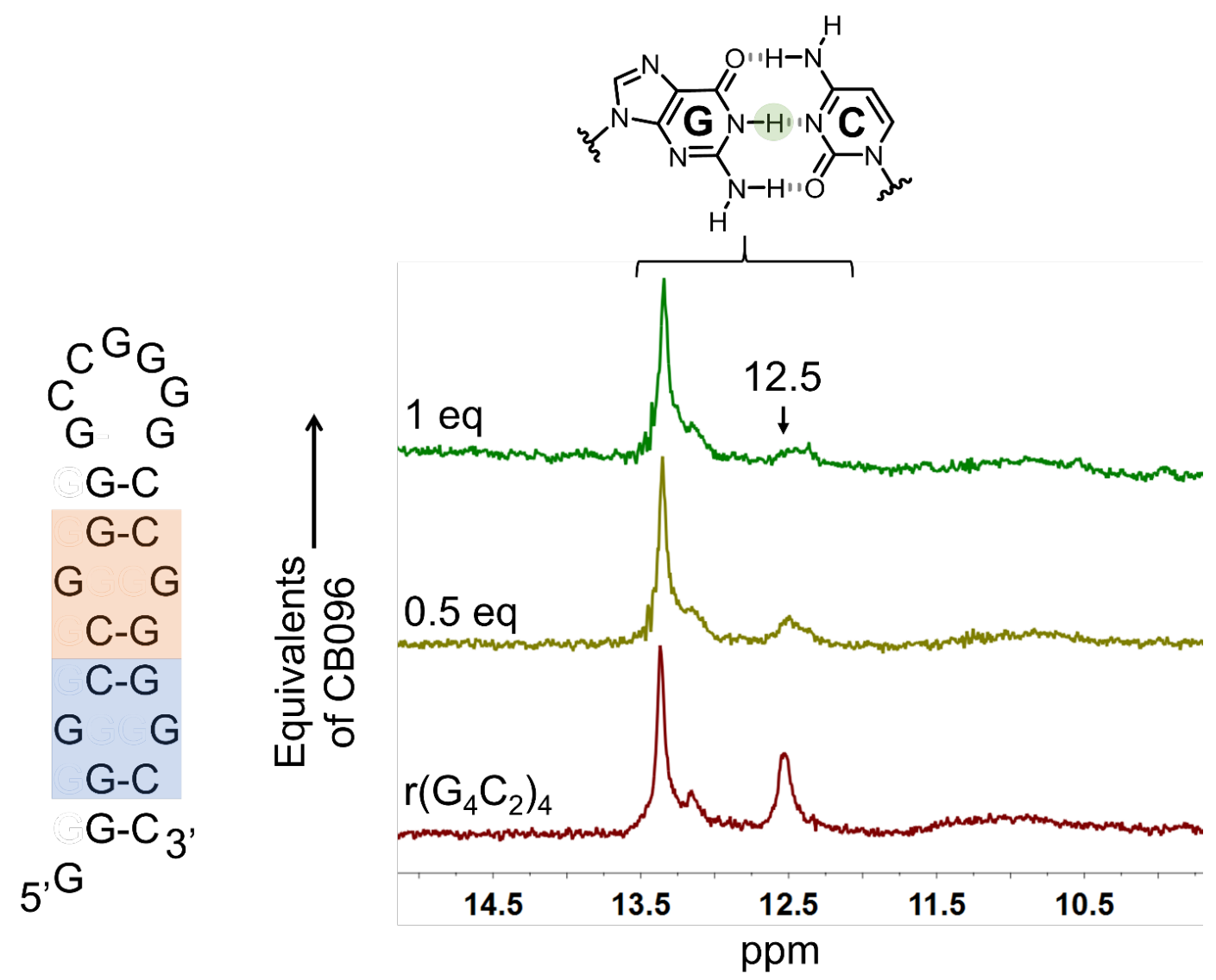

Figure S5. CB096 mode of binding to the $r\left(\mathrm{G}_{4} \mathrm{C}_{2}\right)_{4}$ hairpin. CB096 broadens the imino proton peak of GC/CG base pairs at 12.5 ppm. Blue labels indicate 5' $\mathrm{G} \underline{G} / 3^{\prime} \mathrm{C} \underline{\mathrm{GG}}$ ( $\underline{\mathrm{G}}$ represents the $\mathrm{G}$ residues within the $1 \times 1 \mathrm{GG}$ internal loops) internal loops, whereas the orange labels indicate 5'CGG/3'GGC loops. Further addition of CB096 triggered precipitation. The 1D NMR spectra are representative of two independent experiments. 


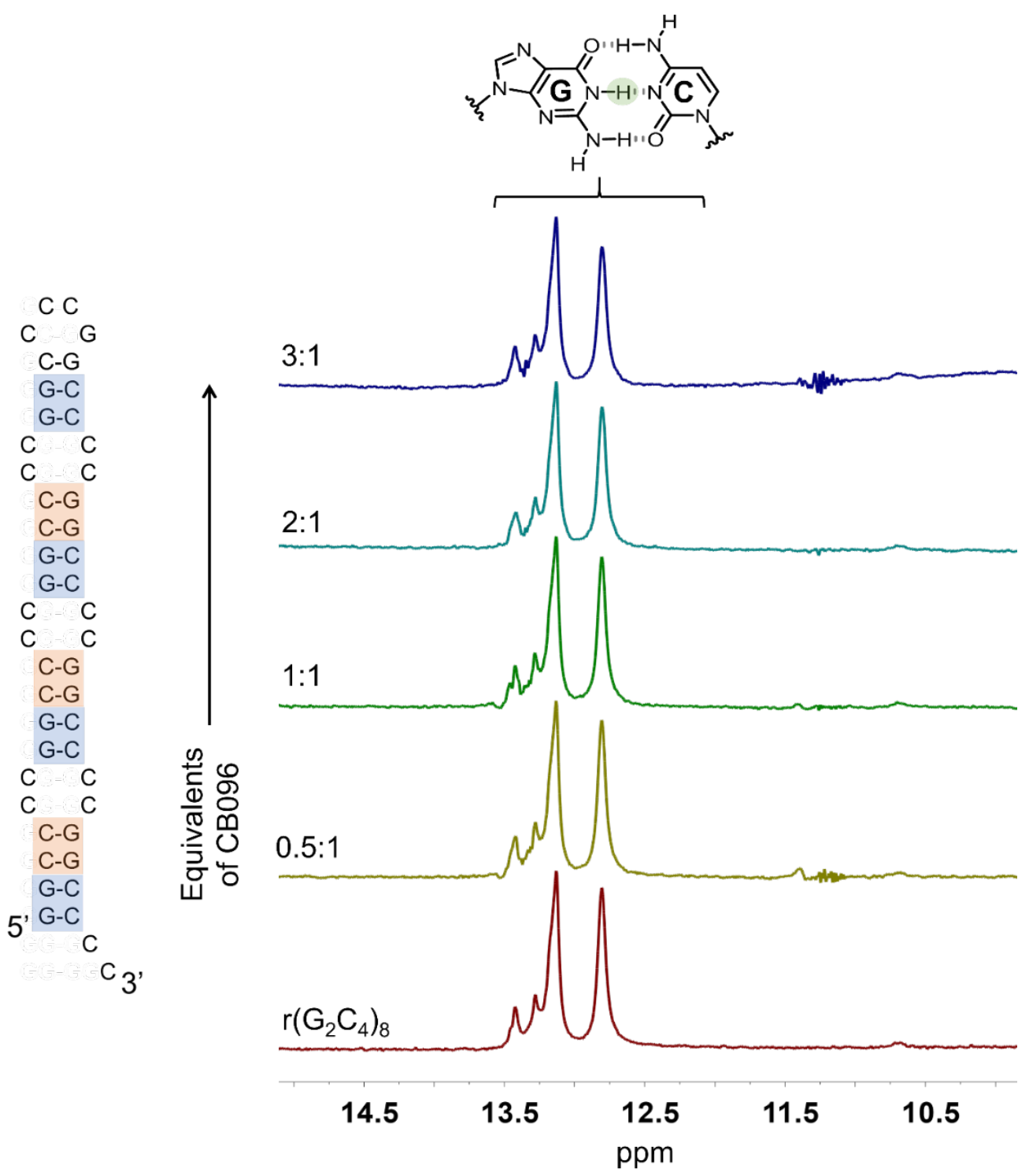

Figure S6. Dose dependent addition of CB096 does not change the imino proton signals of the 5'GG/3'CC (blue squares) and 5'CC/3'GG (orange squares) base pairs at $13.1 \mathrm{ppm}$ and $12.8 \mathrm{ppm}$ within $r\left(\mathrm{G}_{2} \mathrm{C}_{4}\right)_{8}$ (antisense). The 1D NMR spectra are representative of two independent experiments. 
A

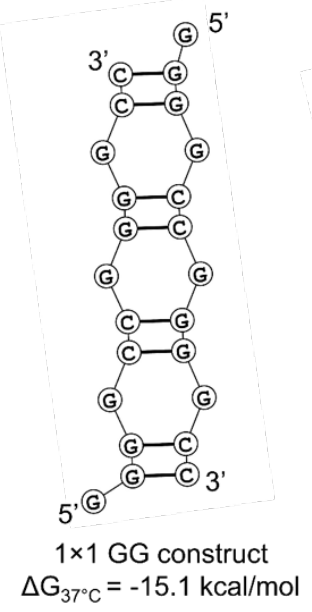

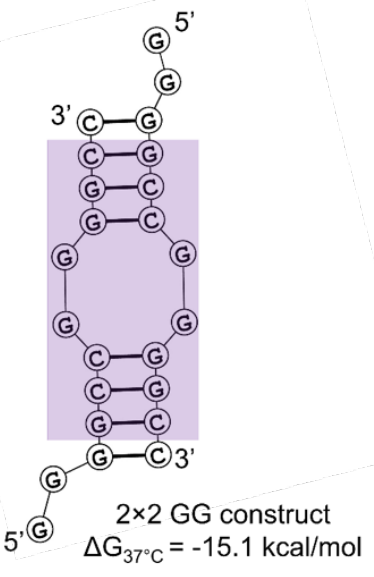

B

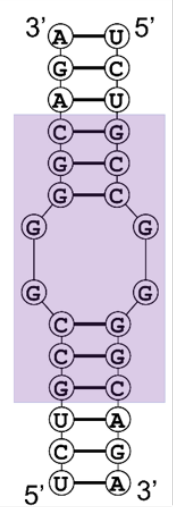

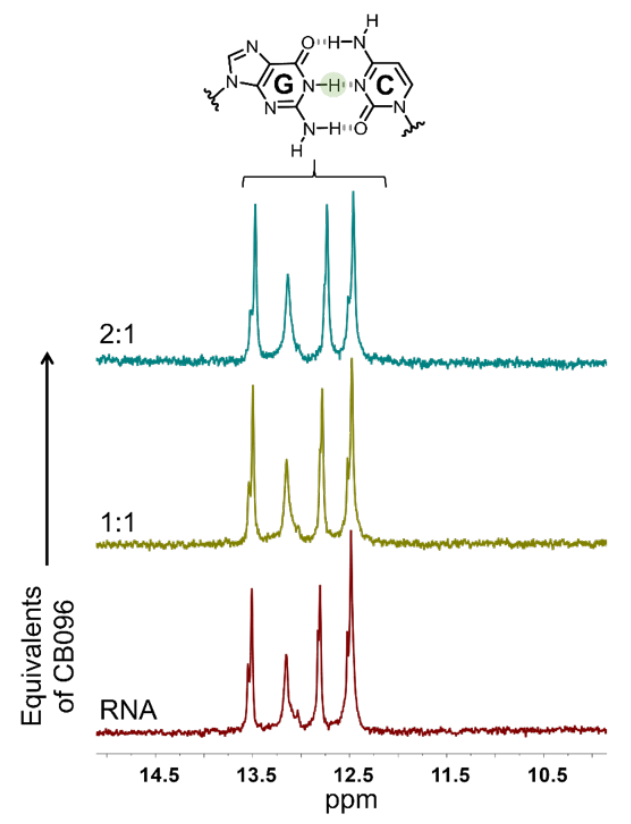

Figure S7. CB096 does not interact with a $2 \times 2$ GG internal loop-containing duplex. a) Free energy minimization (RNAstructure software) of the $r\left(G_{4} \mathrm{C}_{2}\right)_{2}$ duplex predicts secondary structures with $1 \times 1 \mathrm{GG}$ and $2 \times 2 \mathrm{GG}$ loops have the same free energy of folding at $37^{\circ} \mathrm{C}\left(\Delta \mathrm{G}^{\circ}{ }_{37}\right)$. b) Dose dependent addition of CB096 does not affect the imino proton signal of GC/CG base pairs at 12.5 ppm within the $2 \times 2$ GG internal loop containing model construct. The 1D NMR spectra are representative of two independent experiments. 


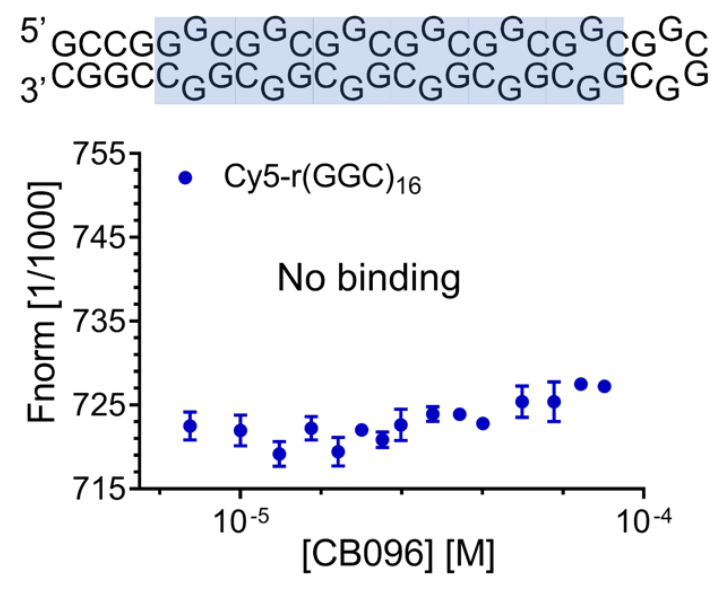

Figure S8. Binding of CB096 to 5'GGC/3'CGG sites (highlighted in blue) within Cy5-r(GGC) 16 via MST. No change in thermophoresis, i.e. no binding, was observed upon dose dependent addition of CB096 to Cy5-r(G $\underline{G C})_{16}$. The secondary structure was predicted by RNAstructure software. The normalized fluorescence was recorded in the Thermophoresis and T jump channels. Data points indicate mean values \pm SD from two independent experiments each performed in duplicate. 

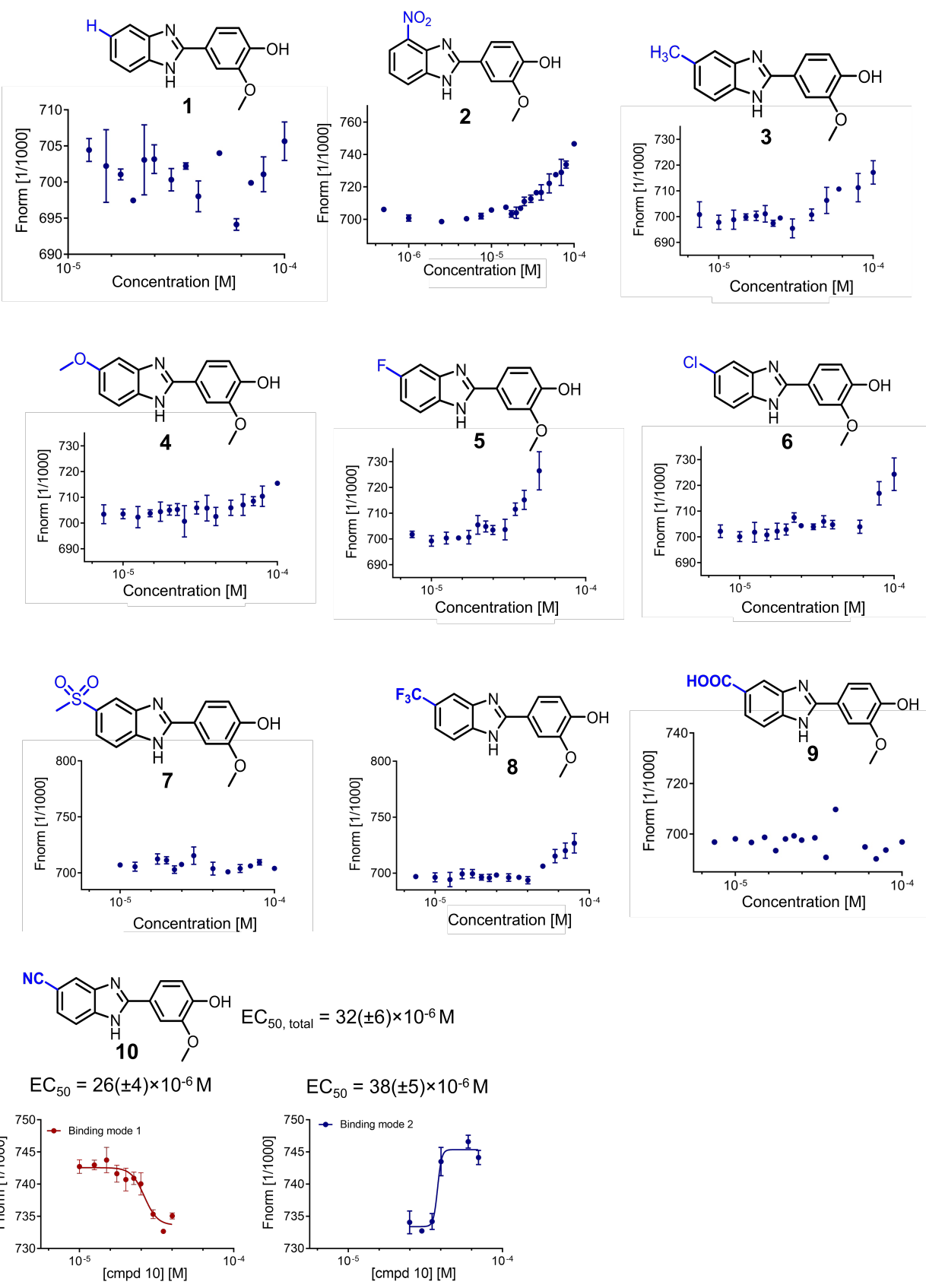

Figure S9. In vitro binding of compounds 1-10 to Cy5-r $\left(\mathrm{G}_{4} \mathrm{C}_{2}\right)_{8}$ hairpin, as measured by MST. No change in thermophoresis or no saturation, i.e. no binding, was observed upon dose dependent addition of derivatives $1-10$ to $\mathrm{Cy} 5-\mathrm{r}\left(\mathrm{G}_{4} \mathrm{C}_{2}\right)_{8}$ as shown by the normalized fluorescence signal recorded in the Thermophoresis and $\mathrm{T}$ jump channels. Saturable binding was observed for derivative 10 only, with $\mathrm{EC}_{50, \text { total }}$ value of $32( \pm 6) \mu \mathrm{M}$, calculated by plotting the changes in

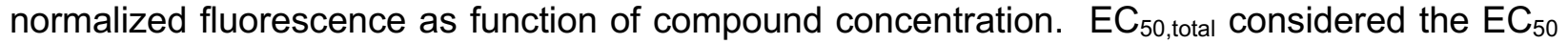
values for the two observed binding modes and was generated by calculating the square root of the first binding mode $\left(\mathrm{EC}_{50,1}\right)$ multiplied by the value of the second binding mode $\left(\mathrm{EC}_{50,2}\right)$. Data points are reported as the mean $\pm S D$ from two independent experiments each performed in duplicate. 

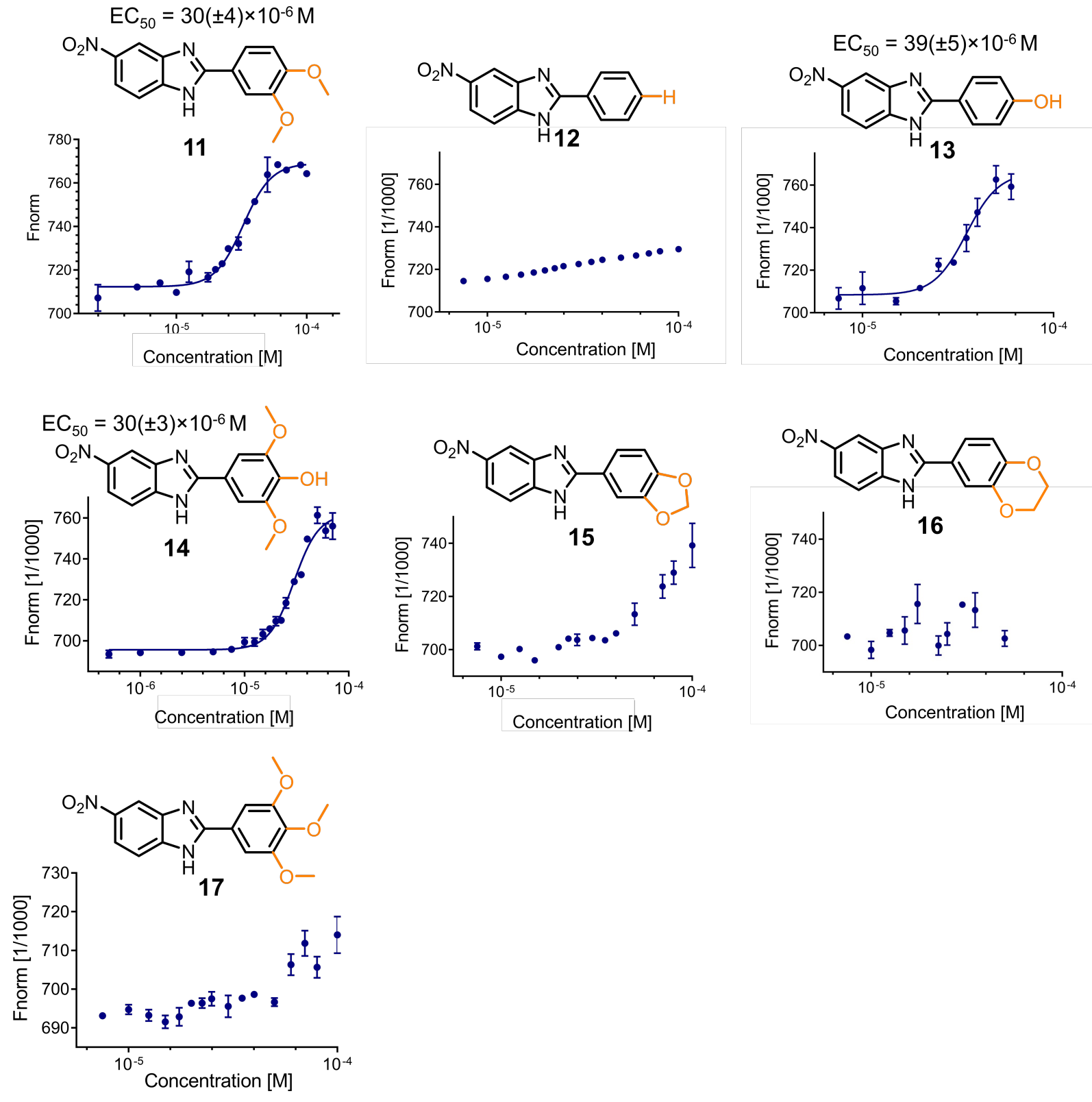

Figure S10. In vitro binding of compounds 11-17 to Cy5-r $\left(\mathrm{G}_{4} \mathrm{C}_{2}\right)_{8}$ hairpin, as measured by MST. Saturable binding was observed for derivatives 11,13 , and 14 only, with $E_{50}$ values of $30( \pm 4) \mu \mathrm{M}, 39( \pm 5) \mu \mathrm{M}$, and $30( \pm 3) \mu \mathrm{M}$, respectively. $\mathrm{EC}_{50}$ values were determined by plotting the changes in normalized fluorescence as function of compound concentration. No change in thermophoresis or no saturation, i.e. no binding, was observed addition of derivatives 12,15-17 to Cy5-r $\left(\mathrm{G}_{4} \mathrm{C}_{2}\right)_{8}$. Data points are reported as mean $\pm \mathrm{SD}$ from two independent experiments each performed in duplicate. Binding curves were fitted using a four-parameter nonlinear regression equation of the GraphPad Prism 8.1.2 suite. 

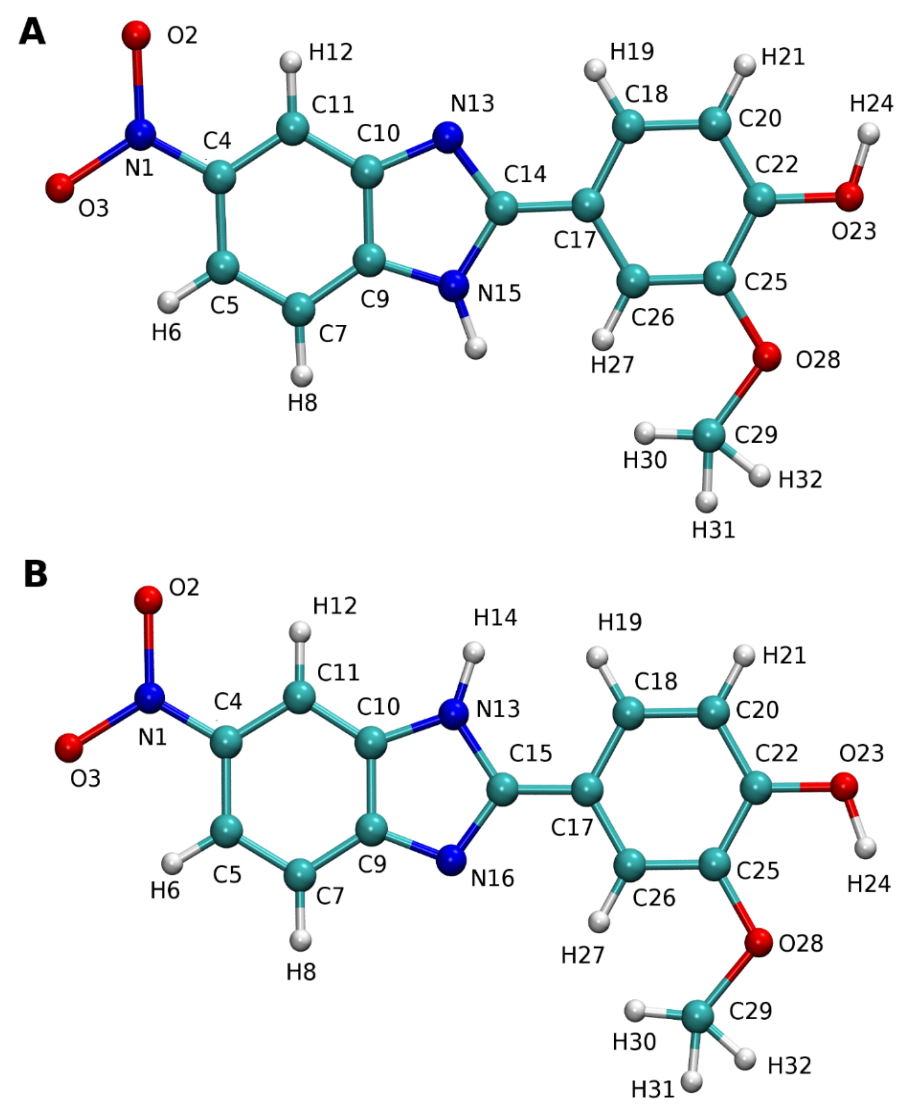

Figure S11. Atom numbering of CB096 (a) and its tautomer $\mathrm{CB} 096_{\mathrm{T}}(\mathrm{b})$. 

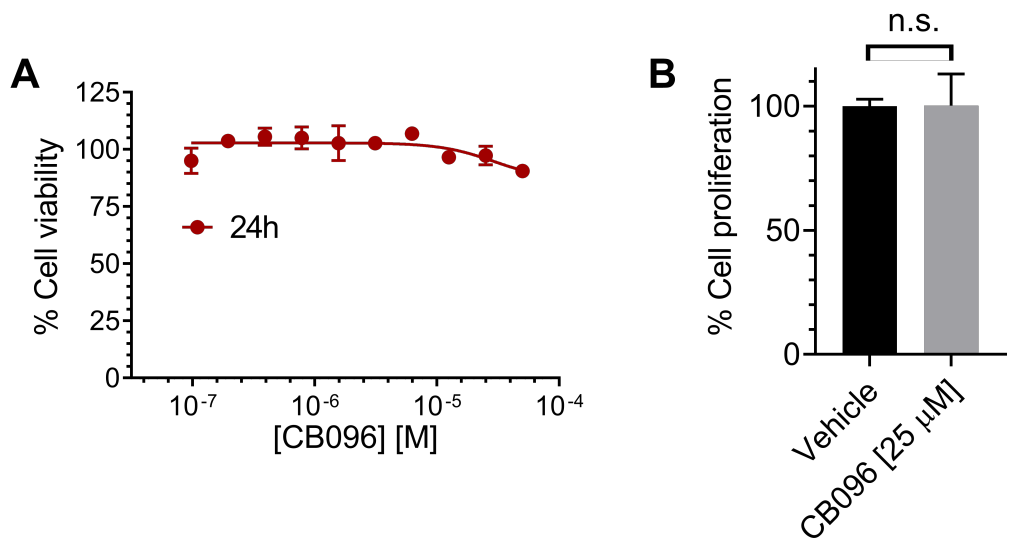

Figure S12. CB096 is not cytotoxic in $r\left(\mathrm{G}_{4} \mathrm{C}_{2}\right)_{66}$-transfected HEK293T cells nor affects cell proliferation. a) Cellular viability of $r\left(\mathrm{G}_{4} \mathrm{C}_{2}\right)_{66}$-transfected HEK293T cells upon incubation with CB096 for $24 \mathrm{~h}$ assessed via CellTiter-Glo. Data points are reported as the mean \pm SD from two independent experiments each performed in triplicate. b) CB096 $(25 \mu \mathrm{M})$ does not alter the cell proliferation of $r\left(\mathrm{G}_{4} \mathrm{C}_{2}\right)_{66}$-transfected HEK293T cells. Data points are reported as the mean $\pm \mathrm{SD}$ relative to vehicle $(0.5 \% \mathrm{DMSO})$ from two independent experiments each performed in triplicate. n.s. = not significant, as determined by a two-tailed Student $t$ test. 


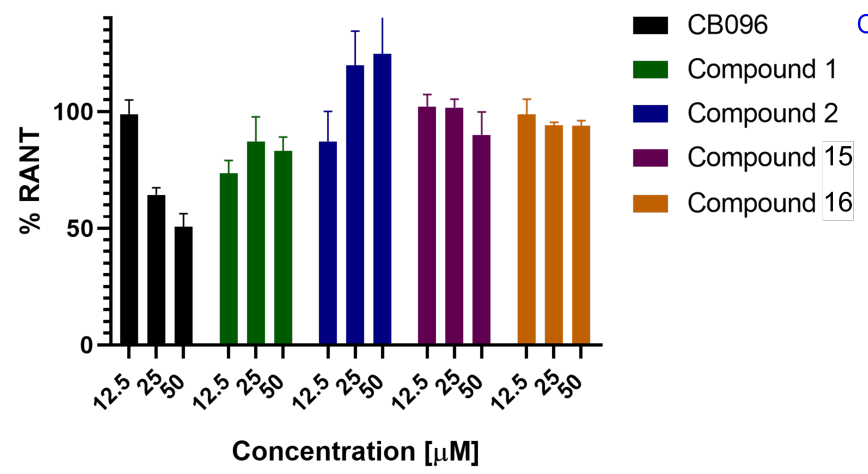<smiles>COc1cc(-c2nc3cc([N+](=O)[O-])ccc3[nH]2)ccc1O</smiles><smiles>COc1cc(-c2nc3c([N+](=O)[O-])cccc3[nH]2)ccc1O</smiles><smiles>COc1cc(-c2nc3ccccc3[nH]2)ccc1O</smiles>

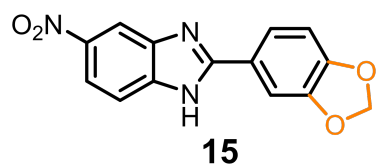

15<smiles>O=[N+]([O-])c1ccc2[nH]c(-c3ccc4c(c3)OCCO4)nc2c1</smiles>

16

Figure S13. Inhibition of RAN translation by CB096 and compounds 1, 2, 15 and 16. CB096 binds $r\left(G_{4} \mathrm{C}_{2}\right)_{8}$ hairpin in vitro and inhibits RAN translation in cells in a dose dependent manner. Conversely, derivatives $1,2,15$ and 16 do not bind $r\left(G_{4} C_{2}\right)_{8}$ and do not block RAN translation. Data are reported as the mean \pm SD from three independent experiments each performed in duplicate. 


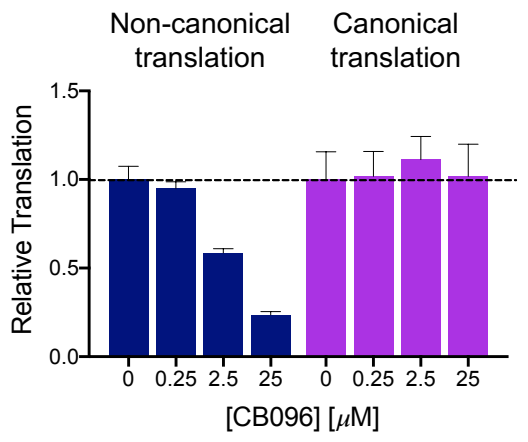

Figure S14. CB096 selectively inhibits RAN translation of $r\left(\mathrm{G}_{4} \mathrm{C}_{2}\right)^{\mathrm{exp}}$ in HEK293T cells that stably express Lentiviral-S-tdTomato co-transfected with plasmind encoding a $\left(\mathrm{G}_{4} \mathrm{C}_{2}\right)_{66}$-No ATG-firefly luciferase (RAN translation), Renilla luciferase (canonical translation), and ATG-GFP. Relative translation was measured by normalizing the signal from firefly luciferase to Renilla luciferase (non-canonical translation) or the signal from Renilla luciferase to GFP (canonical translation). Data are reported as the mean \pm SD $(n=4)$. 


\section{METHODS}

\section{General methods}

RNA oligonucleotides were purchased from Dharmacon (GE Healthcare) and deprotected according to the vendor's recommended procedure. After deprotection, the RNAs were desalted using PD-10 columns (GE Healthcare) and the concentrations were determined using UV spectrometry to measure the absorbance at $260 \mathrm{~nm}$ (extinction coefficients for RNAs were provided by the vendor) and $90{ }^{\circ} \mathrm{C}$ using a Beckman Coulter DU 800 spectrophotometer.

The sequences of the RNA hairpins used herein were $r\left(\mathrm{G}_{4} \mathrm{C}_{2}\right)_{4}, r\left(\mathrm{G}_{2} \mathrm{C}_{4}\right)_{8}, \mathrm{r}(\mathrm{GGCC})_{10}$, $r(C G G)_{16}, r(C A G)_{12}, r(C U G)_{12}$ and r(GGC) $)_{16}:$ '-GCCGGGCGGCGGCGGCGGCGGCGGCGGCG

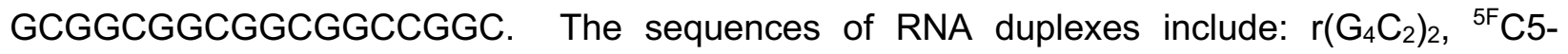
$r\left(\mathrm{G}_{4} \mathrm{C}_{2}\right)_{2}$ : 5'-GGGG ${ }^{5 \mathrm{~F}} \mathrm{CCGGGGCC-3';}{ }^{5 \mathrm{~F}} \mathrm{C6}-\mathrm{r}\left(\mathrm{G}_{4} \mathrm{C}_{2}\right)_{2}$ : 5'-GGGGC ${ }^{5 \mathrm{~F}} \mathrm{CGGGGCC-3';}{ }^{5 \mathrm{~F}} \mathrm{C} 11-\mathrm{r}\left(\mathrm{G}_{4} \mathrm{C}_{2}\right)_{2}$ : 5'-GGGGCCGGGG5FCC-3'. RNA secondary structure predictions shown throughout the study were generated using RNA structure software. ${ }^{1,2}$ All hairpin RNAs were folded in $10 \mathrm{mM}$ $\mathrm{Na}_{2} \mathrm{HPO}_{4}, \mathrm{pH} 7$, for $4 \mathrm{~min}$ at $95{ }^{\circ} \mathrm{C}$ and cooled to room temperature. For duplex sequences, 100 $\mathrm{mM} \mathrm{LiCl}$ solution was added to the RNA solution folded in $10 \mathrm{mM} \mathrm{Na}_{2} \mathrm{HPO}_{4}, \mathrm{pH} 7$ and equilibrated at room temperature.

The RNA-focused library as well as the hit compounds CB096 and derivatives 1, 11 and 12 were purchased from ChemBridge. The characterization of the physicochemical properties of the RNA-focused library was described elsewhere. ${ }^{3}$

\section{IN VITRO STUDIES}

\section{High-throughput TO1 displacement screening in 384-well format}

The RNA $r\left(G_{4} \mathrm{C}_{2}\right)_{8}$ was folded in $8 \mathrm{mM} \mathrm{Na}_{2} \mathrm{HPO}_{4}, 185 \mathrm{mM} \mathrm{NaCl}, 2 \mathrm{mM}$ EDTA, pH = 7.4 for $4 \mathrm{~min}$ at $95{ }^{\circ} \mathrm{C}$ and cooled to room temperature. BSA (40 $\mu \mathrm{g} / \mathrm{mL}$, final concentration) and TO-PRO-1 (TO1, $400 \mathrm{nM}$ ) were added to the solution and were incubated for $15 \mathrm{~min}$ at room temperature 
protected from light (final concentrations of $r\left(\mathrm{G}_{4} \mathrm{C}_{2}\right)_{8}$ and TO1 were 250 and $200 \mathrm{nM}$, respectively). $10 \mu \mathrm{L}$ aliquots of the $\mathrm{r}\left(\mathrm{G}_{4} \mathrm{C}_{2}\right)_{8}$-TO1 solution were dispensed into low volume 384 well black plate (Greiner Bio-One, 784076) using an Aurora liquid handling system. Compounds $(0.1 \mu \mathrm{L}$ from 10 mM compound stock concentration in 100\% DMSO) were added via the Biomek NXP pin transfer tool onto the plate (final compound concentration of $100 \mu \mathrm{M}$ in $1 \%$ DMSO final concentration). The reaction mixture was incubated for 15 minutes before reading the fluorescence via a SpectraMax M5 plate reader (Molecular Device) using $485 \mathrm{~nm}$ (excitation) and $515 \mathrm{~nm}$ (emission). Reported Z-factor represent the average of individual Z-factors calculated for each individual plate considering the vehicle control (DMSO) and Methotrexate $(10 \mu \mathrm{M})$ spotted in pentuplicate. The percentage of decrease in TO1 fluorescence was calculated by using the averaged fluorescence of five vehicle controls on each individual plate according to the following equation:

$$
\% \text { Decrease in T01 Fluorescence }=\frac{(\text { Average Control Fluorescence }- \text { Well Fluoresence })}{\text { Average Control Fluorescence }}
$$

where Average Control Fluorescence is the average fluorescence intensity measured in wells that contain RNA, TO1, and vehicle $(n=5)$ and Well Fluorescence is the fluorescence intensity measured from a compound-treated well of interest.

A cut-off of $\geq 75 \%$ decrease in TO1 fluorescence was selected as it represents the most potent binders of $r\left(\mathrm{G}_{4} \mathrm{C}_{2}\right)_{8}$ hairpin $(\mathrm{n}=26)$.

\section{Hit validation}

Compounds exhibiting $\geq 75 \%$ decrease in TO1 fluorescence were ordered procured from commercial sources, and false positives were removed by applying stringent selection criteria: (i) lack of interference with the signal readout due to intrinsic fluorescence; (ii) lack of aggregation at the tested concentration (visual inspection); and (iii) and dose-dependent displacement of TO1 as described above with a $1 \%$ final concentration of DMSO. Dose-dependent studies were 
measured in duplicate, and the $\mathrm{EC}_{50}$ values were determined by plotting the changes in normalized fluorescence as a function of compound concentration. Data points are reported as the mean \pm SD from two independent experiments, each performed in triplicate. Binding curves were fitted using a four-parameter nonlinear regression equation of the GraphPad Prism 8.1.2 suite.

\section{Affinity measurements via microscale thermophoresis (MST)}

Fluorescently labeled (5'-Cy5) RNAs were folded in $10 \mathrm{mM} \mathrm{Na}_{2} \mathrm{HPO}_{4}, \mathrm{pH}$ 7, and $100 \mathrm{mM} \mathrm{LiCl}$ for 4 min at $95{ }^{\circ} \mathrm{C}$ and cooled to room temperature. Compound dilutions (with $0.5 \%$ final DMSO concentration) were added to the RNA solution (final concentration of $10 \mathrm{nM}$ ) and incubated at room temperature for 5 min. MST measurements were performed on a Monolith NT.115 (NanoTemper) instrument using standard capillaries and the following settings: LED power $5 \%$; MST power $80 \%$; fluorescence before $5 \mathrm{~s}$; MST on $30 \mathrm{~s}$; fluorescence after $5 \mathrm{~s}$, and delay $25 \mathrm{~s}$. Individual experiments were measured in duplicate, and $\mathrm{EC}_{50}$ values were determined by plotting the changes in normalized fluorescence in the Thermophoresis and $\mathrm{T}$ jump channels as a function of small molecule concentration. Data points are reported as the mean $\pm S D$ from two independent experiments. Binding curves were fitted using a four-parameter nonlinear regression equation of the GraphPad Prism 8.1.2 suite.

\section{Binding stoichiometry of CB096 to $r\left(G_{4} C_{2}\right)_{8}$ via CD spectroscopy}

CD experiments were performed on a J-815 Jasco spectropolarimeter over the spectral range of $220-450 \mathrm{~nm}$ using a bandwidth of $2 \mathrm{~nm}$ and a scan speed of $50 \mathrm{~nm} / \mathrm{min}$ and a step resolution of $0.2 \mathrm{~nm}$. The RNA sample was folded in $10 \mathrm{mM} \mathrm{Na}_{2} \mathrm{HPO}_{4}, \mathrm{pH}$ 7, for $4 \mathrm{~min}$ at $95{ }^{\circ} \mathrm{C}$ and cooled to room temperature at a final concentration of $10 \mu \mathrm{M}$. CB096 was then added from a $10 \mathrm{mM}$ stock solution prepared in DMSO. CD spectra were recorded using a $1 \mathrm{~mm}$ Quartz Suprasil cuvette 
(Hellma Analytics, 110-128-1-40) at $25{ }^{\circ} \mathrm{C}$ and are representative of two independent experiments. Data points were exported and processed using the GraphPad Prism 8.1.2 software suite.

\section{NMR spectroscopy studies}

All NMR measurements were performed on a Bruker $600 \mathrm{MHz}$ NMR spectrometer equipped with a cryoprobe (Bruker, USA). 1D imino proton spectra were recorded in $90 \% \mathrm{H}_{2} \mathrm{O}-10 \% \mathrm{D}_{2} \mathrm{O}$ using a WATERGATE pulse sequence for water suppression. Typical RNA concentration was $0.1 \mathrm{mM}$, and the recording time for individual NMR spectra was 16 min (512 scans) using a 600 MHz NMR spectrometer. Small molecules were typically added to the folded RNA solution from a $10 \mathrm{mM}$ stock solution in 100\% DMSO-d6 (DMSO-d6 content did not exceed $3 \%$ of the final volume). NMR spectra were processed using MestreNOVA software using 4,4-dimethyl-4silapentane-1-sulfonic acid (DSS, $0.1 \mathrm{mM}$ ) as an internal reference. All NMR spectra are representative of two independent experiments.

\section{COMPUTATIONAL STUDIES}

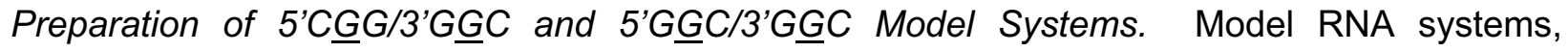
r(CCCGGGG $)_{2}$ and $r(G G G \underline{G C C C})_{2}$, representing 5'CGG/3' $\underline{G G C}$ and 5'GGC/3'C $\underline{G G}$ sites of $r\left(G_{4} C_{2}\right)^{\text {exp }}$ were prepared for MD simulations using the nucgen module of AMBER16. ${ }^{4}$ The $1 \times 1$ GG internal loops in the initial structures were designed to have syn-anti orientations. The initial structures were minimized using a mix of positional and geometric restraints to maintain the global structure in A-form and GG base pairs in cis Watson-Crick/Hoogsteen orientations. The systems were then neutralized with $12 \mathrm{Na}^{+}$ions ${ }^{5}$ and solvated with $4305 \mathrm{TIP}^{2} \mathrm{P}^{6}$ water molecules in a truncated octahedral box. An extra $5 \mathrm{Na}^{+}$and $\mathrm{Cl}^{-}$ions were included in each system. The $\mathrm{Na}^{+}$ concentrations in both systems were $0.21 \mathrm{M}$ once they had reached equilibration. The AMBER forcefield with revised $X^{7}$ and $\alpha / Y^{8}$ torsional parameters was used in the MD simulations. 
Molecular Dynamics (MD) Simulations of 5' $\underline{G} G / 3^{\prime} G G C$ and 5'G $\underline{G} C / 3^{\prime} C \underline{G} G$. The structures were first minimized and then equilibrated as previously described. ${ }^{9,10}$ For each system, $1 \mu \mathrm{s}$ MD simulation with a $2 \mathrm{ps}$ time step were run after minimization and equilibration. NPT dynamics was utilized in each MD simulation where isotropic positional scaling was turned on with a reference pressure of $1 \mathrm{~atm}$ and a pressure relaxation time of $2 \mathrm{ps}$. SHAKE was used to constrain bonds involving hydrogen atoms. ${ }^{11}$ An atom-based long-range hard cutoff of $8.0 \AA$ was used in the production runs. The reference temperature was $300 \mathrm{~K}$ in all the MD simulations. The pmemd.cuda code of AMBER16 was used to perform the MD simulations. ${ }^{4}$

Analysis. The ptraj module of AMBER $16^{4}$ was used to analyze the MD trajectories. X3DNA ${ }^{12}$ was also used to extract global structural properties from the MD trajectories such as the overlap areas displayed in Figure 4A.

\section{CB096's Binding Mode to 5'C $\underline{G} G / 3$ 'G $\underline{G} C$ via MD simulations}

Parameterization of compounds. The force field parameters of CB096 (Supplemental Figure S13A) and $\mathrm{CB} 0966_{T}$ (the tautomeric structure of $\mathrm{CB} 096$; Supplemental Figure S13B) were prepared as previously described. ${ }^{13-16}$ Each compound was parameterized using the Generalized Amber Force Field. ${ }^{17}$ Gaussian $09^{18}$ was used to calculate the RESP charges. ${ }^{19,} 20$ Structures were first optimized, and then the electrostatic potentials as a set of grid points were calculated using the HF/6-31G* basis set (Supplemental Tables S1 \& S2).

The $C B 096-5$ 'C $\underline{G} G / 3^{\prime} G \underline{G} C$ complex. Previously, we applied the dynamic binding approach to study small molecule-RNA interactions. ${ }^{13,14,16,21}$ The same approach was utilized to investigate the binding properties of $\mathrm{CB} 096$ and $\mathrm{CB}_{096}$ to the 5'CGG3' motif within model $r\left(\mathrm{G}_{4} \mathrm{C}_{2}\right)$ RNA duplex. The dynamic binding methodology is a series of simulation technique to investigate small molecule-RNA interactions, where Amber $16 \mathrm{MD}$ package ${ }^{22}$ is utilized under implicit solvent mode $^{23}\left(\mathrm{CG}^{\mathrm{OBC}}, 0.3 \mathrm{M}\right.$ salt concentrations). First, we determined initial bound conformations for 
the CB096 and CB096 ${ }_{\text {T }}$ interacting with the 5'CGG3' binding site by slowly moving the compounds to the RNA using a "reaction coordinate" defined as the distance between the center-of-mass (COM) of the heavy atoms of the closing base pairs and the COM of the heavy atoms of the СВ096 (or СВ096т). Initially, the reaction coordinate between the compound and the closing base pairs was set to be $40 \AA$. The compound was then gradually moved towards the closing base pairs by $1 \AA$ intervals using restraints imposed on the reaction coordinate until it became $0 \AA$. During this process, Watson-Crick (WC) base pairing, torsional and chirality restraints were imposed on the RNA except the loop region so that it maintained the native A-form conformation. Then, the compound was slowly moved away from the closing base pairs by $1 \AA$ intervals until the distance reached to $40 \AA$. During this process, WC base pairing, torsional and chirality restraints were applied to all the RNA residues to transform the RNA back to its apo structure.

We repeated this forced binding process 50 times sequentially and obtained 50 different initial structures for the CB096/CB096 - - 5'CGG/3'GGC binding site complex. We then conducted 50 independent implicit-solvent MD simulations starting from the conformations discovered in the previous step. No restraints were imposed on the loop residues so that the loop freely sampled the conformational space. WC base pairing, torsional, and chirality restraints, however, were imposed on the rest of the RNA residues to maintain the global A-form. One restraint was applied to the reaction coordinate in the MD simulations, so that the distance between the COM of the closing base pairs and COM of the compound did not exceed $10 \AA$ and, thus, made the compound stay around the RNA loop while reorienting itself with respect to the force field to find the optimum bound state.

Each MD simulation was run for 120 ns yielding a total of $6 \mu$ s combined MD trajectory (60K snapshots). Cluster analyses were conducted by using an in-house code. Root-meansquare deviation (RMSD) was calculated throughout the trajectory and the snapshots with RMSD $\leq 1.0 \AA$ were clustered into the same group. The binding free energies of the clusters having more than 100 snapshots were calculated using MM-PBSA method. ${ }^{24}$ Supplemental Tables S3 
and S4 display the results for $\mathrm{CB} 096-5^{\prime} \mathrm{C} \underline{G} \mathrm{G} / 3^{\prime} \mathrm{G} \underline{\mathrm{G}} \mathrm{C}$ and $\mathrm{CB} 096_{\mathrm{T}}-5^{\prime} \mathrm{C} \underline{\mathrm{G}} \mathrm{G} / 3^{\prime} \mathrm{G} \underline{\mathrm{G}} \mathrm{C}$, respectively.

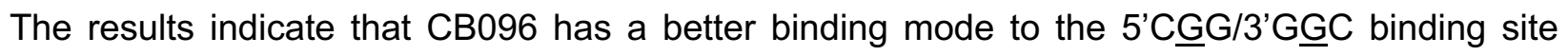
compared to its tautomer $\mathrm{CB} 096_{\mathrm{T}}$ with $\sim 5 \mathrm{kcal} / \mathrm{mol}$ lower binding free energy (Supplemental Tables S3 \& S4). 
Supplementary Table S1. Atom names, types, and charges used to define CB096.

\begin{tabular}{c|c|r|r|r|r} 
Atom Name & Atom Type & Charge & Atom Name & Atom Type & \multicolumn{1}{c}{ Charge } \\
\hline N1 & no & 0.844281 & C17 & ca & -0.205337 \\
O2 & o & -0.486904 & C18 & ca & -0.136146 \\
O3 & o & -0.486904 & H19 & ha & 0.151091 \\
C4 & ca & -0.026529 & C20 & ca & -0.340963 \\
C5 & ca & -0.216291 & H21 & ha & 0.177511 \\
H6 & ha & 0.206435 & C22 & ca & 0.316526 \\
C7 & ca & -0.291092 & O23 & oh & -0.646484 \\
H8 & ha & 0.200664 & H24 & ho & 0.473607 \\
C9 & ca & 0.241924 & C25 & ca & 0.284489 \\
C10 & ca & 0.345253 & C26 & ca & -0.186112 \\
C11 & ca & -0.294583 & H27 & ha & 0.134388 \\
H12 & ha & 0.230853 & O28 & os & -0.279257 \\
N13 & n2 & -0.640793 & C29 & c3 & -0.078466 \\
C14 & c2 & 0.674209 & H30 & h1 & 0.091352 \\
N15 & na & -0.645754 & H31 & h1 & 0.091352 \\
H16 & hn & 0.406328 & H32 & h1 & 0.091352
\end{tabular}


Supplementary Table S2. Atom names, types, and charges used to define CB096 $\mathrm{T}$.

\begin{tabular}{c|c|r|r|r|r} 
Atom Name & Atom Type & Charge & Atom Name & Atom Type & \multicolumn{1}{c}{ Charge } \\
\hline N1 & no & 0.862957 & C17 & ca & -0.199055 \\
O2 & o & -0.493264 & C18 & ca & -0.188256 \\
O3 & o & -0.493264 & H19 & ha & 0.148808 \\
C4 & ca & -0.036346 & C20 & ca & -0.245241 \\
C5 & ca & -0.213894 & H21 & ha & 0.195974 \\
H6 & ha & 0.200056 & C22 & ca & 0.314614 \\
C7 & ca & -0.267065 & O23 & oh & -0.580521 \\
H8 & ha & 0.195480 & H24 & ho & 0.420537 \\
C9 & ca & 0.367402 & C25 & ca & 0.137979 \\
C10 & ca & 0.224604 & C26 & ca & -0.095830 \\
C11 & ca & -0.318666 & H27 & ha & 0.116994 \\
H12 & ha & 0.234547 & O28 & os & -0.281539 \\
N13 & na & -0.654439 & C29 & c3 & -0.128854 \\
H14 & hn & 0.423669 & H30 & h1 & 0.110359 \\
C15 & c2 & 0.684071 & H31 & h1 & 0.110359 \\
N16 & n2 & -0.662535 & H32 & h1 & 0.110359
\end{tabular}




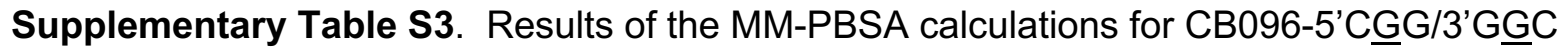
complex.

\begin{tabular}{|c|c|c|c|c|}
\hline \multirow{2}{*}{$\begin{array}{c}\text { Cluster Name } \\
\text { cluster_2087 }\end{array}$} & \multicolumn{3}{|c|}{$\Delta \mathbf{G}_{\text {MM-PBSA }}(\mathrm{kcal} / \mathrm{mol})$} & \multirow{2}{*}{$\begin{array}{c}\text { Total \# of snapshots observed in } \\
\text { combined trajectory } \\
136\end{array}$} \\
\hline & -38.3098 & \pm & 3.6351 & \\
\hline cluster_2083 & -38.2729 & \pm & 3.3501 & 201 \\
\hline cluster_2086 & -35.6766 & \pm & 3.5327 & 146 \\
\hline cluster 2082 & -35.5177 & \pm & 3.3708 & 174 \\
\hline cluster_2085 & -35.1116 & \pm & 3.7389 & 156 \\
\hline cluster_2088 & -34.7147 & $\overline{ \pm}$ & 3.1510 & 172 \\
\hline cluster_1309 & -32.3591 & \pm & 2.9876 & 151 \\
\hline cluster-1306 & -31.7013 & $\overline{ \pm}$ & 3.1161 & 220 \\
\hline cluster_1323 & -31.2877 & \pm & 2.8212 & 189 \\
\hline cluster_1319 & -31.0363 & \pm & 2.9796 & 135 \\
\hline cluster-1314 & -30.7889 & \pm & 3.3544 & 186 \\
\hline cluster 1331 & -29.7572 & \pm & 3.0228 & 146 \\
\hline cluster_358 & -28.5350 & \pm & 2.5924 & 171 \\
\hline cluster_375 & -28.3780 & \pm & 2.6119 & 111 \\
\hline cluster_362 & -27.8432 & \pm & 2.7535 & 289 \\
\hline cluster_369 & -26.6504 & \pm & 2.3511 & 100 \\
\hline cluster_442 & -26.5997 & \pm & 2.6541 & 129 \\
\hline cluster_359 & -26.0381 & \pm & 3.1311 & 745 \\
\hline cluster_40 & -25.8937 & \pm & 2.9074 & 144 \\
\hline cluster_977 & -25.6091 & \pm & 3.1931 & 642 \\
\hline cluster_973 & -25.6060 & $\overline{ \pm}$ & 2.8887 & 523 \\
\hline cluster_368 & -24.7888 & \pm & 3.1254 & 113 \\
\hline cluster 45 & -24.6061 & $\overline{ \pm}$ & 2.7683 & 155 \\
\hline cluster-990 & -24.2917 & \pm & 3.2381 & 105 \\
\hline cluster_57 & -24.1080 & \pm & 3.0285 & 119 \\
\hline cluster_62 & -23.7731 & \pm & 3.1252 & 112 \\
\hline cluster_31 & -23.0697 & $\overline{ \pm}$ & 3.1359 & 121 \\
\hline cluster_24 & -22.4502 & \pm & 2.6247 & 145 \\
\hline cluster_22 & -22.2837 & \pm & 2.8815 & 118 \\
\hline cluster 158 & -21.4862 & \pm & 2.6857 & 419 \\
\hline cluster_159 & -21.1214 & \pm & 2.8140 & 273 \\
\hline cluster_164 & -20.6947 & \pm & 2.8311 & 141 \\
\hline cluster_165 & -20.5476 & \pm & 2.7262 & 349 \\
\hline cluster_386 & -18.7385 & \pm & 3.3414 & 476 \\
\hline cluster_384 & -18.2930 & \pm & 3.4650 & 325 \\
\hline cluster_383 & -17.7997 & \pm & 3.3337 & 608 \\
\hline cluster_388 & -17.6021 & \pm & 3.7131 & 119 \\
\hline cluster_389 & -17.3088 & \pm & 3.5051 & 103 \\
\hline cluster 99 & -16.9507 & \pm & 3.3292 & 190 \\
\hline cluster_101 & -16.7598 & \pm & 3.2184 & 306 \\
\hline cluster 124 & -16.5387 & \pm & 3.3764 & 261 \\
\hline cluster 459 & -16.3805 & \pm & 3.4146 & 204 \\
\hline cluster_380 & -15.9509 & \pm & 3.1245 & 127 \\
\hline cluster_385 & -15.8978 & \pm & 3.2898 & 309 \\
\hline cluster_241 & -15.1147 & \pm & 3.8866 & 144 \\
\hline cluster_114 & -14.4825 & \pm & 4.1515 & 144 \\
\hline cluster_327 & -14.4774 & \pm & 3.7118 & 146 \\
\hline cluster 108 & -14.1982 & \pm & 3.3056 & 304 \\
\hline cluster 267 & -14.1211 & \pm & 4.2036 & 164 \\
\hline cluster_95 & -13.9526 & \pm & 3.1216 & 190 \\
\hline cluster 96 & -13.9159 & \pm & 3.7154 & 226 \\
\hline cluster_519 & -13.8698 & \pm & 4.9501 & 117 \\
\hline cluster 87 & -13.8459 & \pm & 3.5874 & 278 \\
\hline cluster 102 & -13.7604 & \pm & 3.1105 & 616 \\
\hline cluster 382 & -13.4985 & \pm & 3.9416 & 158 \\
\hline cluster_266 & -13.4506 & \pm & 5.6052 & 191 \\
\hline cluster_245 & -13.2236 & \pm & 4.0775 & 205 \\
\hline cluster 236 & -13.1579 & \pm & 4.7586 & 248 \\
\hline cluster_91 & -12.9026 & \pm & 3.2068 & 194 \\
\hline cluster_94 & -12.5219 & \pm & 3.2317 & 175 \\
\hline cluster_331 & -12.1887 & \pm & 3.0228 & 118 \\
\hline cluster_97 & -11.9813 & \pm & 3.7607 & 117 \\
\hline cluster_-1363 & -11.6895 & $\overline{ \pm}$ & 3.2304 & 121 \\
\hline cluster 487 & -10.1032 & \pm & 3.3089 & 425 \\
\hline
\end{tabular}


Supplementary Table S4. Results of the MM-PBSA calculations for CB096 ${ }_{T}-5^{\prime} \mathrm{C} \underline{G} G / 3^{\prime} G \underline{G} C$ complex.

\begin{tabular}{|c|c|c|c|c|}
\hline \multirow{2}{*}{$\begin{array}{l}\text { Cluster Name } \\
\text { cluster_2132 }\end{array}$} & \multicolumn{3}{|c|}{$\Delta \mathbf{G}_{\text {MM-PBSA }}(\mathrm{kcal} / \mathrm{mol})$} & \multirow{2}{*}{$\begin{array}{c}\text { Total \# of snapshots observed in } \\
\text { combined trajectory }\end{array}$} \\
\hline & -32.9371 & \pm & 3.3677 & \\
\hline cluster_2136 & -32.5730 & \pm & 4.2201 & 242 \\
\hline cluster 934 & -32.2999 & \pm & 3.3458 & 107 \\
\hline cluster_ 1538 & -29.5342 & \pm & 2.8160 & 189 \\
\hline cluster_920 & -29.2003 & \pm & 3.1827 & 121 \\
\hline cluster 825 & -29.0788 & \pm & 3.3713 & 114 \\
\hline cluster_1175 & -29.0423 & \pm & 2.4422 & 105 \\
\hline cluster_1537 & -28.5862 & \pm & 2.6508 & 108 \\
\hline cluster 913 & -28.4990 & \pm & 3.4795 & 114 \\
\hline cluster 134 & -28.4708 & \pm & 2.6072 & 182 \\
\hline cluster_1176 & -28.3592 & \pm & 2.4346 & 115 \\
\hline cluster 904 & -28.3440 & \pm & 3.1245 & 110 \\
\hline cluster 136 & -28.1889 & \pm & 2.6470 & 939 \\
\hline cluster_427 & -27.8128 & \pm & 2.7866 & 140 \\
\hline cluster 1117 & -27.7955 & \pm & 3.3753 & 101 \\
\hline cluster 341 & -27.5654 & \pm & 2.5727 & 111 \\
\hline cluster_909 & -27.2871 & \pm & 3.8306 & 231 \\
\hline cluster 167 & -27.2593 & \pm & 3.0054 & 158 \\
\hline cluster 163 & -27.0794 & \pm & 3.0109 & 105 \\
\hline cluster 138 & -26.9226 & \pm & 2.5081 & 165 \\
\hline cluster 1115 & -26.8378 & \pm & 4.2568 & 121 \\
\hline cluster_137 & -26.7023 & \pm & 2.7429 & 368 \\
\hline cluster 145 & -26.5099 & \pm & 2.4066 & 262 \\
\hline cluster 144 & -26.4283 & \pm & 2.8507 & 594 \\
\hline cluster 146 & -26.3119 & \pm & 2.9124 & 609 \\
\hline cluster_911 & -26.2083 & \pm & 4.1131 & 131 \\
\hline cluster 416 & -25.8326 & \pm & 3.1630 & 118 \\
\hline cluster 147 & -25.6621 & \pm & 3.3245 & 141 \\
\hline cluster-142 & -25.5717 & \pm & 3.0370 & 1145 \\
\hline cluster 158 & -25.4473 & \pm & 2.5918 & 119 \\
\hline cluster_156 & -25.4412 & \pm & 2.8547 & 102 \\
\hline cluster 135 & -25.3932 & \pm & 2.5309 & 306 \\
\hline cluster 43 & -25.0490 & \pm & 2.8737 & 103 \\
\hline cluster_509 & -24.1601 & \pm & 3.0768 & 222 \\
\hline cluster 396 & -24.0872 & \pm & 2.8728 & 149 \\
\hline cluster 169 & -24.0144 & \pm & 2.8901 & 223 \\
\hline cluster_328 & -23.8380 & \pm & 2.9049 & 144 \\
\hline cluster 165 & -23.7224 & \pm & 2.8580 & 288 \\
\hline cluster 543 & -23.5349 & \pm & 3.7203 & 112 \\
\hline cluster 830 & -23.2613 & \pm & 2.6464 & 222 \\
\hline cluster_32 & -23.2071 & \pm & 2.9203 & 116 \\
\hline cluster 833 & -22.6317 & \pm & 2.5474 & 198 \\
\hline cluster_828 & -22.5417 & \pm & 2.8628 & 106 \\
\hline cluster 327 & -22.2657 & \pm & 2.6976 & 356 \\
\hline cluster 404 & -22.0311 & \pm & 3.1319 & 120 \\
\hline cluster_860 & -20.7424 & \pm & 2.8592 & 137 \\
\hline cluster 129 & -16.2530 & \pm & 3.7666 & 145 \\
\hline cluster 205 & -15.6768 & \pm & 3.0266 & 107 \\
\hline cluster_208 & -15.5632 & \pm & 3.4594 & 139 \\
\hline cluster 110 & -15.5286 & \pm & 2.9056 & 580 \\
\hline cluster 348 & -15.0474 & \pm & 3.2987 & 114 \\
\hline cluster_139 & -14.9313 & \pm & 2.9333 & 317 \\
\hline cluster 121 & -14.8348 & \pm & 3.0479 & 653 \\
\hline cluster 197 & -14.7984 & \pm & 3.3079 & 155 \\
\hline cluster_400 & -14.6873 & \pm & 3.4565 & 140 \\
\hline cluster 209 & -14.6722 & \pm & 3.6763 & 170 \\
\hline cluster 122 & -14.5168 & \pm & 3.1401 & 698 \\
\hline cluster_100 & -14.3993 & \pm & 3.0601 & 844 \\
\hline cluster 330 & -14.2558 & \pm & 3.1549 & 287 \\
\hline cluster 149 & -14.2484 & \pm & 3.3336 & 343 \\
\hline cluster 109 & -14.1837 & \pm & 3.4238 & 101 \\
\hline cluster 563 & -14.1219 & \pm & 3.3276 & 115 \\
\hline cluster_115 & -13.8233 & \pm & 3.5485 & 493 \\
\hline cluster 107 & -13.7813 & \pm & 3.2851 & 102 \\
\hline
\end{tabular}




\section{CELLULAR STUDIES}

\section{Cell Culture}

HEK293T cells (CRL-3216) were purchased from ATCC and maintained in growth medium [Dulbecco's Modified Eagle Medium (DMEM; Corning) supplemented with 10\% fetal bovine serum (FBS; Sigma Aldrich), 1\% penicillin-streptomycin (P/S; Corning) and 1\% glutaGRO supplement (Corning)] at $37^{\circ} \mathrm{C}$ and $5 \% \mathrm{CO}_{2}$.

\section{Cytotoxicity of CB096 in $\left(\mathrm{G}_{4} \mathrm{C}_{2}\right)_{66}$-transfected HEK293T cells}

HEK293T cells $\left(4 \times 10^{6}\right.$ cells $)$ were plated in a $100 \mathrm{~mm}$ diameter dish and grown overnight at 37 ${ }^{\circ} \mathrm{C} / 5 \% \mathrm{CO}_{2}$. The cells were then transfected for at least $6 \mathrm{~h}$ with $9 \mu \mathrm{g}$ of a plasmid encoding $r\left(G_{4} C_{2}\right)_{66}$-noATG-GFP ${ }^{15}$ using JetPrime reagent (Polyplus) according to the vendor's procedure. Afterwards, the cells were washed twice with $1 \times$ DPBS (10 mL each), collected using trypsin$\operatorname{EDTA}(0.25 \%)$ (Gibco), plated (8000 cells/20 $\mu \mathrm{L}$ ) in a 384-well clear bottom white plate (Corning) in growth medium, and incubated overnight. In addition, reference wells without cells were also generated. The next day, $5 \mu \mathrm{L}$ of growth medium containing vehicle $(0.5 \%$ DMSO final concentration/well) or CB096 at varying concentrations (0.5\% DMSO final concentration/well) was added, and the cells were incubated for $24 \mathrm{~h}$. After the incubation period, $25 \mu \mathrm{L}$ CellTiter-Glo reagent (Promega) was added to each well, and the samples were mixed for $5 \mathrm{~min}$ on an orbital shaker. After an additional incubation at room temperature for $10 \mathrm{~min}$ (protected from light), the luminescent signal was recorded using the Molecular Devices SpectraMax M5 plate reader. The reported data were generated by subtracting the luminescence signal of the reference wells (without cells) and normalized to signal generated from the vehicle-treated samples. The reported results from two independent experiments each performed in triplicate. 


\section{Cell proliferation assay in $\left(G_{4} C_{2}\right)_{66}$-transfected HEK293T cells}

HEK293T cells ( $\sim 60-70 \%$ confluency) in $60 \mathrm{~mm}$ diameter dishes were transfected for at least $6 \mathrm{~h}$ with $4.5 \mu \mathrm{g}$ of a plasmid encoding $r\left(\mathrm{G}_{4} \mathrm{C}_{2}\right)_{66}{ }^{15}$ using Lipofectamine 3000 (Thermo Fisher Scientific) according to the manufacturer's procedure. Afterwards, cells were washed twice with $1 \times$ DPBS (5 mL each), collected using Trypsin-EDTA (0.25\%) solution, and plated in a clear 96 -well plates. Each well contained 10,000 HEK293T cells in a final volume of $90 \mu \mathrm{L}$ of growth medium. After overnight incubation, the cells were treated with $10 \mu \mathrm{L}$ growth medium containing vehicle $(0.5 \%$ DMSO final concentration/well) or CB096 (25 $\mu \mathrm{M}$ final concentration in 0.5\% DMSO/well) and incubated for an addition $24 \mathrm{~h}$ at $37^{\circ} \mathrm{C}$. Background absorption at $450 \mathrm{~nm}$ and $600 \mathrm{~nm}$ (reference wavelength) was measured with a Molecular Devices SpectraMax M5 plate reader. Then, $10 \mu \mathrm{L}$ of the WST-1 reagent (Sigma Aldrich) was added, and the absorption of the formazan product formed was measured at $450 \mathrm{~nm}$ as well as at the reference wavelength of $600 \mathrm{~nm}$ (reference

wavelength). Background measured prior to addition of WST-1 was then subtracted from all samples. An assessment of cell proliferation was generated by subtracting the reference signal at $600 \mathrm{~nm}$ from the absorbance readout at $450 \mathrm{~nm}$ and were reported relative to the vehicletreated samples. The reported results are from two independent experiments, each performed in triplicate.

\section{Inhibition of RAN translation in $r\left(G_{4} C_{2}\right)_{66}$-transfected HEK293T cells}

Approximately $4 \times 10^{6}$ HEK293T cells were plated in $100 \mathrm{~mm}$ diameter cell culture dishes overnight

and co-transfected the following day with $9 \mu \mathrm{g}$ of a plasmid encoding $\left(\mathrm{G}_{4} \mathrm{C}_{2}\right)_{66}-$ No ATG-GFP ${ }^{15}$ and $1 \mu \mathrm{g}$ of a plasmid encoding mCherry (for normalization) using JetPrime transfection reagent (Polyplus) according to the manufacturer's instructions. After at least $4 \mathrm{~h}$, cells were washed with $1 \times$ DPBS, trypsinized, and plated (8000 cells/well) in $20 \mu \mathrm{L}$ of growth medium into 384-well clear bottom black plates. After at least $2 \mathrm{~h}$ incubation, the compound of interest at the indicated 
concentration (final concentration of $0.5 \%$ DMSO) or vehicle $(0.5 \%$ DMSO) was added in $5 \mu \mathrm{L}$ growth medium. After overnight incubation, the growth medium was removed, and the cells were lysed in $100 \mathrm{mM}$ potassium phosphate lysis buffer, $\mathrm{pH} 7.8$, and $0.2 \%(\mathrm{v} / \mathrm{v})$ Triton X-100. Fluorescence was measured using a BioTek FLx800 with 530/25 nm (excitation) and 590/35 nm (emission) filters for mCherry and 485/20 nm (excitation) and 528/20 nm (emission) filters for GFP as previously reported. ${ }^{15}$ Background was determined by measuring the corresponding fluorescence intensity of untransfected cells. The background-corrected ratio of GFP to mCherry was used to determine the biological effect of the compounds on RAN translation relative to the vehicle treated samples. The reported results are from two independent experiments performed in triplicate. The effect of compound on canonical translation was completed analogously except a plasmid encoding GFP was used instead of $\left(\mathrm{G}_{4} \mathrm{C}_{2}\right)_{66}-$ No $A T G-G F P$.

Alternatively HEK293T cells stably expressing Lentiviral-S-tdTomato (Addgene Plasmid $\# 112579)^{25}$ were seeded into $10 \mathrm{~cm}$ diameter dishes and grown to $\sim 80 \%$ confluency, and then co-transfected with plasmids encoding $\left(\mathrm{G}_{4} \mathrm{C}_{2}\right)_{66}-$ No ATG-firefly luciferase, Renilla luciferase, and ATG-GFP using Invitrogen Lipofectamine 3000 following manufacturer's protocol. Following transfection, cells were seeded into 384 -well plates at a density of $0.4 \times 10^{6}$ cells $/ \mathrm{mL}$ and allowed to adhere overnight. Compound was then added for $24 \mathrm{~h}$ with a final concentration of $<1 \% \mathrm{DMSO}$. Luciferase activity was measured using Nano-Glo® Dual-Luciferase $®$ Reporter Assay System (Promega) following the manufacturer's recommendations. Luminescence was measured by a Molecular Devices SpectraMax M5 plates reader and integration time of $500 \mathrm{~ms}$.

\section{Determination of $r\left(G_{4} C_{2}\right)_{66}-$ No ATG-GFP levels via RT-qPCR}

Transfection of HEK293T cells was performed as described above. Approximately $5 \mathrm{~h}$ posttransfection, the cells were collected and seeded into 24 -well plates $(125,000$ cells per well in 0.8 $\mathrm{mL}$ of growth medium). After at least $4 \mathrm{~h}$, vehicle (0.5\% DMSO final concentration/well) or CB096 (0.5\% DMSO final concentration/well) were added in a final volume of $200 \mu \mathrm{L}$, and the cells were 
incubated for $24 \mathrm{~h}$. After the incubation period, the medium was removed, and total RNA was extracted using a Quick-RNA Miniprep Kit (Zymo Research) according to the manufacturer's protocol. Approximately $0.2 \mu \mathrm{g}$ of total RNA, as determined by its absorbance at $260 \mathrm{~nm}$ using a Nanodrop UV spectrophotometer, was used for reverse transcription using qScript Kit (Quantbio) according to the manufacturer's protocol. RT-qPCR was performed on $4 \mathrm{ng}$ cDNA on a $7900 \mathrm{HT}$ Fast Real Time PCR System (Applied Biosystem) using Power SYBR Green Master Mix (Applied Biosystems) as previously reported. ${ }^{15}$ Expression levels of mRNAs were normalized to $18 S$.

\section{Rescue of tdTomato Mislocalization}

HEK293T cells that stably express Lentiviral-S-tdTomato ${ }^{25}$ were seeded into $10 \mathrm{~cm}$ diameter dishes and grown to $\sim 80 \%$ confluency. They were then co-transfected with plasmids encoding $\left(\mathrm{G}_{4} \mathrm{C}_{2}\right)_{66}$-No ATG-firefly luciferase, Renilla luciferase, and ATG-GFP using Lipofectamine 3000 following manufacturer's protocol. Following transfection, cells were seeded into 24-well glass bottom plates at a density of $0.4 \times 10^{6}$ cells/well and incubated overnight at $37^{\circ} \mathrm{C}$. The following day fresh growth medium containing compound or vehicle was added to each well. As a positive control, cells were treated with $10 \mu \mathrm{M}$ KPT-350 (KPT). After a $24 \mathrm{~h}$ incubation with compound, the cells were fixed with $4 \%$ paraformaldehyde prepared in $1 \times$ DPBS, and the nuclei were stained with DAPI. Cells were imaged by confocal microscopy at 554/581 nm (tdTomato), 488/510 nm (GFP), and 358/461 nm (DAPI). The ratio of tdTomato in the nucleus and cytoplasm was quantified from three biological replicates; five images were taken from each replicate and 200 cells were evaluated per image. Statistics were measured using a one-way ANOVA test.

\section{Rescue of Stress Granule Formation}

HEK293T cells that stably express Lentiviral-S-tdTomato were maintained in growth medium and grown to $\sim 80 \%$ confluency in $10 \mathrm{~cm}$ diameter dishes. Two types of stress granules were studied: 
those induced by $r\left(G_{4} C_{2}\right)^{\text {exp }}$ expression and those chemically induced with sodium arsenite. To study the former, the aforementioned HEK293T cells were were transfected with $4.3 \mu \mathrm{g}$ of a plasmid encoding $\left(\mathrm{G}_{4} \mathrm{C}_{2}\right)_{66}-$ No ATG-GFP using Lipofectamine 3000 transfection agent per the manufacturer's protocol. To induce the latter, the aforementioned HEK293T cells were transfected with $4.3 \mu \mathrm{g}$ of a plasmid encoding ATG-GFP (akin to $\left(\mathrm{G}_{4} \mathrm{C}_{2}\right)_{66}$-No ATG-GFP) followed by treatment with $0.5 \mathrm{mM}$ sodium arsenite treatment for $1 \mathrm{~h}$ at $37^{\circ} \mathrm{C}$, as previously described. ${ }^{26}$

To determine if compounds could rescue nuclear pore dysfunction, following transfection the cells were seeded into 24 -well glass bottom plates at a density of $0.4 \times 10^{6}$ cells/well and incubated overnight at $37^{\circ} \mathrm{C}$. The next day fresh growth medium containing compound or vehicle was added to each well, and the samples were incubated for $24 \mathrm{~h}$ at $37^{\circ} \mathrm{C}$. After the treatment period, the cells were fixed in 4\% paraformaldehyde prepared in $1 \times$ DPBS for 20 min and then permeabilized by treatment with $0.1 \%(\mathrm{v} / \mathrm{v})$ Triton X-100 in $1 \times$ DPBS for $10 \mathrm{~min}$, both steps at room temperature. The cells were washed three times with $1 \times$ DPBS, followed by blocking with $1 \times$ TBST supplemented with $5 \%$ goat serum for $1 \mathrm{~h}$ at room temperature. After, the cells were incubated with Rabbit anti-ATXN2/SCA2 (1:200 dilution; Bethyl Laboratories; Catalog \#: A301$118 \mathrm{~A}$ ) in $1 \times$ TBST supplemented with $5 \%$ goat serum for $16 \mathrm{~h}$ at $4{ }^{\circ} \mathrm{C}$ (with shaking). The cells were washed three times with $1 \times$ TBST for 10 min each at room temperature, and the secondary antibody [Goat anti-Rabbit IgG (H+L) Secondary Antibody, DyLight 650; 1:200 dilution; ThermoFisher Scientific; Catalog \#: 84546] was added in 1× TBST supplemented with 5\% goat serum for $1 \mathrm{~h}$ at room temperature (with shaking). The cells were then washed three times with $1 \times$ TBST, stained with $1 \mu \mathrm{g} / \mathrm{mL}$ DAPI in $1 \times$ PBS for $10 \mathrm{~min}$, and then imaged by confocal microscopy at 554/581 nm (tdTomato), 488/510 nm (GFP), 358/461 nm (DAPI), and 633/649 nm (DyLight 650). 


\section{SYNTHETIC METHODS}

\section{General Synthetic Methods}

All reagents and solvents used for chemical synthesis were purchased from commercial sources

(Sigma Aldrich and Alfa Aesar) and used without further purification unless mentioned otherwise.

DMSO-d6, MeOD and $\mathrm{D}_{2} \mathrm{O}$ solvents for NMR experiments were acquired from Cambridge Isotope Labs and used as received.

\section{Instrumentation}

${ }^{1} \mathrm{H}$ - and ${ }^{13} \mathrm{C}-\mathrm{NMR}$ spectra were acquired on a $400 \mathrm{MHz}$ Bruker Avance spectrometer and a Bruker $600 \mathrm{MHz}$ spectrometer equipped with a cryoprobe. Chemical shifts (ס) are reported in ppm relative to tetramethylsilane (TMS) or the respective NMR solvent; coupling constants $(\mathrm{J})$ are in Hertz (Hz). Abbreviations used are s, singlet; bs, broad singlet; d, doublet; dd, doublet of doublets; $\mathrm{t}$, triplet; dt, doublet of triplets; td, triplet of doublets; $\mathrm{tt}$, triplet of triplets; bt, broad triplet; q, quartet; m, multiplet; and bm, broad multiplet.

Mass spectra were recorded on a Varian 500-MS IT mass spectrometer.

General procedure for the synthesis of CB096-derivatives (compounds 2-10, 13-17)

Experimental procedure for the synthesis of derivatives 2-10 and 13-17 was slightly modified from previous reports, ${ }^{27-30}$ e.g. the reaction temperature was set to $\sim 100^{\circ} \mathrm{C}$ instead of $65^{\circ} \mathrm{C}$.

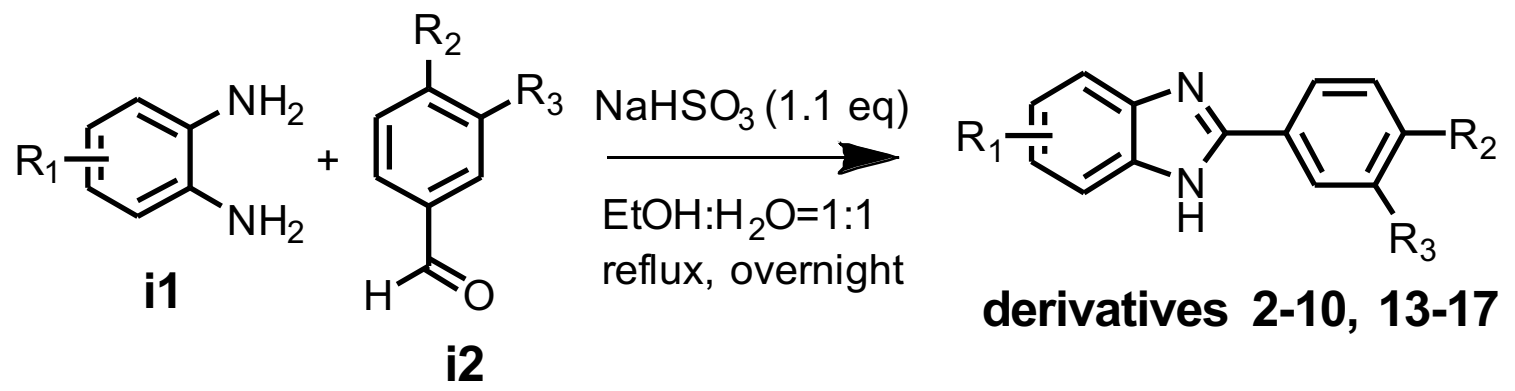

Scheme 1. General procedure for the synthesis of CB096-like derivatives 2-10, 13-17. 
To a $0{ }^{\circ} \mathrm{C}$ cooled solution of i2 (4-hydroxy-3-methoxybenzaldehyde; $\mathrm{R}_{2}=\mathrm{OH}, \mathrm{R}_{3}=\mathrm{OMe} ; 154.14$ $\mathrm{mg}, 1 \mathrm{mmol}, 1 \mathrm{eq})$ in $\mathrm{EtOH}(2.5 \mathrm{~mL})$ was added dropwise a solution of sodium bisulfite $(115 \mathrm{mg}$, $1.1 \mathrm{mmol}, 1.1 \mathrm{eq})$ in $\mathrm{H}_{2} \mathrm{O}\left(2.5 \mathrm{~mL}\right.$ ) and the resulting mixture was stirred at $0{ }^{\circ} \mathrm{C}$ for $30 \mathrm{~min}$. $\mathbf{I 1}$ (ophenylenediamine; $\left.\mathrm{R}_{1}=-\mathrm{H} ; 108 \mathrm{mg}, 1 \mathrm{mmol}, 1 \mathrm{eq}\right)$ in $1: 1 \mathrm{EtOH}: \mathrm{H}_{2} \mathrm{O}(2.5 \mathrm{~mL})$ was added dropwise and the mixture was stirred at reflux overnight. The volatiles were removed under reduced pressure and the residue was adsorbed onto silica and purified via silica gel chromatography $(0-100 \%$ EtOAc in Hexanes) to give 4-(1H-benzo[d]imidazol-2-yl)-2methoxyphenol (1, $129.6 \mathrm{mg}, 0.54 \mathrm{mmol}, 54 \%)$.

Compounds $2-10$ and $13-17$ were obtained in yields varying from 35 to $77 \%$ and were also characterized in previous reports. ${ }^{29-31,32,33,34,28,35}$ Compounds 2-10 and 13-17 obtained by the procedure herein were fully characterized by means of ${ }^{1} \mathrm{H}$ and ${ }^{13} \mathrm{C}-\mathrm{NMR}$ as well as high-resolution mass spectrometry (HRMS).

2-methoxy-4-(4-nitro-1H-benzo[d]imidazol-2-yl)phenol (compound 2)<smiles>COc1cc(-c2nc3cccc([N+](=O)[O-])c3[nH]2)ccc1O</smiles>

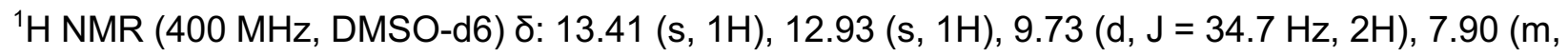
$8 \mathrm{H}), 7.39(\mathrm{t}, \mathrm{J}=8.0 \mathrm{~Hz}, 6 \mathrm{H}), 6.93(\mathrm{~d}, \mathrm{~J}=8.3 \mathrm{~Hz}, 6 \mathrm{H}), 3.92(\mathrm{~s}, 6 \mathrm{H})$.

${ }^{13} \mathrm{C}$ NMR (151 MHz, DMSO-d6) $\delta: 155.60,155.30,149.59,149.37,147.94,147.69,146.80$, 138.09, 137.68, 137.54, 132.89, 129.23, 126.03, 121.68, 121.43, 121.22, 120.91, 120.07, 119.99, $118.27,118.14,117.61,115.91,115.58,111.66,110.80,55.90,55.79$.

HRMS: Calcd. for $\mathrm{C}_{14} \mathrm{H}_{12} \mathrm{~N}_{3} \mathrm{O}_{4} 286.0828\left[\mathrm{M}+\mathrm{H}^{+}\right]$; Found: 286.0830 . 
2-methoxy-4-(5-methyl-1H-benzo[d]imidazol-2-yl)phenol (compound 3)<smiles>COc1cc(-c2nc3cc(C)ccc3[nH]2)ccc1O</smiles>

${ }^{1} \mathrm{H}$ NMR (400 MHz, DMSO-d6) ס: 12.65 (s, 1H), 9.53 (s, 1H), 7.75 (t, J = 3.6 Hz, 1H), 7.61 (dd, J $=8.2,1.9 \mathrm{~Hz}, 2 \mathrm{H}), 7.48(\mathrm{~s}, 1 \mathrm{H}), 7.15(\mathrm{~d}, \mathrm{~J}=3.9 \mathrm{~Hz}, 2 \mathrm{H}), 6.91(\mathrm{~d}, \mathrm{~J}=8.2 \mathrm{~Hz}, 1 \mathrm{H}), 3.89(\mathrm{~s}, 3 \mathrm{H})$, $3.35(\mathrm{~s}, 3 \mathrm{H})$.

${ }^{13} \mathrm{C}$ NMR (151 MHz, DMSO-d6) ס: 151.82, 148.45, 147.85, 121.44, 119.64, 115.68, 110.32, 55.67. HRMS: Calcd. for $\mathrm{C}_{15} \mathrm{H}_{15} \mathrm{~N}_{2} \mathrm{O}_{2} 255.1134\left[\mathrm{M}+\mathrm{H}^{+}\right]$; Found: 255.1138.

2-methoxy-4-(5-methoxy-1H-benzo[d]imidazol-2-yl)phenol (compound 4)<smiles>COc1ccc2[nH]c(-c3ccc(O)c(OC)c3)nc2c1</smiles>

${ }^{1} \mathrm{H}$ NMR (400 MHz, DMSO-d6) ס: 12.49 (s, 2H), 9.48 (d, J = $\left.12.2 \mathrm{~Hz}, 2 \mathrm{H}\right), 7.70$ (d, J = 6.8 Hz, 2H), $7.56(\mathrm{t}, \mathrm{J}=9.2 \mathrm{~Hz}, 2 \mathrm{H}), 7.48(\mathrm{~d}, \mathrm{~J}=8.6 \mathrm{~Hz}, 1 \mathrm{H}), 7.35(\mathrm{~d}, \mathrm{~J}=7.8 \mathrm{~Hz}, 1 \mathrm{H}), 7.15(\mathrm{~s}, 1 \mathrm{H}), 6.95$ $(\mathrm{s}, 1 \mathrm{H}), 6.90(\mathrm{~d}, \mathrm{~J}=8.2 \mathrm{~Hz}, 2 \mathrm{H}), 6.79(\mathrm{t}, \mathrm{J}=6.8 \mathrm{~Hz}, 2 \mathrm{H}), 3.88(\mathrm{~s}, 6 \mathrm{H}), 3.79(\mathrm{~s}, 6 \mathrm{H})$.

${ }^{13} \mathrm{C}$ NMR (151 MHz, DMSO-d6) $\delta: 155.70,155.25,152.13,151.01,148.28,148.11,144.74$, 138.38, 135.58, 129.40, 121.72, 121.61, 119.43, 119.20, 118.80, 115.66, 111.31, 111.10, 110.50, $110.17,110.02,101.20,94.40,55.84,55.66,55.47,55.40$.

HRMS: Calcd. for $\mathrm{C}_{15} \mathrm{H}_{15} \mathrm{~N}_{2} \mathrm{O}_{3} 271.1083\left[\mathrm{M}+\mathrm{H}^{+}\right]$; Found: 271.1086.

4-(5-fluoro-1H-benzo[d]imidazol-2-yl)-2-methoxyphenol (compound 5)<smiles>COc1cc(-c2nc3cc(F)ccc3[nH]2)ccc1O</smiles>

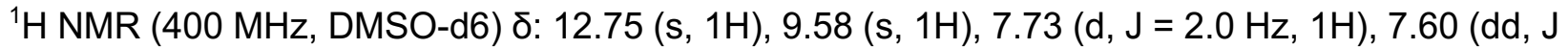
= 8.2, $2.0 \mathrm{~Hz}, 1 \mathrm{H}), 7.52(\mathrm{dd}, \mathrm{J}=8.4,4.9 \mathrm{~Hz}, 1 \mathrm{H}), 7.34(\mathrm{~d}, \mathrm{~J}=8.2 \mathrm{~Hz}, 1 \mathrm{H}), 7.06-6.96(\mathrm{~m}, 1 \mathrm{H})$, $6.92(\mathrm{~d}, \mathrm{~J}=8.2 \mathrm{~Hz}, 1 \mathrm{H}), 3.89(\mathrm{~s}, 3 \mathrm{H})$.

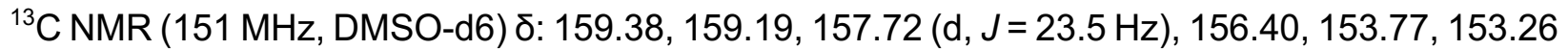
(d, $J=121.2 \mathrm{~Hz}), 148.69,131.66,121.15,119.77,119.12,115.74,114.43(\mathrm{~d}, J=9.6 \mathrm{~Hz}), 111.48$, 110.33, 109.84, 109.67, 109.43, 109.27, 103.99, 103.84, 97.53, 97.35, 55.69. 
HRMS: Calcd. for $\mathrm{C}_{14} \mathrm{H}_{12} \mathrm{FN}_{2} \mathrm{O}_{2} 259.0883\left[\mathrm{M}+\mathrm{H}^{+}\right]$; Found: 259.0885 .

4-(5-chloro-1H-benzo[d]imidazol-2-yl)-2-methoxyphenol (compound 6)<smiles>COc1cc(-c2nc3cc(Cl)ccc3[nH]2)ccc1O</smiles>

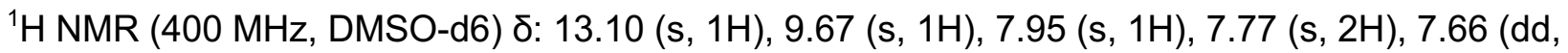
$J=8.3,1.7 \mathrm{~Hz}, 1 \mathrm{H}), 7.48(\mathrm{~d}, J=8.4 \mathrm{~Hz}, 1 \mathrm{H}), 6.95$ (dd, $J=8.2,0.7 \mathrm{~Hz}, 1 \mathrm{H}), 3.90(\mathrm{~s}, 3 \mathrm{H})$.

${ }^{13} \mathrm{C}$ NMR (151 MHz, DMSO-d6) $\delta: 153.22,148.91,147.91,126.05,121.96,120.71,119.98$, $115.76,110.45,55.72$.

HRMS: Calcd. for $\mathrm{C}_{14} \mathrm{H}_{12}{ }^{35} \mathrm{CIN}_{2} \mathrm{O}_{2} 275.0587$ [M+H']; Found: 275.0589.

2-methoxy-4-(5-(methylsulfonyl)-1H-benzo[d]imidazol-2-yl)phenol (compound 7)<smiles>COc1cc(-c2nc3cc(S(C)(=O)=O)ccc3[nH]2)ccc1O</smiles>

${ }^{1} \mathrm{H}$ NMR (400 MHz, MeOD) $\delta: ~ 8.14(\mathrm{~s}, 1 \mathrm{H}), 7.80$ (dd, J = 8.5, $\left.1.7 \mathrm{~Hz}, 1 \mathrm{H}\right), 7.73(\mathrm{t}, \mathrm{J}=4.1 \mathrm{~Hz}, 2 \mathrm{H})$, 7.59 (dd, J = 8.3, 2.1 Hz, 1H), 6.94 (dd, J = 7.8, 4.1 Hz, 1H), 3.98 (s, 3H), $3.15(\mathrm{~s}, 3 \mathrm{H})$.

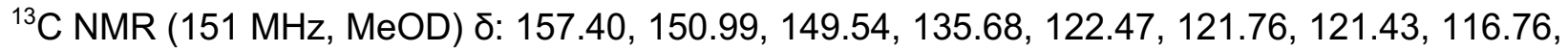
111.43, 56.49, 45.04 .

HRMS: Calcd. for $\mathrm{C}_{15} \mathrm{H}_{15} \mathrm{~N}_{2} \mathrm{O}_{4} \mathrm{~S} 319.0753\left[\mathrm{M}+\mathrm{H}^{+}\right]$; Found: 319.0756 .

2-methoxy-4-(5-(trifluoromethyl)-1H-benzo[d]imidazol-2-yl)phenol (compound 8)<smiles>COc1cc(-c2nc3cc(C(F)(F)F)ccc3[nH]2)ccc1O</smiles>

${ }^{1} \mathrm{H}$ NMR (400 MHz, DMSO-d6) ס: 13.11 (s, 1H), 9.69 (d, J = 6.7 Hz, 1H), 7.96 (s, 1H), 7.79 (d, J $=12.8 \mathrm{~Hz}, 2 \mathrm{H}), 7.72-7.63(\mathrm{~m}, 2 \mathrm{H}), 7.53-7.45(\mathrm{~m}, 1 \mathrm{H}), 6.95(\mathrm{~d}, \mathrm{~J}=8.2 \mathrm{~Hz}, 1 \mathrm{H}), 3.91(\mathrm{~s}, 3 \mathrm{H})$.

${ }^{13} \mathrm{C}$ NMR (151 MHz, DMSO-d6) $\delta: 154.49,149.16,147.96,126.07,124.27,120.55,120.23$, $118.49,115.81,110.59,55.73$. 
HRMS: Calcd. for $\mathrm{C}_{15} \mathrm{H}_{12} \mathrm{~F}_{3} \mathrm{~N}_{2} \mathrm{O}_{2} 309.0851$ [M+H']; Found: 309.0854 .

2-(4-hydroxy-3-methoxyphenyl)-1H-benzo[d]imidazole-5-carboxylic acid (compound 9)<smiles>COc1cc(-c2nc3cc(C(=O)O)ccc3[nH]2)ccc1O</smiles>

${ }^{1} \mathrm{H}$ NMR (400 MHz, DMSO-d6) ס: 12.97 (s, 1H), 12.66 (s, 1H), 9.64 (s, 1H), 8.12 (s, 1H), 7.80 (d, $\mathrm{J}=8.3 \mathrm{~Hz}, 1 \mathrm{H}), 7.76(\mathrm{~d}, \mathrm{~J}=2.0 \mathrm{~Hz}, 1 \mathrm{H}), 7.64(\mathrm{dd}, \mathrm{J}=8.2,2.0 \mathrm{~Hz}, 2 \mathrm{H}), 6.94(\mathrm{~d}, \mathrm{~J}=8.3 \mathrm{~Hz}, 1 \mathrm{H})$, $3.90(\mathrm{~s}, 3 \mathrm{H})$.

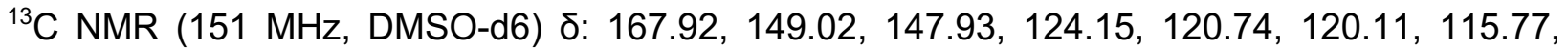
$110.53,55.73$.

HRMS: Calcd. for $\mathrm{C}_{15} \mathrm{H}_{13} \mathrm{~N}_{2} \mathrm{O}_{4} 285.0875\left[\mathrm{M}+\mathrm{H}^{+}\right]$; Found: 285.0879 .

2-(4-hydroxy-3-methoxyphenyl)-1H-benzo[d]imidazole-5-carbonitrile (compound 10)

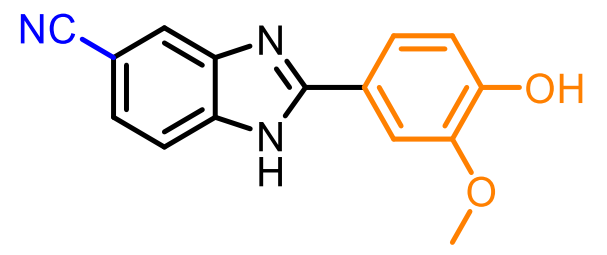

${ }^{1} \mathrm{H}$ NMR (400 MHz, DMSO-d6) $\delta: ~ 13.21(s, 1 H), 9.74(\mathrm{~s}, 1 \mathrm{H}), 8.06(\mathrm{~s}, 1 \mathrm{H}), 7.76(\mathrm{~d}, J=1.8 \mathrm{~Hz}$, $1 \mathrm{H}), 7.66(\mathrm{dd}, J=8.3,1.7 \mathrm{~Hz}, 2 \mathrm{H}), 7.55(\mathrm{dd}, J=8.3,1.4 \mathrm{~Hz}, 1 \mathrm{H}), 6.94(\mathrm{~d}, J=8.3 \mathrm{~Hz}, 1 \mathrm{H}), 3.89$ $(\mathrm{s}, 3 \mathrm{H})$.

${ }^{13} \mathrm{C}$ NMR (151 MHz, DMSO-d6) $\delta: ~ 149.38,148.01,125.48,120.43,120.31,120.25,115.87$, 110.67, 103.54, 55.77.

HRMS: Calcd. for $\mathrm{C}_{15} \mathrm{H}_{12} \mathrm{~N}_{3} \mathrm{O}_{2} 266.0930\left[\mathrm{M}+\mathrm{H}^{+}\right]$; Found: 266.0933.

4-(5-nitro-1H-benzo[d]imidazol-2-yl)phenol (compound 13)<smiles>O=[N+]([O-])c1ccc2[nH]c(-c3ccc(O)cc3)nc2c1</smiles> 
${ }^{1} \mathrm{H}$ NMR (400 MHz, DMSO-d6) ס: $13.36(\mathrm{~s}, 1 \mathrm{H}), 10.20$ (s, 1H), 8.46 (s, 1H), 8.07 (dd, J = 18.4, $8.2 \mathrm{~Hz}, 3 \mathrm{H}), 7.67(\mathrm{~s}, 1 \mathrm{H}), 6.95(\mathrm{~d}, \mathrm{~J}=8.7 \mathrm{~Hz}, 2 \mathrm{H})$.

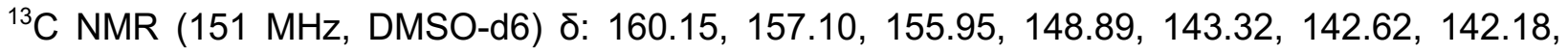
139.93, 134.33, 128.89, 119.91, 118.30, 117.90, 117.63, 116.01, 114.26, 111.33, 107.41.

HRMS: Calcd. for $\mathrm{C}_{13} \mathrm{H}_{10} \mathrm{~N}_{3} \mathrm{O}_{3}$ 256.0722 [M+H']; Found: 256.0726.

2,6-dimethoxy-4-(5-nitro-1H-benzo[d]imidazol-2-yl)phenol (compound 14)

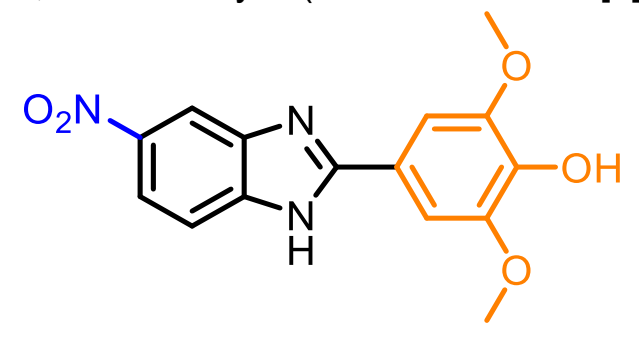

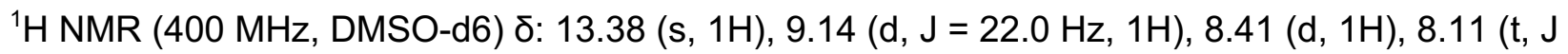
$=8.1 \mathrm{~Hz}, 1 \mathrm{H}), 7.73(\mathrm{dd}, \mathrm{J}=36.2,8.8 \mathrm{~Hz}, 1 \mathrm{H}), 7.52(\mathrm{~s}, 2 \mathrm{H}), 3.90(\mathrm{~s}, 6 \mathrm{H})$.

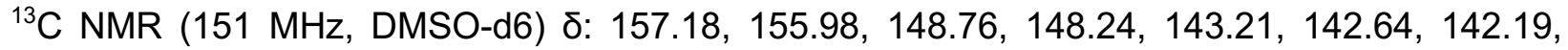
$139.89,138.75,138.47,134.33,118.90,118.81,118.28,117.93,117.57,114.23,111.27,107.32$, 104.75, 104.53, 56.17.

HRMS: Calcd. for $\mathrm{C}_{15} \mathrm{H}_{14} \mathrm{~N}_{3} \mathrm{O}_{5} 316.0933\left[\mathrm{M}+\mathrm{H}^{+}\right]$; Found: 316.0937.

2-(benzo[d][1,3]dioxol-5-yl)-5-nitro-1H-benzo[d]imidazole (compound 15)

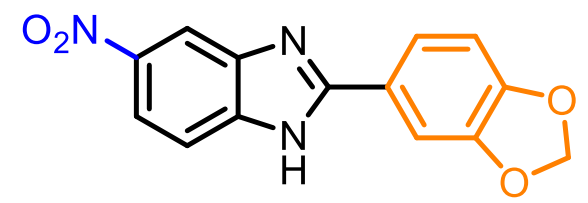

${ }^{1} \mathrm{H}$ NMR (400 MHz, DMSO-d6) $\delta: ~ 8.41(\mathrm{~d}, \mathrm{~J}=1.8 \mathrm{~Hz}, 1 \mathrm{H}), 8.10$ (dd, J = 8.9, 2.2 Hz, 1H), 7.76 $(\mathrm{dd}, \mathrm{J}=8.2,1.7 \mathrm{~Hz}, 1 \mathrm{H}), 7.73-7.67(\mathrm{~m}, 2 \mathrm{H}), 7.13(\mathrm{~d}, \mathrm{~J}=8.2 \mathrm{~Hz}, 1 \mathrm{H}), 6.15(\mathrm{~s}, 2 \mathrm{H})$.

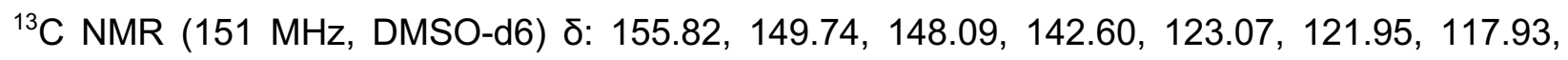
108.98, 106.84, 101.94.

HRMS: Calcd. for $\mathrm{C}_{14} \mathrm{H}_{10} \mathrm{~N}_{3} \mathrm{O}_{4} 284.0671\left[\mathrm{M}+\mathrm{H}^{+}\right]$; Found: 284.0675.

2-(2,3-dihydrobenzo[b][1,4]dioxin-6-yl)-5-nitro-1H-benzo[d]imidazole (compound 16) 


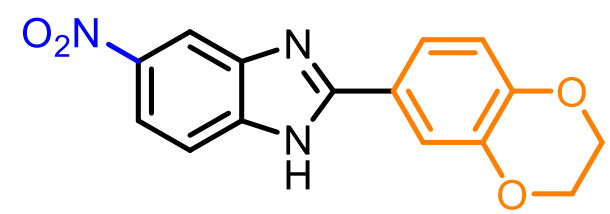

${ }^{1} \mathrm{H}$ NMR (400 MHz, DMSO-d6) ס: 13.42 (s, 1H), 8.47 (s, 1H), 8.09 (d, J = 8.0 Hz, 1H), 7.70 (d, J $=6.4 \mathrm{~Hz}, 3 \mathrm{H}), 7.06(\mathrm{~d}, J=9.0 \mathrm{~Hz}, 1 \mathrm{H}), 4.33(\mathrm{~s}, 4 \mathrm{H})$.

${ }^{13} \mathrm{C}$ NMR (151 MHz, DMSO-d6) ס: 143.79, 122.18, 120.50, 117.92, 115.73, 64.48, 64.19.

HRMS: Calcd. for $\mathrm{C}_{15} \mathrm{H}_{12} \mathrm{~N}_{3} \mathrm{O}_{4} 298.0828\left[\mathrm{M}+\mathrm{H}^{+}\right]$; Found: 298.0830.

5-nitro-2-(3,4,5-trimethoxyphenyl)-1H-benzo[d]imidazole (compound 17)

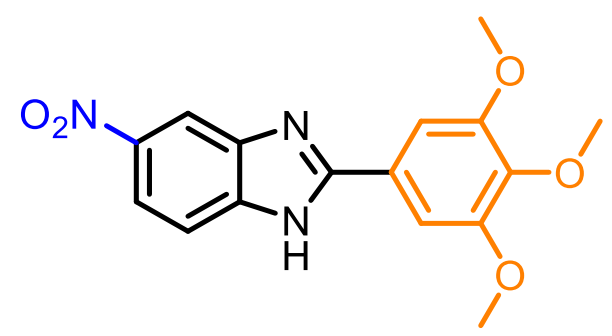

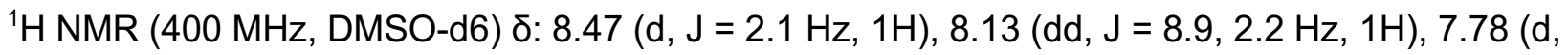
$\mathrm{J}=8.9 \mathrm{~Hz}, 1 \mathrm{H}), 7.57(\mathrm{~s}, 2 \mathrm{H}), 3.92(\mathrm{~s}, 6 \mathrm{H}), 3.76(\mathrm{~s}, 3 \mathrm{H})$.

${ }^{13} \mathrm{C}$ NMR (151 MHz, DMSO-d6) ס: 155.66, 153.34, 142.78, 139.91, 123.95, 118.13, 104.49, 60.23, 56.15.

HRMS: Calcd. for $\mathrm{C}_{16} \mathrm{H}_{16} \mathrm{~N}_{3} \mathrm{O}_{5} 330.1090\left[\mathrm{M}+\mathrm{H}^{+}\right]$; Found: 330.1095. 


\section{COMPOUND CHARACTERIZATION}

\section{Compound 2}

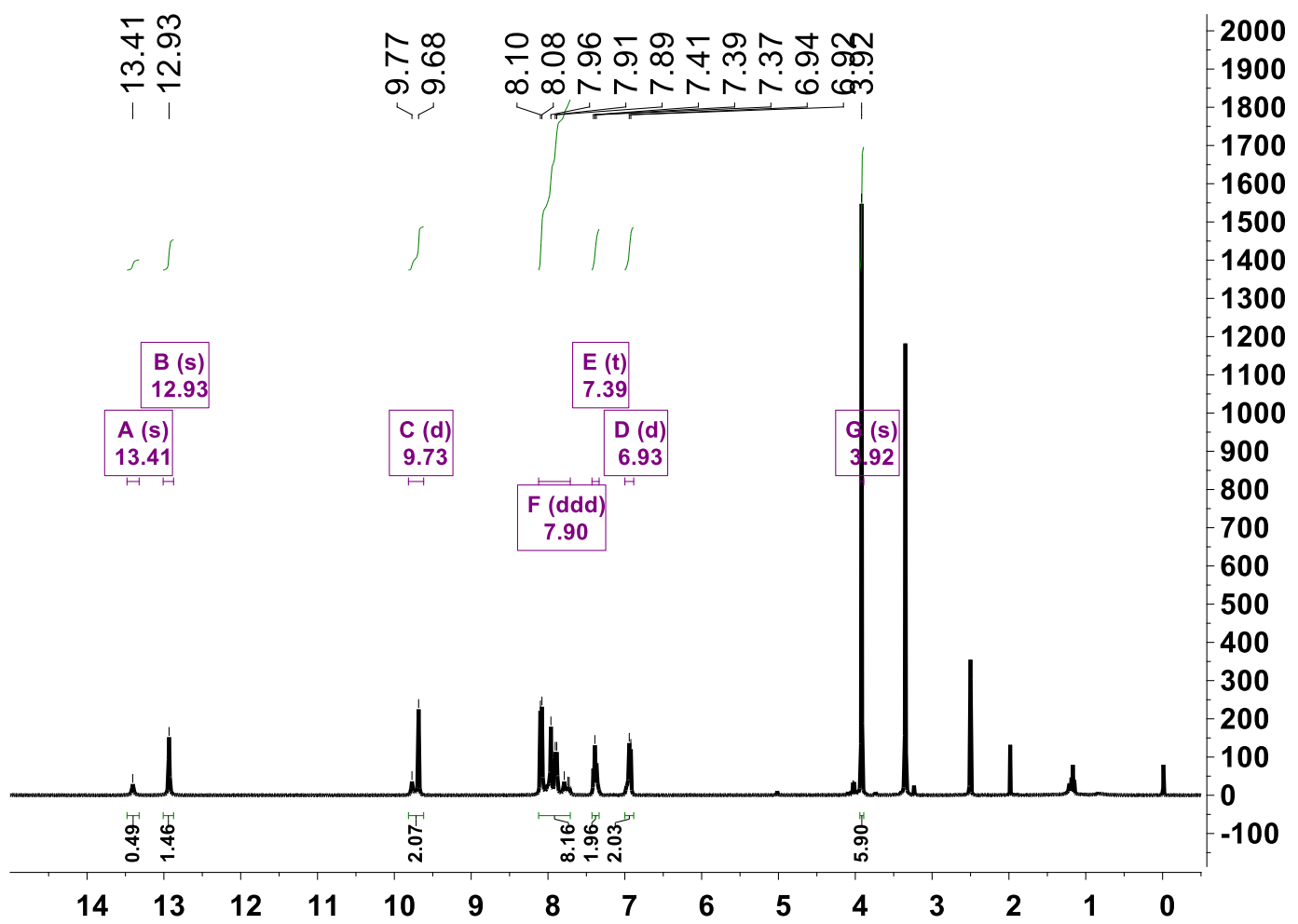

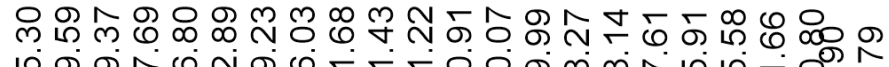

吕守守守付

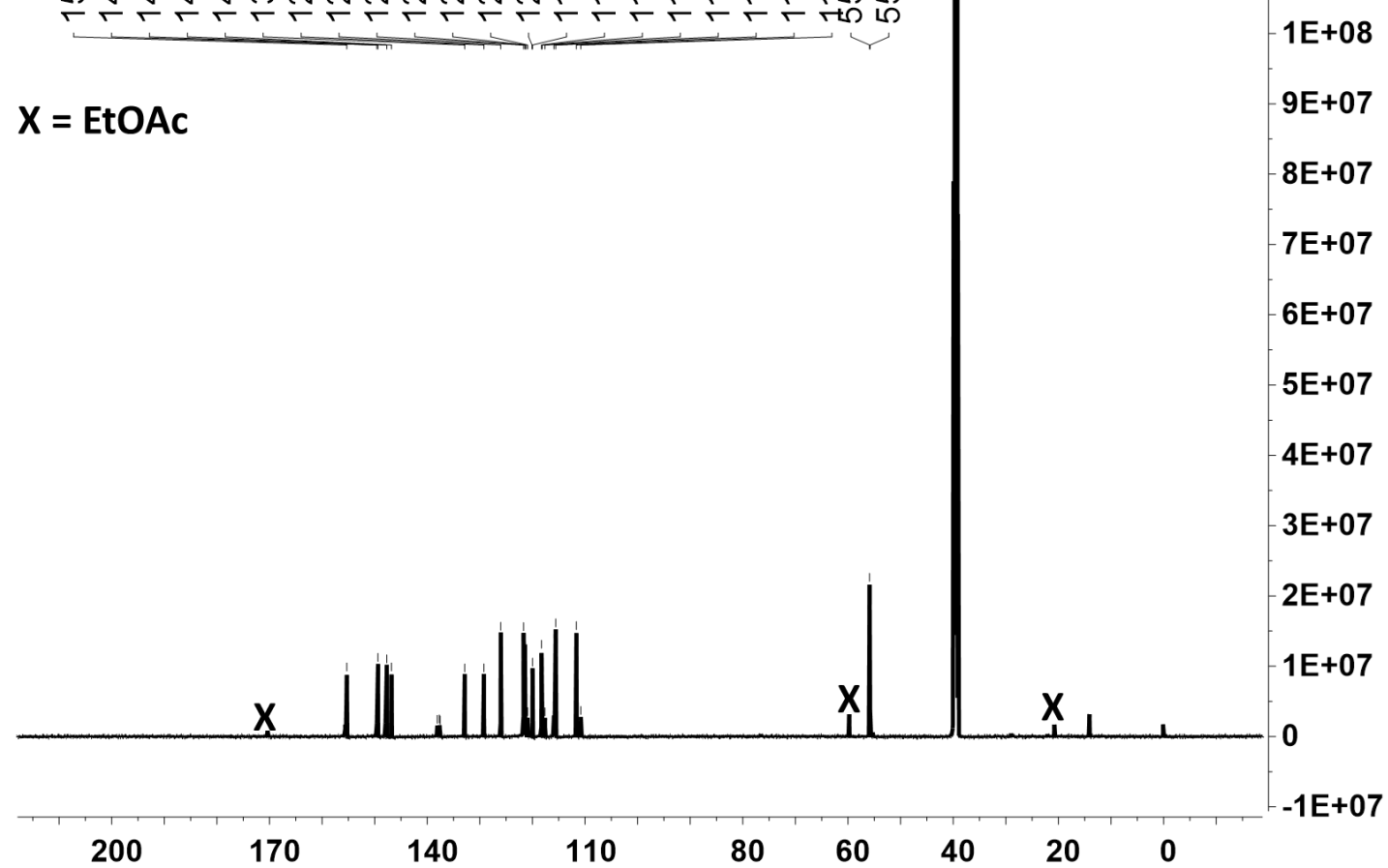


Compound 3
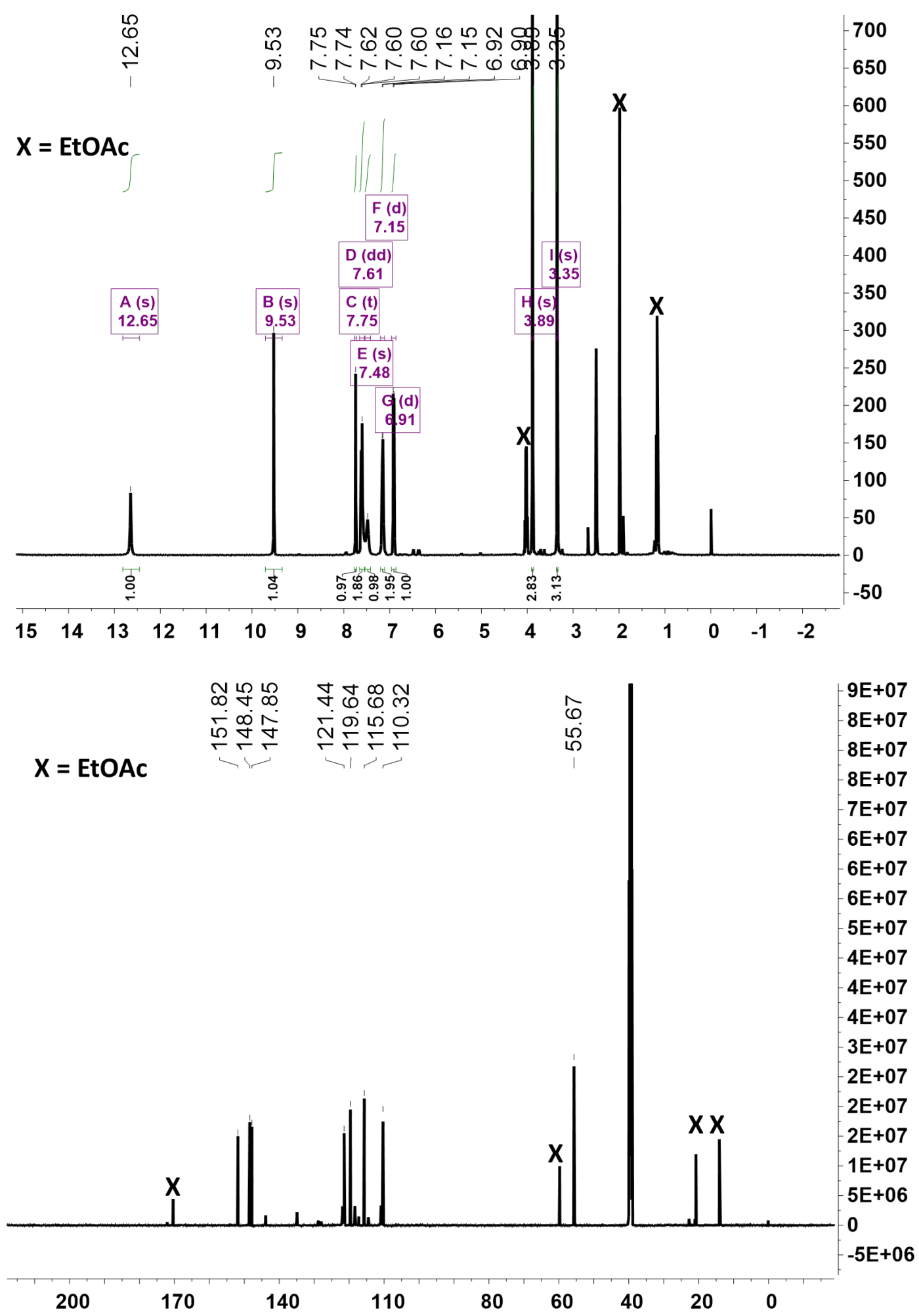
Compound 4
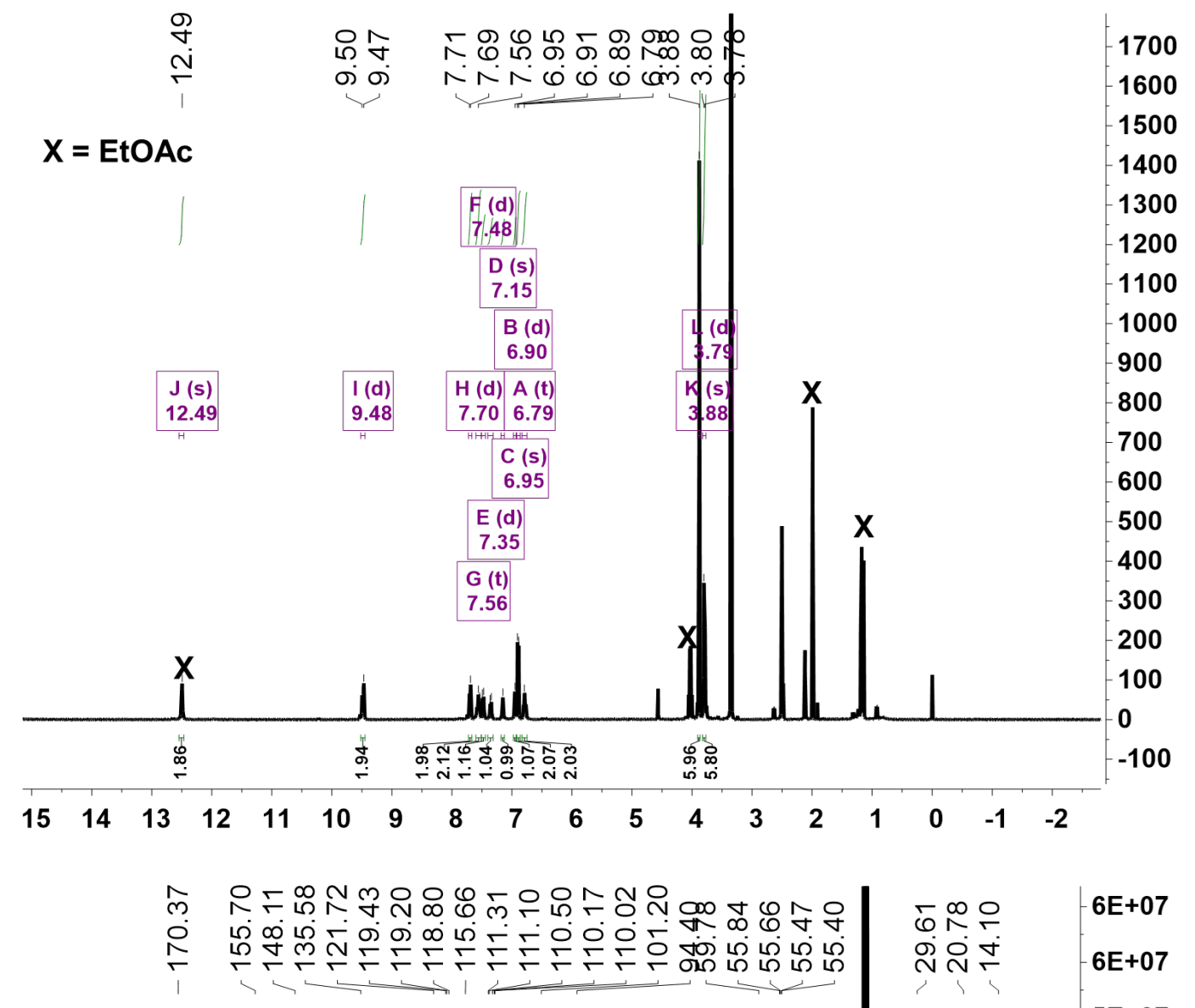

$X=$ EtOAc

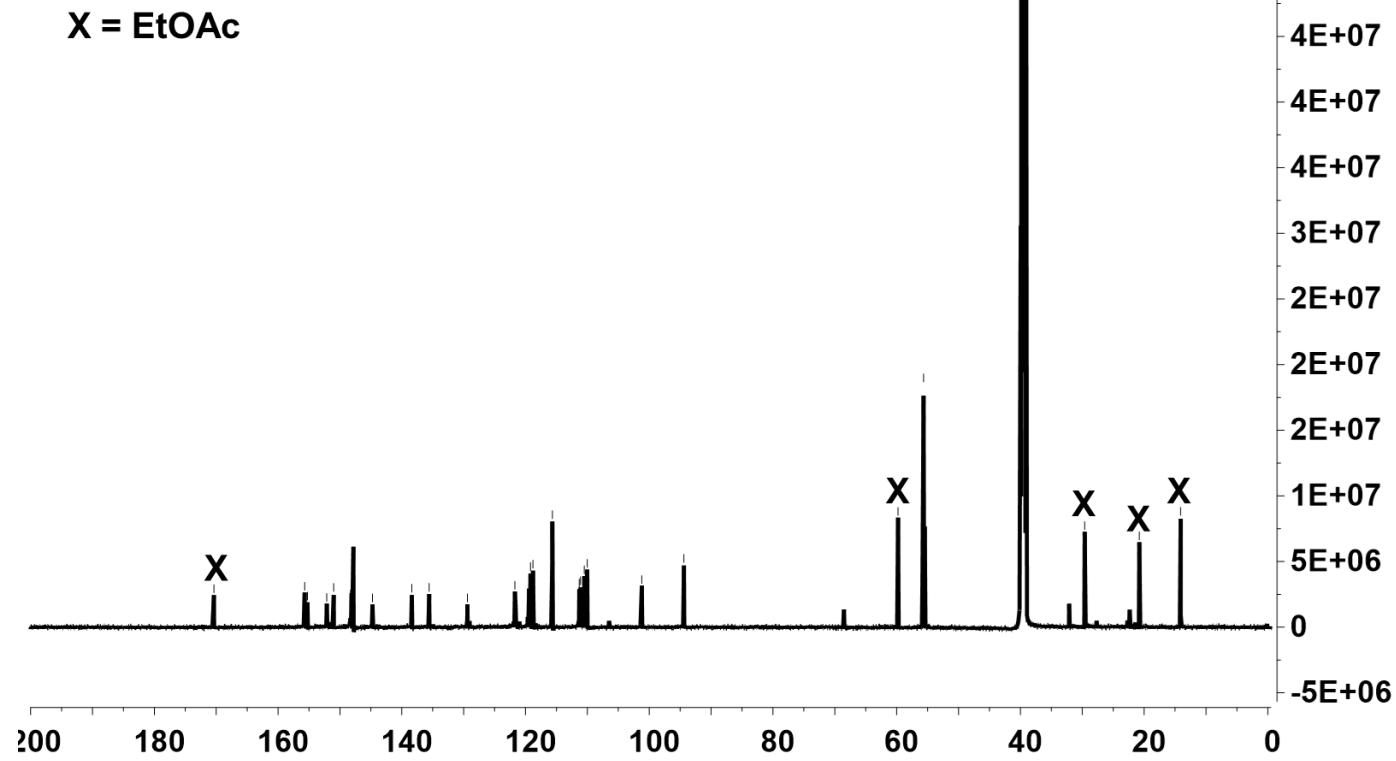




\section{Compound 5}

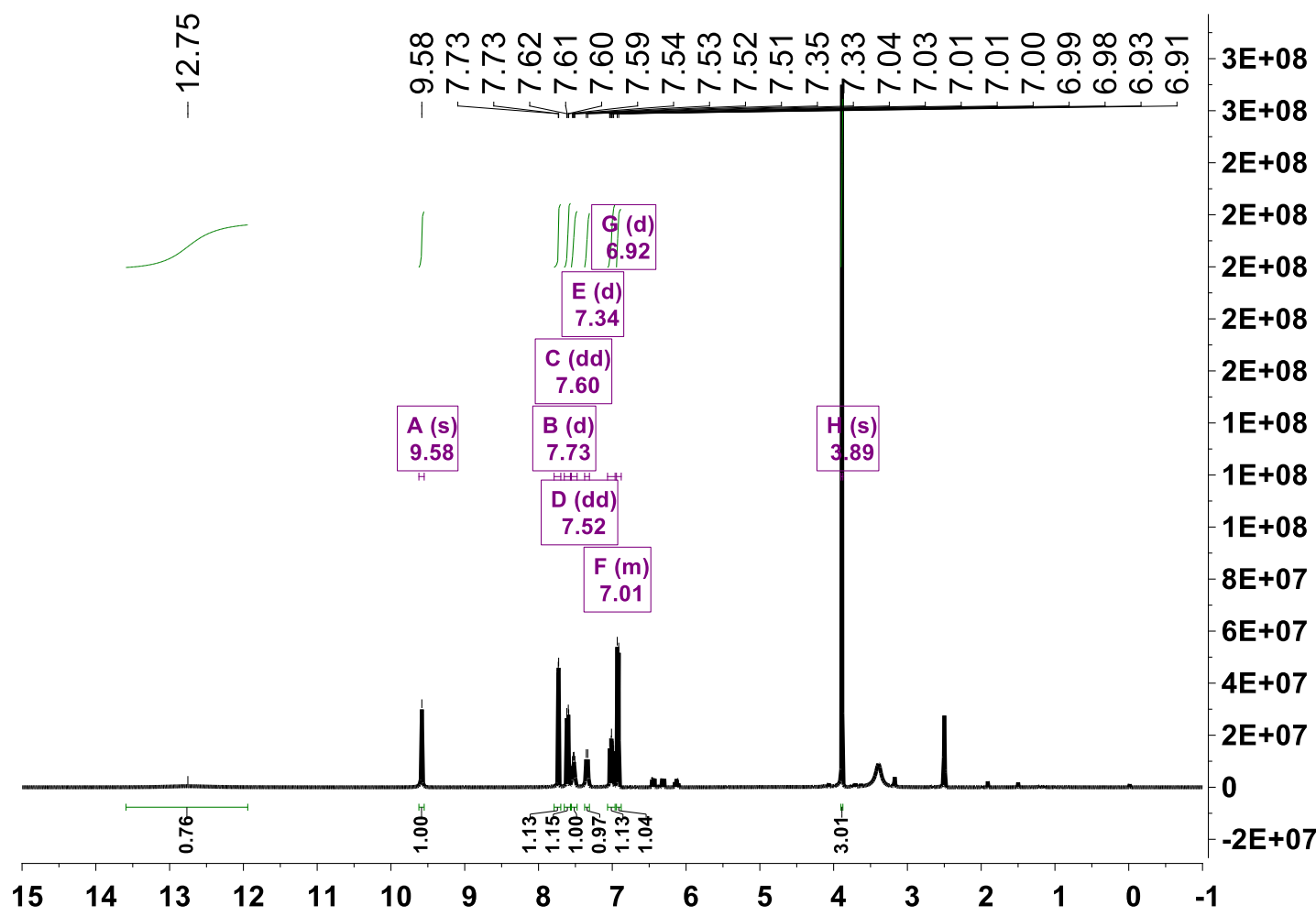

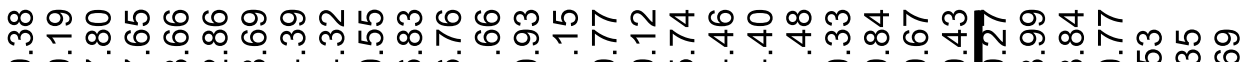
官官 占

$9 E+07$

$8 E+07$

7E+07

$6 E+07$

$5 E+07$

$4 E+07$

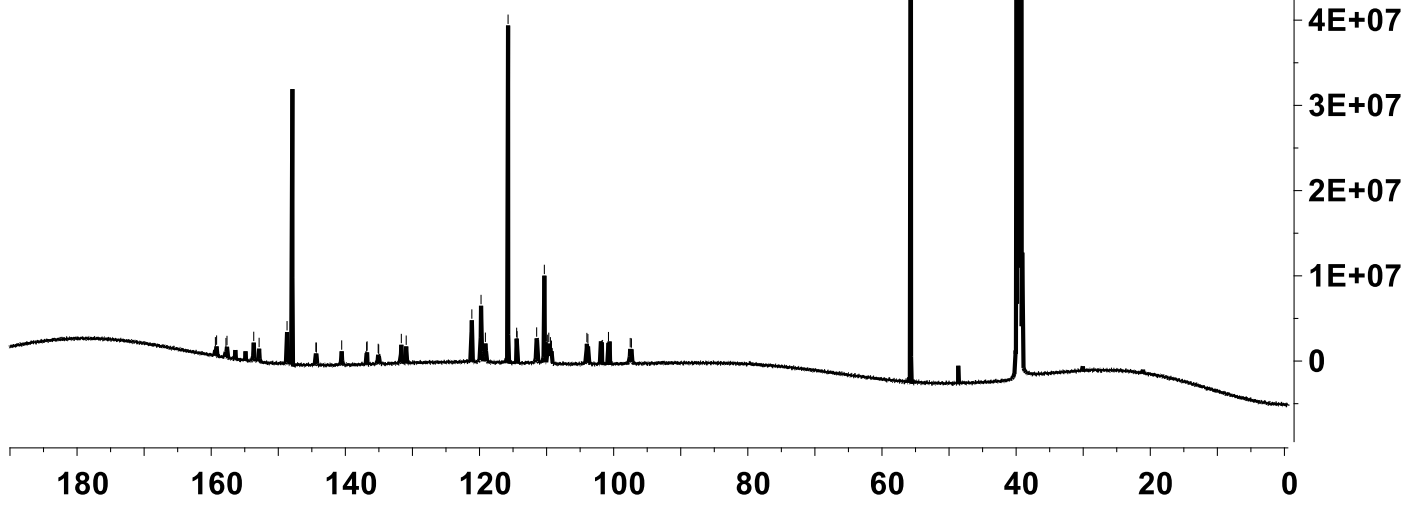




\section{Compound 6}
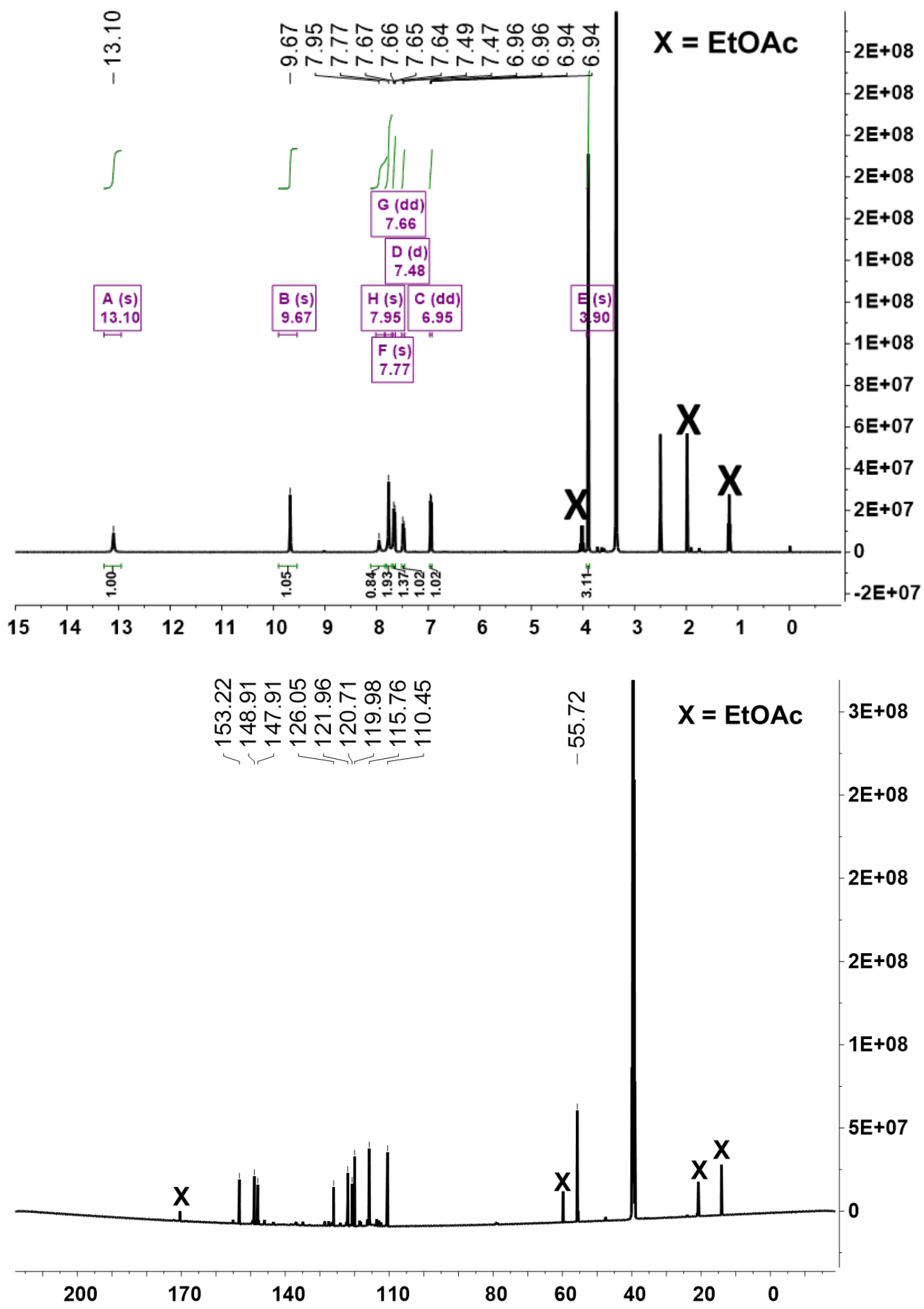


\section{Compound 7}

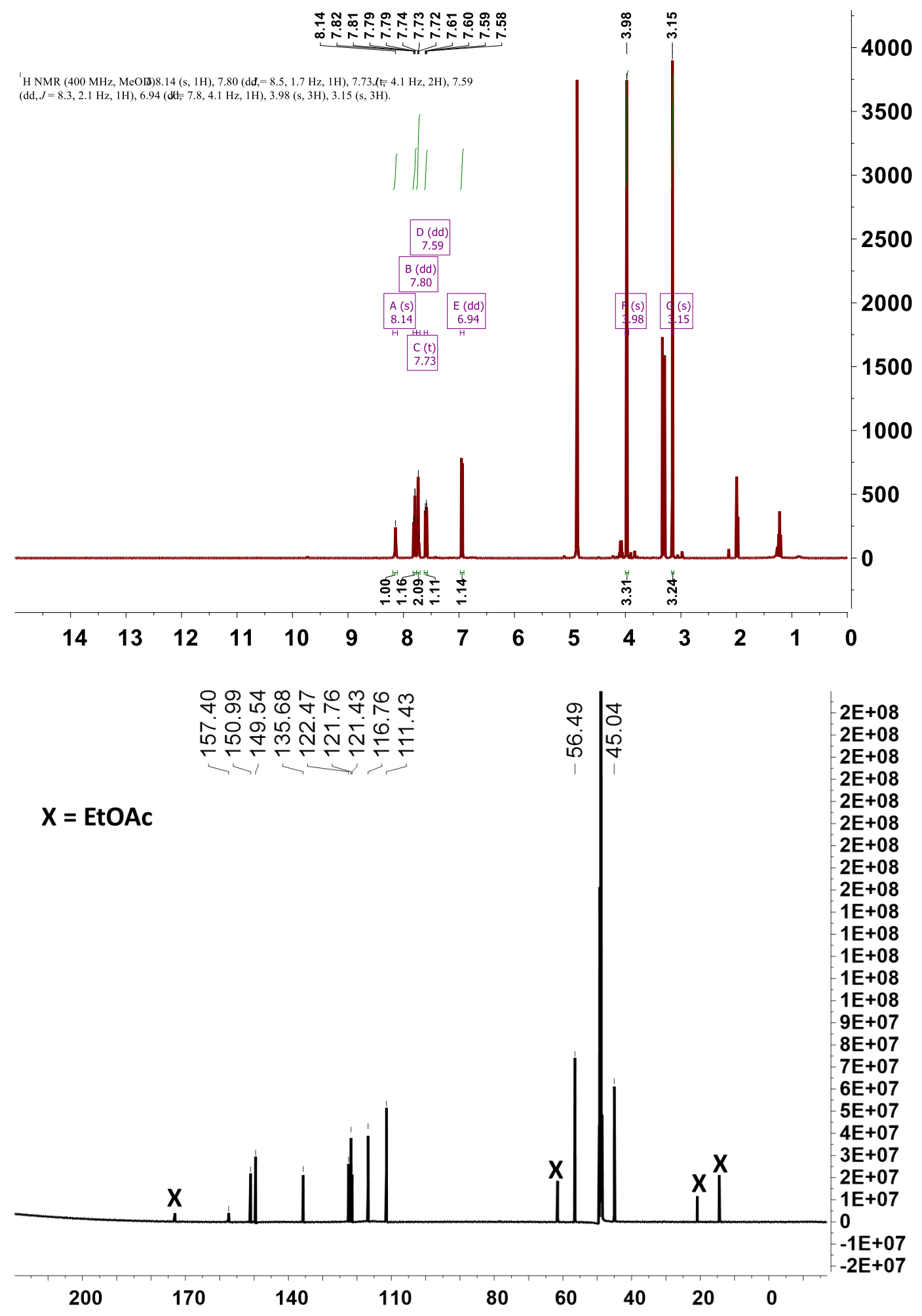




\section{Compound 8}
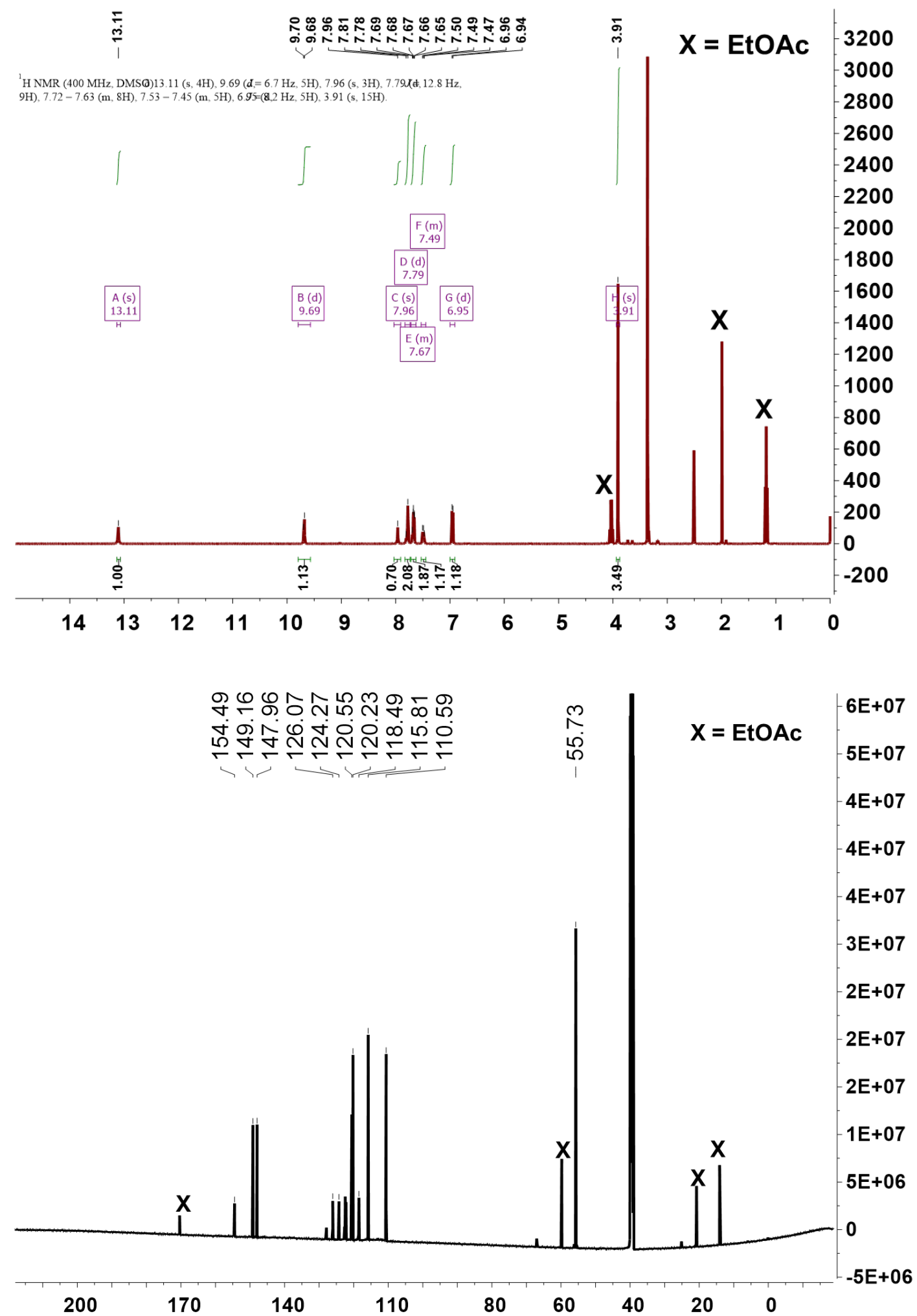


\section{Compound 9}
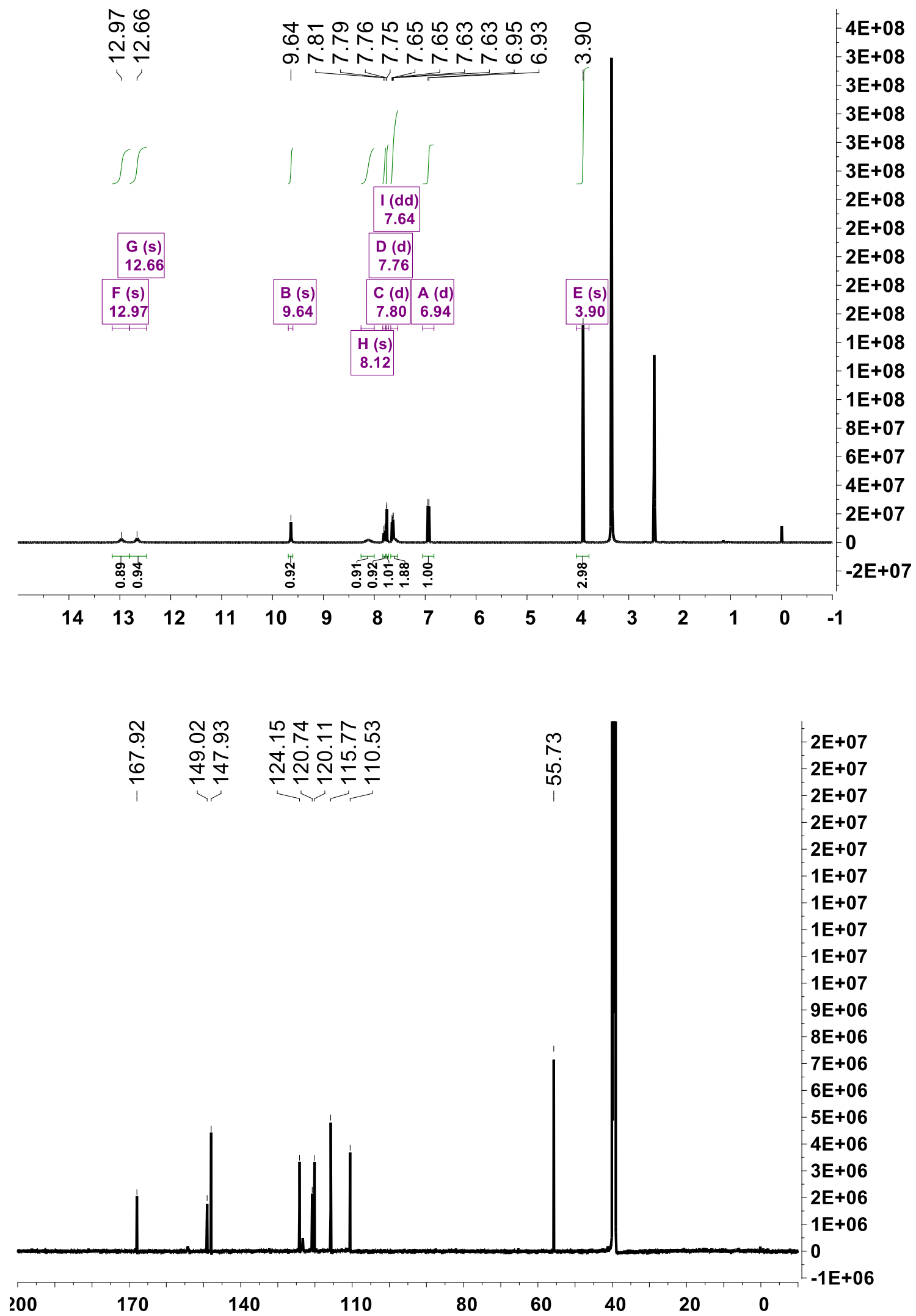


\section{Compound 10}

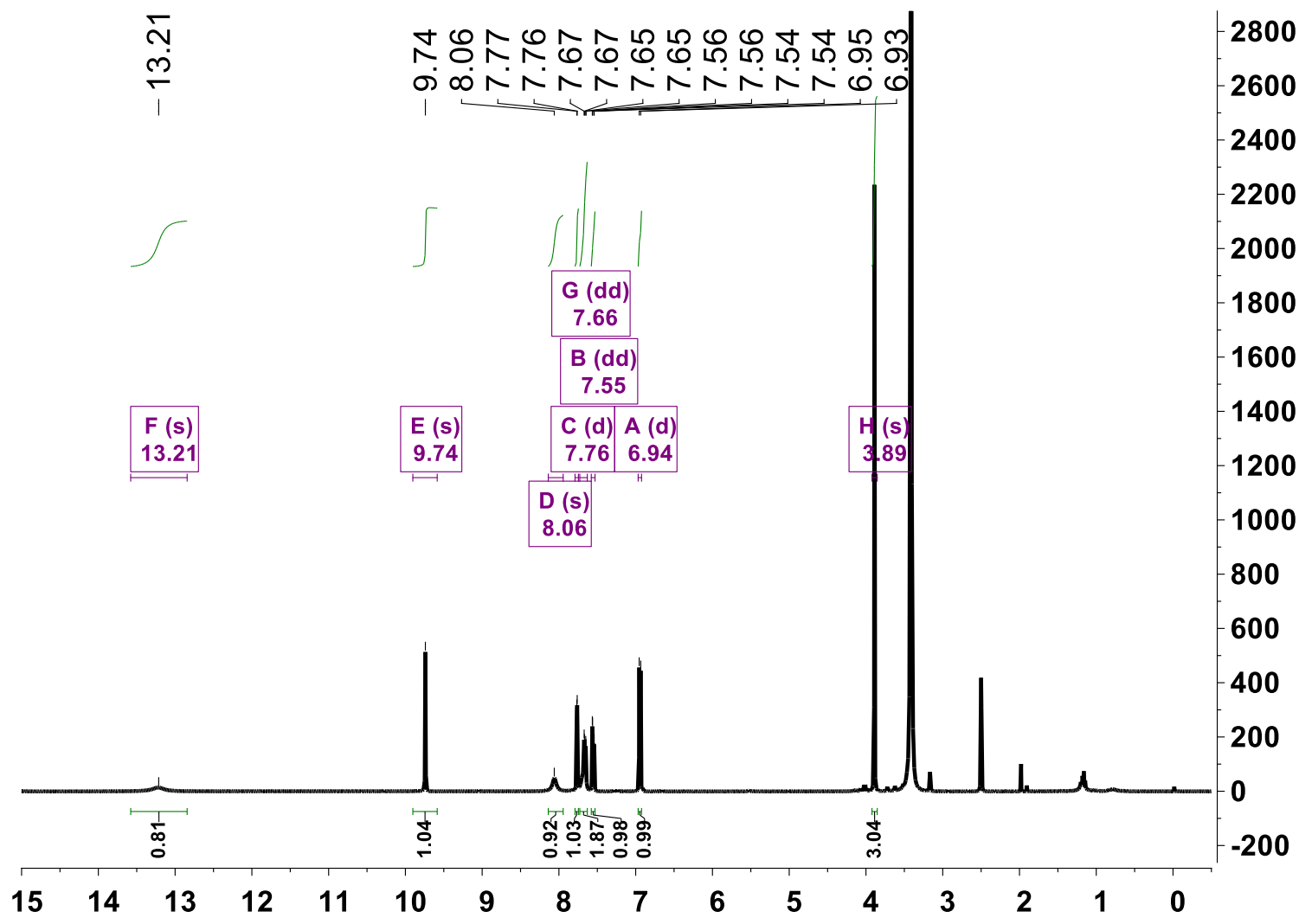

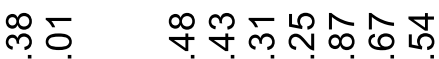

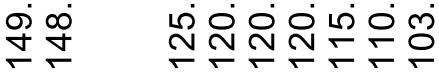

ए;

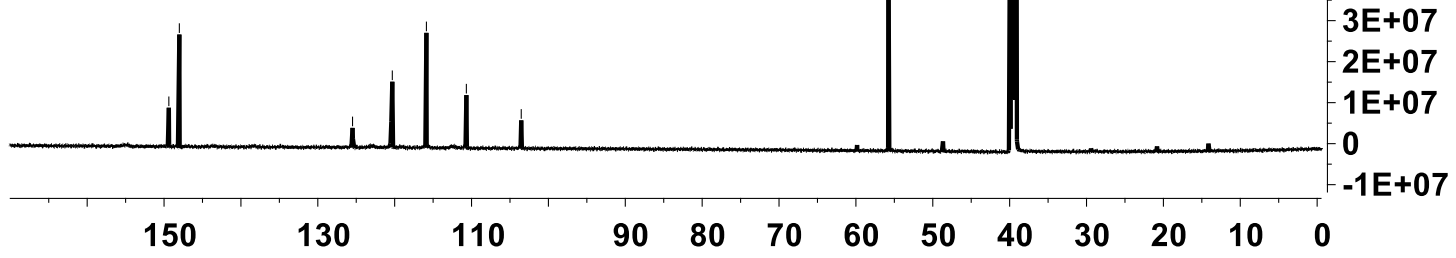




\section{Compound 13}

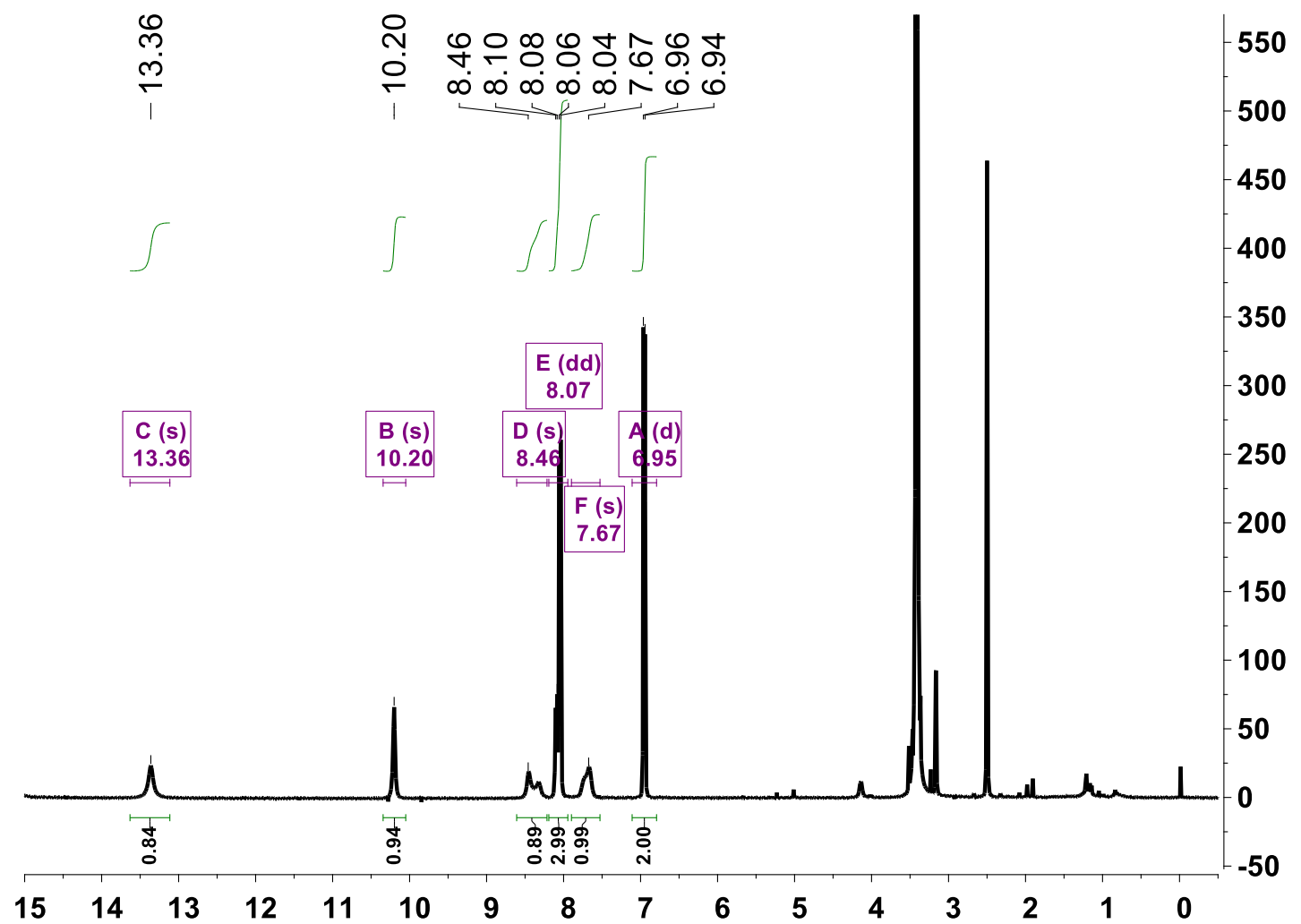

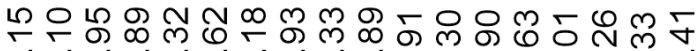

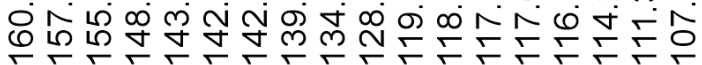

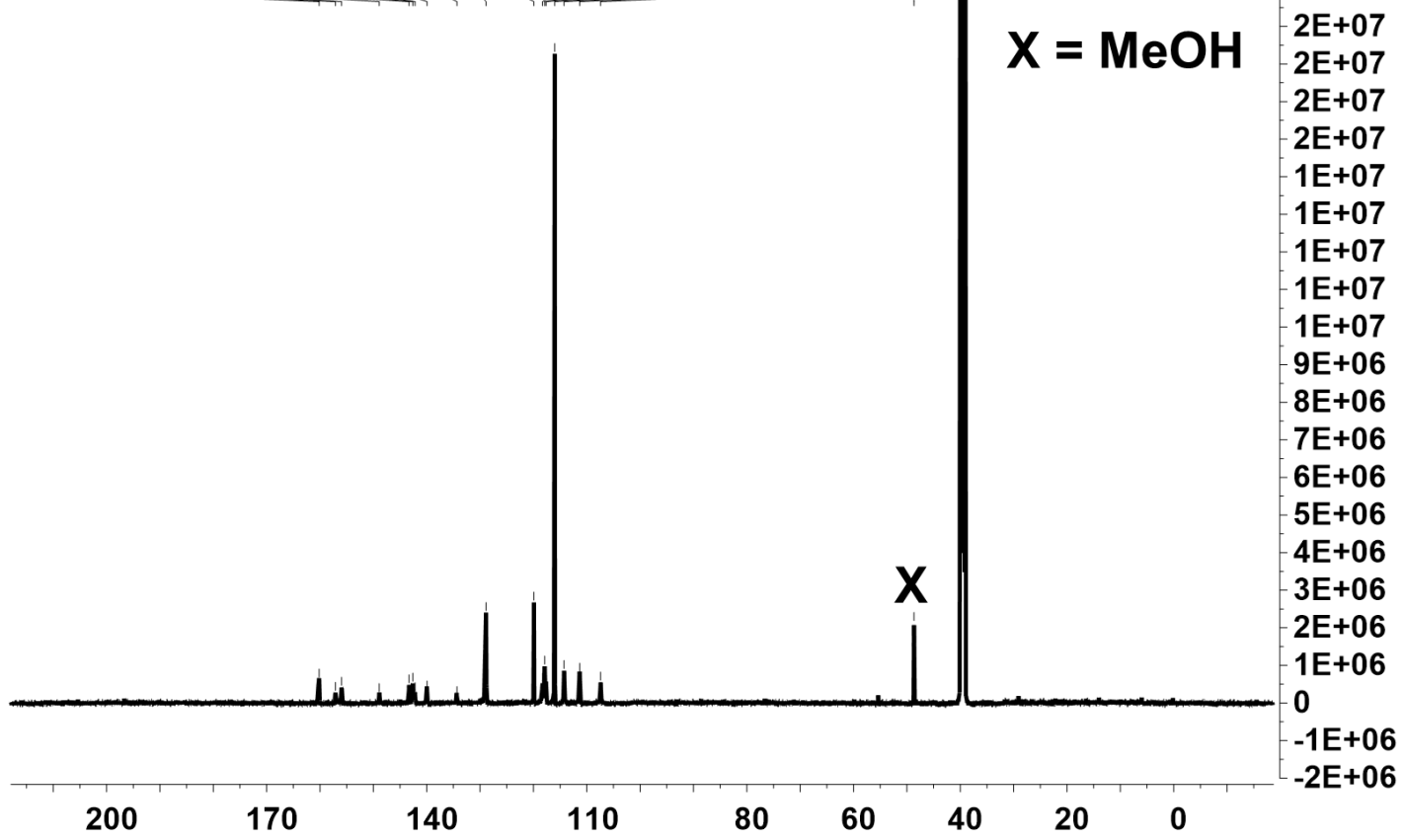




\section{Compound 14}
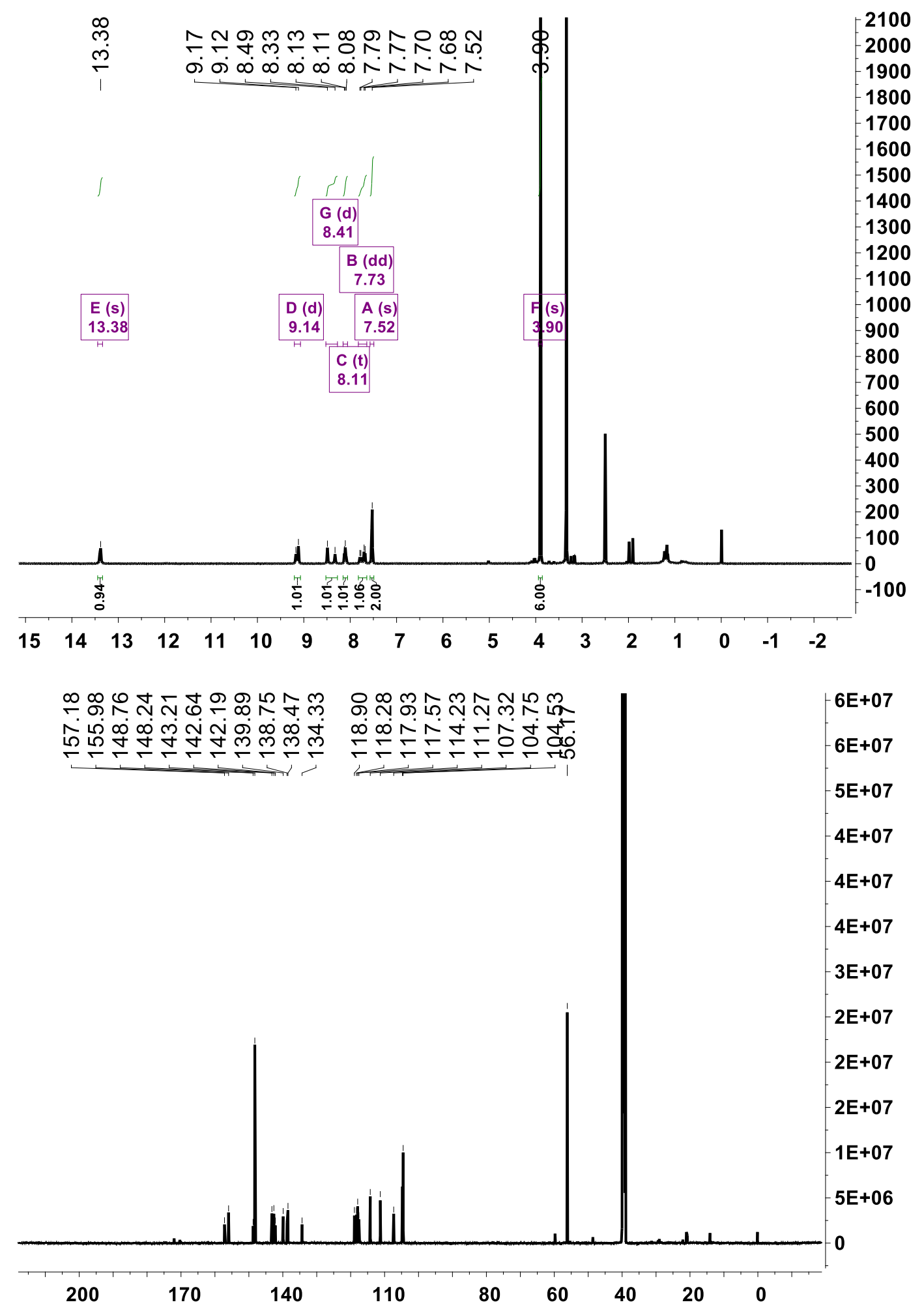


\section{Compound 15}
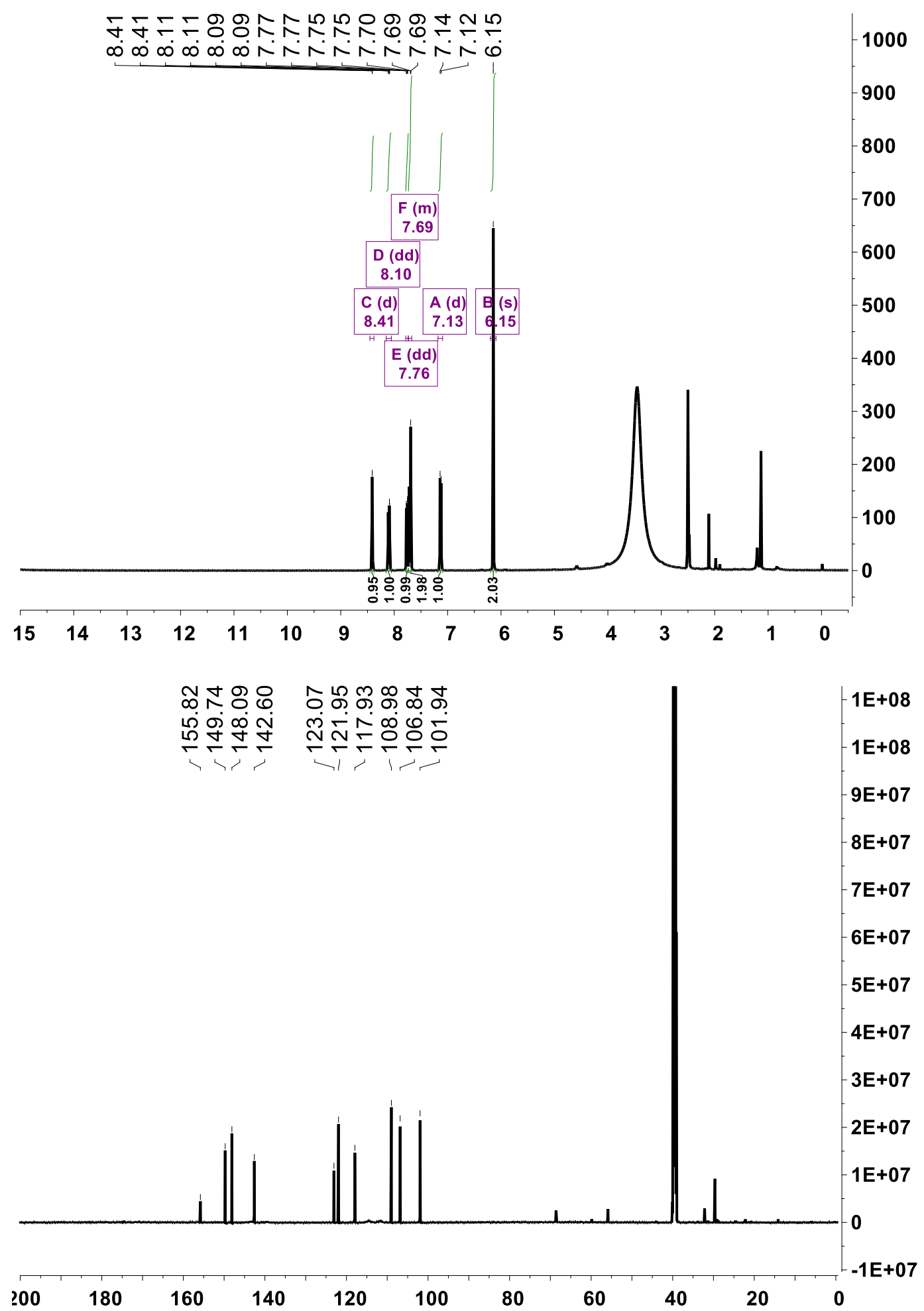


\section{Compound 16}

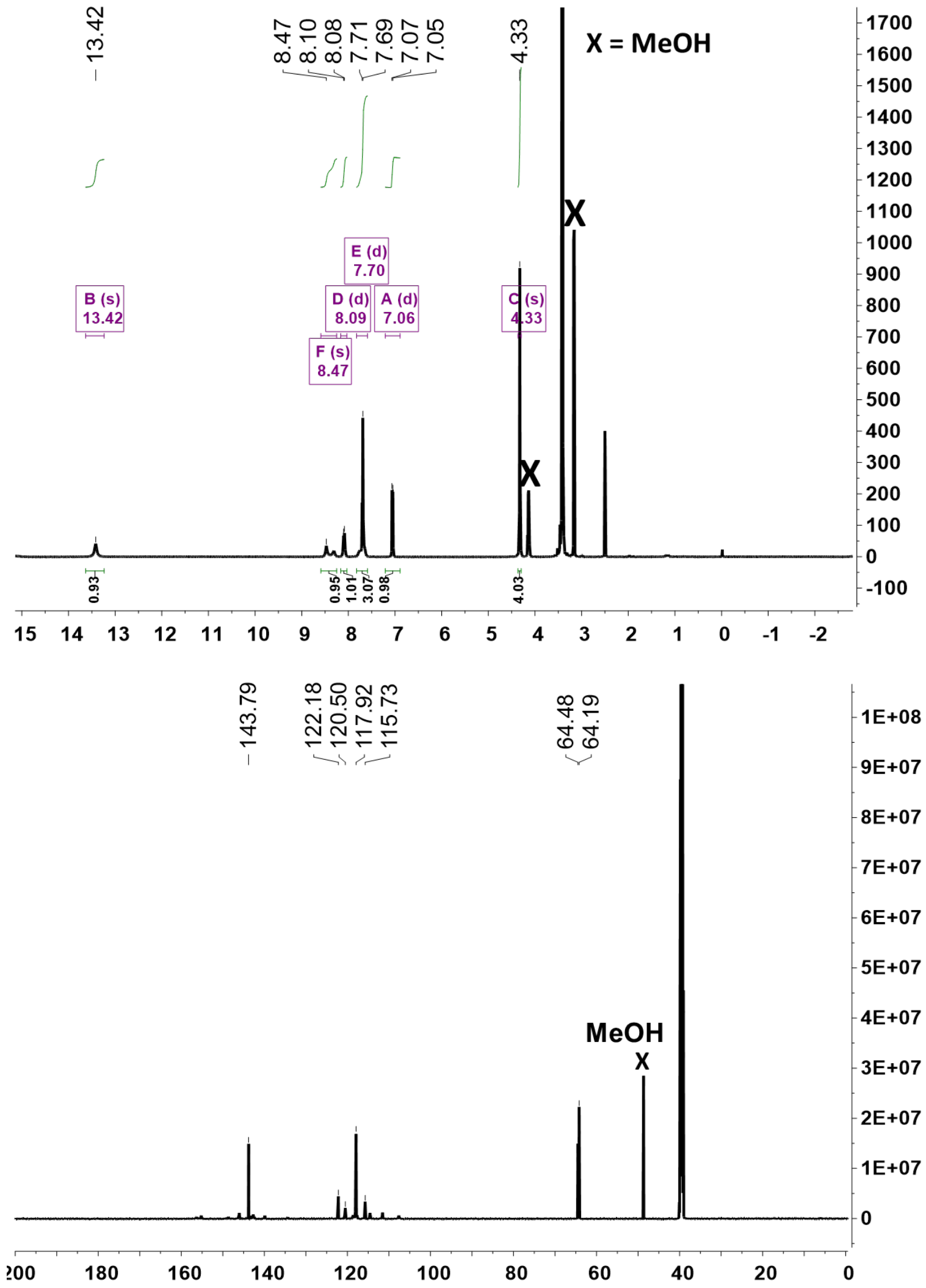




\section{Compound 17}
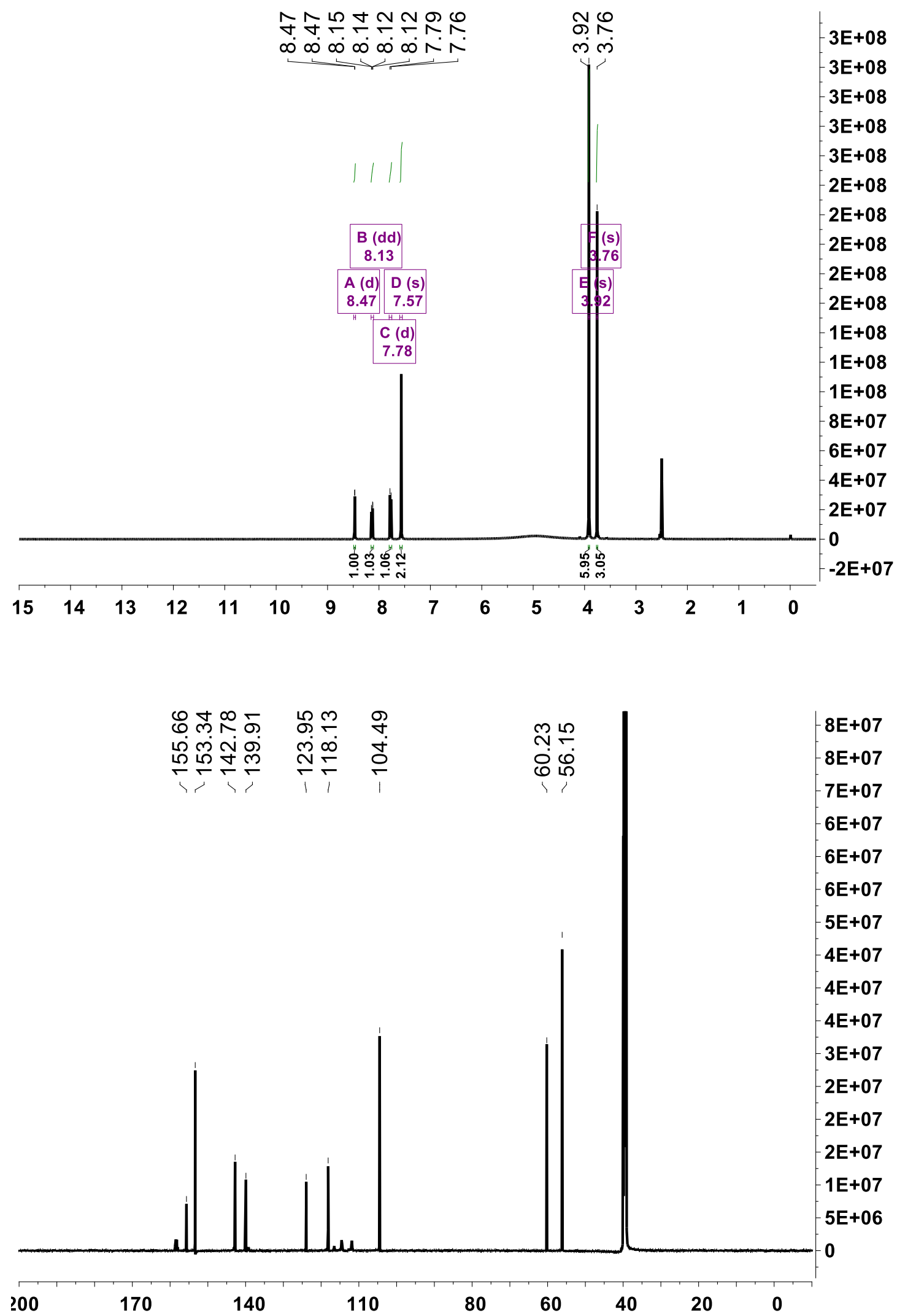


\section{REFERENCES}

1. Bellaousov, S., Reuter, J. S., Seetin, M. G., and Mathews, D. H. (2013) RNAstructure: web servers for RNA secondary structure prediction and analysis, Nucleic Acids Res. 41, W471-W474.

2. Mathews, D. H. (2014) RNA secondary structure analysis using RNAstructure, Curr. Protoc. Bioinformatics 46, 1-25.

3. Haniff, H. S., Graves, A., and Disney, M. D. (2018) Selective small molecule recognition of RNA base pairs, ACS Comb. Sci. 20, 482-491.

4. Case, D. A., Betz, R. M., Botello-Smith, W., Cerutti, D. S.,Cheatham, T. E. I., Darden, T. A., Duke, R. E., Giese, T. J., Gohlke, H.,Goetz, A. W., Homeyer, N., Izadi, S., Janowski, P., Kaus, J., Kovalenko,A., Lee, T. S., LeGrand, S., Li, C., Lin, T., Luchko, T., Luo, R., Madej, B.,Mermelstein, D., Merz, K. M., Monard, G., Nguyen, H., Nguyen, H. T.,Omelyan, I., Onufriev, A., Roe, D. R., Roitberg, A., Sagui, C., Simmerling,C. L., Swails, J., Walker, R. C., Wang, J., Wolf, R. M., Wu, X., Xiao, L., York, D. M., and Kollman, P. A. . (2016) AMBER 16, University of California, San Francisco, San Francisco.

5. Joung, I. S., and Cheatham, T. E. (2008) Determination of alkali and halide monovalent ion parameters for use in explicitly solvated bomolecular simulations, J. Phys. Chem. B 112, 9020-9041.

6. Jorgensen, W. L., Chandrasekhar, J., Madura, J. D., Impey, R. W., and Klein, M. L. (1983) Comparison of simple potential functions for simulating liquid water, J. Chem. Phys. 79, 926-935.

7. Yildirim, I., Stern, H. A., Kennedy, S. D., Tubbs, J. D., and Turner, D. H. (2010) Reparameterization of RNA $\mathrm{X}$ torsion parameters for the AMBER force field and comparison to NMR spectra for cytidine and uridine, J. Chem. Theory Comput. 6, 15201531. 
8. Wales, D. J., and Yildirim, I. (2017) Improving computational pedictions of single-stranded RNA tetramers with revised $\alpha / y$ torsional parameters for the AMBER frce field, J. Phys. Chem. B 121, 2989-2999.

9. Yildirim, I., Park, H., Disney, M. D., and Schatz, G. C. (2013) A dynamic structural model of expanded RNA CAG repeats: a refined X-ray structure and computational investigations using molecular dynamics and umbrella sampling simulations, J. Am. Chem. Soc. 135, 3528-3538.

10. Yildirim, I., Stern, H. A., Sponer, J., Spackova, N., and Turner, D. H. (2009) Effects of restrained sampling space and nonplanar amino groups on free-energy predictions for RNA with imino and sheared tandem GA base pairs flanked by GC, CG, iGiC or iCiG Base pairs, J. Chem. Theory Comput. 5, 2088-2100.

11. Ryckaert, J.-P., Ciccotti, G., and Berendsen, H. J. C. (1977) Numerical integration of the cartesian equations of motion of a system with constraints: molecular dynamics of nalkanes, J. Comput. Phys. 23, 327-341.

12. Lu, X. J., and Olson, W. K. (2008) 3DNA: a versatile, integrated software system for the analysis, rebuilding and visualization of three-dimensional nucleic-acid structures, Nat. Protoc. 3, 1213-1227.

13. Childs-Disney, J. L., Stepniak-Konieczna, E., Tran, T., Yildirim, I., Park, H., Chen, C. Z., Hoskins, J., Southall, N., Marugan, J. J., Patnaik, S., Zheng, W., Austin, C. P., Schatz, G. C., Sobczak, K., Thornton, C. A., and Disney, M. D. (2013) Induction and reversal of myotonic dystrophy type 1 pre-mRNA splicing defects by small molecules, Nat. Commun. $4,2044$.

14. Childs-Disney, J. L., Yildirim, I., Park, H., Lohman, J. R., Guan, L., Tran, T., Sarkar, P., Schatz, G. C., and Disney, M. D. (2014) Structure of the myotonic dystrophy type 2 RNA and designed small molecules that reduce toxicity, ACS Chem. Biol. 9, 538-550. 
15. Wang, Z.-F., Ursu, A., Childs-Disney, J. L., Guertler, R., Yang, W.-Y., Bernat, V., Rzuczek, S. G., Fuerst, R., Zhang, Y.-J., Gendron, T. F., Yildirim, I., Dwyer, B. G., Rice, J. E., Petrucelli, L., and Disney, M. D. (2019) The hairpin form of $r(G 4 C 2) \exp$ in c9ALS/FTD is repeatassociated non-ATG translated and a target for bioactive small molecules, Cell Chem. Biol. 26, 179-190.

16. Costales, M. G., Aikawa, H., Li, Y., Childs-Disney, J. L., Abegg, D., Hoch, D. G., Pradeep Velagapudi, S., Nakai, Y., Khan, T., Wang, K. W., Yildirim, I., Adibekian, A., Wang, E. T., and Disney, M. D. (2020) Small-molecule targeted recruitment of a nuclease to cleave an oncogenic RNA in a mouse model of metastatic cancer, Proc. Natl. Acad. Sci. U. S. A. $117,2406-2411$.

17. Wang, J., Wolf, R. M., Caldwell, J. W., Kollman, P. A., and Case, D. A. (2004) Development and testing of a general amber force field, J. Comput. Chem. 25, 1157-1174.

18. Frisch, M., Trucks, G., Schlegel, H., Scuseria, G., Robb, M., Cheeseman, J., Scalmani, G., Barone, V., Mennucci, B., and Petersson, G. (2005) Gaussian 09; Gaussian, Inc: Wallingford, CT.

19. Bayly, C. I., Cieplak, P., Cornell, W., and Kollman, P. A. (1993) A well-behaved electrostatic potential based method using charge restraints for deriving atomic charges: the RESP model, J. Phys. Chem. 97, 10269-10280.

20. Cornell, W. D., Cieplak, P., Bayly, C. I., and Kollman, P. A. (1993) Application of RESP charges to calculate conformational energies, hydrogen bond energies, and free energies of solvation, J. Am. Chem. Soc. 115, 9620-9631.

21. Wang, Z.-F., Ursu, A., Childs-Disney, J. L., Guertler, R., Yang, W.-Y., Bernat, V., Rzuczek, S. G., Fuerst, R., Zhang, Y.-J., Gendron, T. F., Yildirim, I., Dwyer, B. G., Rice, J. E., Petrucelli, L., and Disney, M. D. (2019) The hairpin form of $r\left(G_{4} C_{2}\right)^{\exp }$ in c9ALS/FTD Is repeatassociated non-ATG translated and a target for bioactive small molecules, Cell Chem. Biol. 26, 179-190.e112. 
22. D.A. Case, R. M. B., D.S. Cerutti, T.E. Cheatham, III, T.A. Darden, R.E. Duke, T.J. Giese, H. Gohlke,, A.W. Goetz, N. H., S. Izadi, P. Janowski, J. Kaus, A. Kovalenko, T.S. Lee, S. LeGrand, P. Li, C., Lin, T. L., R. Luo, B. Madej, D. Mermelstein, K.M. Merz, G. Monard, H. Nguyen, H.T. Nguyen, I., Omelyan, A. O., D.R. Roe, A. Roitberg, C. Sagui, C.L. Simmerling, W.M. Botello-Smith, J. Swails, , and R.C. Walker, J. W., R.M. Wolf, X. Wu, L. Xiao and P.A. Kollman (2016) AMBER 2016, University of California, San Francisco.

23. Onufriev, A., Bashford, D., and Case, D. A. (2004) Exploring protein native states and largescale conformational changes with a modified generalized born model, Proteins 55, 383394.

24. Miller, B. R., McGee, T. D., Swails, J. M., Homeyer, N., Gohlke, H., and Roitberg, A. E. (2012) MMPBSA.py: an efficient program for end-state free energy calculations, J. Chem. Theory Comput. 8, 3314-3321.

25. Zhang, K., Donnelly, C. J., Haeusler, A. R., Grima, J. C., Machamer, J. B., Steinwald, P., Daley, E. L., Miller, S. J., Cunningham, K. M., Vidensky, S., Gupta, S., Thomas, M. A., Hong, I., Chiu, S. L., Huganir, R. L., Ostrow, L. W., Matunis, M. J., Wang, J., Sattler, R., Lloyd, T. E., and Rothstein, J. D. (2015) The C9orf72 repeat expansion disrupts nucleocytoplasmic transport, Nature 525, 56-61.

26. Bernstam, L., and Nriagu, J. (2000) Molecular aspects of arsenic stress, J. Toxicol. Environ. Health B Crit. Rev. 3, 293-322.

27. Dikusar, E. A., and Potkin, V. I. (2011) Synthesis of 2-[3-alkoxy-4-(hydroxy, alkoxy, acyloxy)phenyl]-5-methyl-1H-benzimidazoles, Russ. J.Org. Chem. 47, 694-701.

28. Alpan, A. S., Sarıkaya, G., Çoban, G., Parlar, S., Armagan, G., and Alptüzün, V. (2017) Mannich-benzimidazole derivatives as antioxidant and anticholinesterase inhibitors: synthesis, biological evaluations, and molecular docking study, Arch. Pharm. (Weinheim) 350, e1600351. 
29. Penieres-Carrillo, J.-G., Ríos-Guerra, H., Pérez-Flores, J., Rodríguez-Molina, B., TorresReyes, Á., Barrera-Téllez, F., González-Carrillo, J., Moreno-González, L., MartínezZaldívar, A., Nolasco-Fidencio, J.-J., Matus-Meza, A.-S., and Luna-Mora, R.-A. (2020) Reevaluating the synthesis of 2,5-disubstituted-1H-benzimidazole derivatives by different green activation techniques and their biological activity as antifungal and antimicrobial inhibitor, J Heterocycl. Chem. 57, 436-455.

30. Shaukat, A., Mirza, H. M., Ansari, A. H., Yasinzai, M., Zaidi, S. Z., Dilshad, S., and Ansari, F. L. (2013) Benzimidazole derivatives: synthesis, leishmanicidal effectiveness, and molecular docking studies, Med. Chem. Res. 22, 3606-3620.

31. Navarrete-Vázquez, G., Moreno-Diaz, H., Estrada-Soto, S., Torres-Piedra, M., León-Rivera, I., Tlahuext, H., Muñoz-Muñiz, O., and Torres-Gómez, H. (2007) Microwave-assisted onepot synthesis of 2-(substituted phenyl)-1H-benzimidazole derivatives, Synth. Commun. $37,2815-2825$.

32. Navarrete-Vázquez, G., Hidalgo-Figueroa, S., Torres-Piedra, M., Vergara-Galicia, J., RiveraLeyva, J. C., Estrada-Soto, S., León-Rivera, I., Aguilar-Guardarrama, B., Rios-Gómez, Y., Villalobos-Molina, R., and Ibarra-Barajas, M. (2010) Synthesis, vasorelaxant activity and antihypertensive effect of benzo[d]imidazole derivatives, Bioorg. Med. Chem. 18, 39853991.

33. Savall, B. M., Fontimayor, J. R., and Edwards, J. P. (2009) Selective phenol alkylation for an improved synthesis of 2-arylbenzimidazole H4 receptor ligands, Tetrahedron Lett. 50, 2490-2492.

34. Chaturvedi, A. K., Verma, A. K., Thakur, J. P., Roy, S., Bhushan Tripathi, S., Kumar, B. S., Khwaja, S., Sachan, N. K., Sharma, A., Chanda, D., Shanker, K., Saikia, D., and Negi, A. S. (2018) A novel synthesis of 2-arylbenzimidazoles in molecular sieves-MeOH system and their antitubercular activity, Bioorg. Med. Chem. 26, 4551-4559. 
35. Brătulescu, G. (2017) Mild, one-pot preparation of 2-substituted benzimidazoles from organic halides, Synth. Commun. 47, 811-817. 